NUREG/CR-6695

PNNL-13375

\title{
Hydrologic Uncertainty Assessment for Decommissioning Sites: Hypothetical Test Case Applications
}

Prepared by

P. D. Meyer and R. Y. Taira

T. J. Nicholson, NRC Project Manager

Pacific Northwest National Laboratory

Richland, WA 99352

January 2001

Prepared for

Division of Risk Analysis and Applications

Office of Nuclear Regulatory Research

U. S. Nuclear Regulatory Commission

Washington, DC 20555-0001

NRC JCN W6933 



\begin{abstract}
This report uses hypothetical decommissioning test cases to illustrate an uncertainty assessment methodology for dose assessments conducted as part of decommissioning analyses for NRC-licensed facilities. This methodology was presented previously in NUREG/CR-6656. The hypothetical test case source term and scenarios are based on an actual decommissioning case and the physical setting is based on the site of a field experiment carried out for the NRC in Arizona. The emphasis in the test case was on parameter uncertainty. The analysis is limited to the hydrologic aspects of the exposure pathway involving infiltration of water at the ground surface, leaching of contaminants, and transport of contaminants through the groundwater to a point of expo-
\end{abstract}

Abstract

sure. The methodology uses generic parameter distributions based on national or regional databases for estimating parameter uncertainty. A Bayesian updating method is used in one of the test case applications to combine site-specific information with the generic parameter distributions. Sensitivity analyses and probabilistic simulations are used to describe the impact of parameter uncertainty on predicted dose. Emphasis is placed on understanding the conceptual and computational behavior of the dose assessment codes as they are applied to the test cases. The primary code used in these applications was RESRAD v. 6.0, although DandD v. 1.0 results are also reported. The methods presented and the issues discussed are applicable to other codes as well. 



\section{Contents}

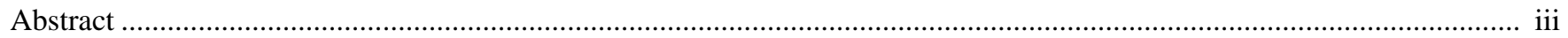

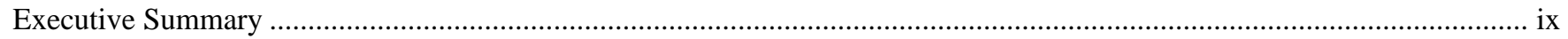

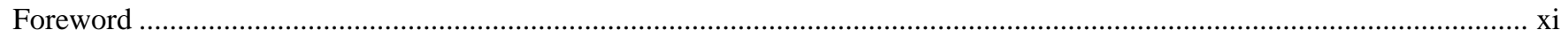

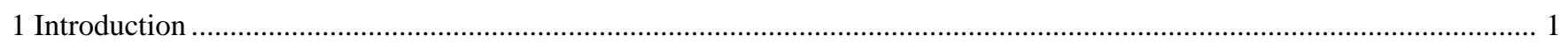

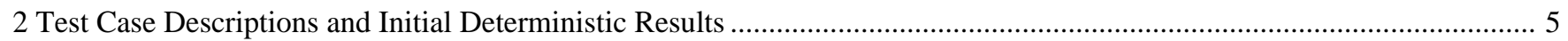

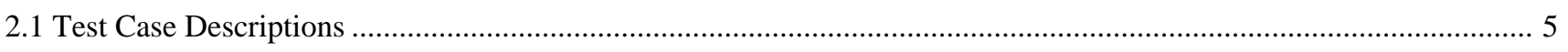

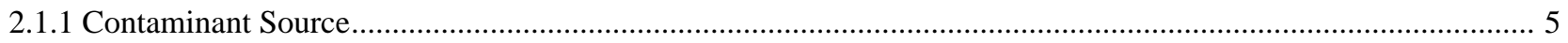

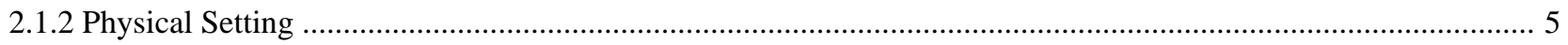

2.2 Initial Deterministic Simulations ................................................................................................................... 7

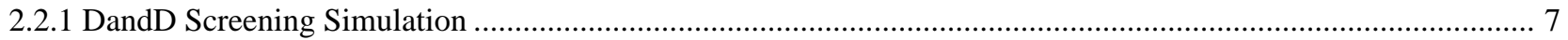

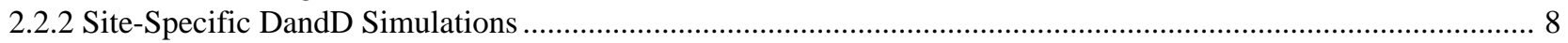

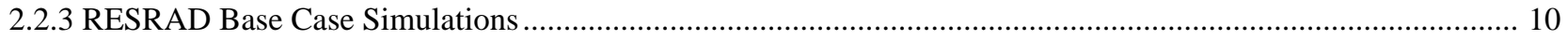

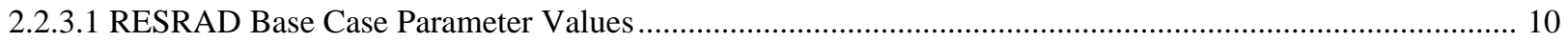

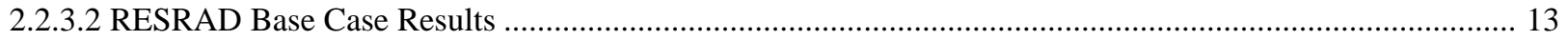

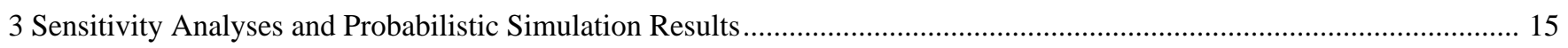

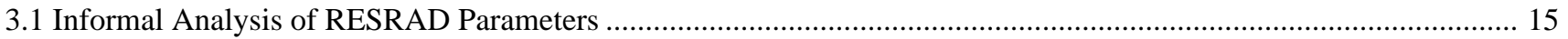

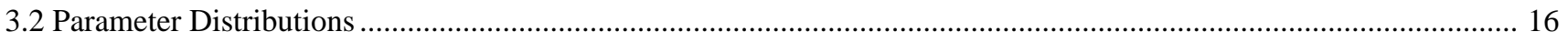

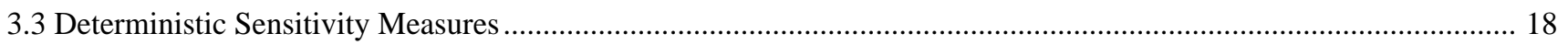

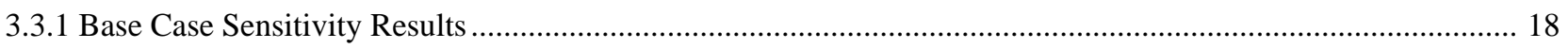

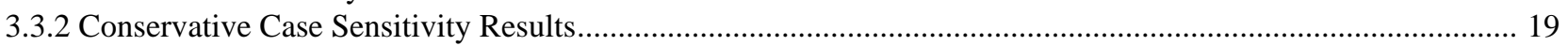

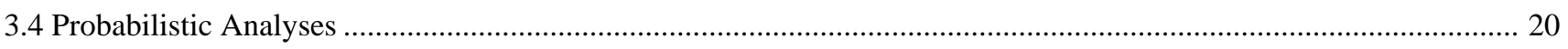

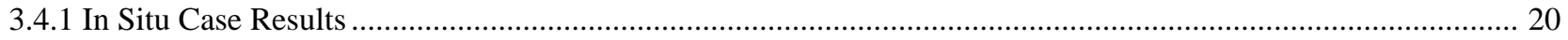

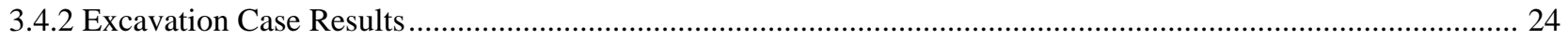

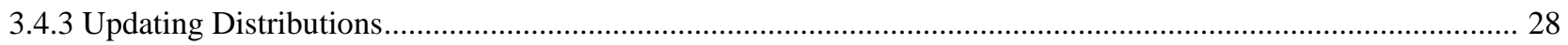

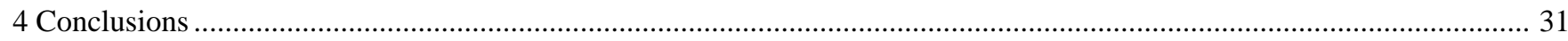

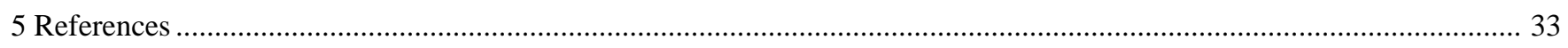

Appendix A Recommended Soil Bulk Density Distributions ................................................................................. A-1

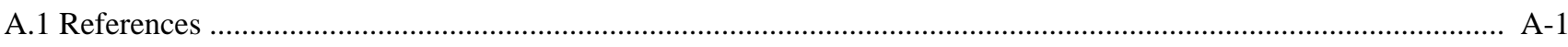

Appendix B Recommended Soil Parameter Distributions .......................................................................................... B-1

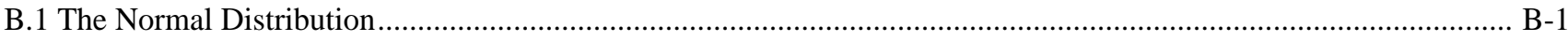

B.2 The Lognormal distribution ............................................................................................................. B-1

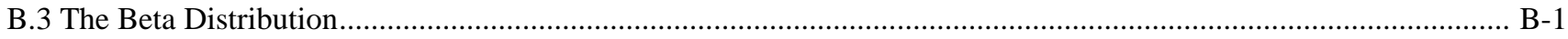

B.4 Recommended Probability Distributions for Soil Hydraulic Parameters by Soil Texture ........................................ B-2

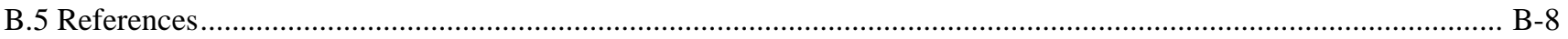

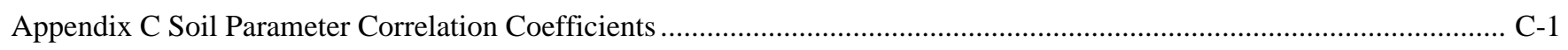


D.1 Van Genuchten Model.

D.2 Brooks-Corey Model

\section{Figures}

2-1 Geologic characterization from a deep borehole on the Maricopa Agricultural Center, and near-surface characterization interpreted from shallow boreholes on the test case site ......................................................................................... 6

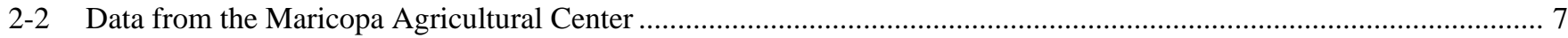

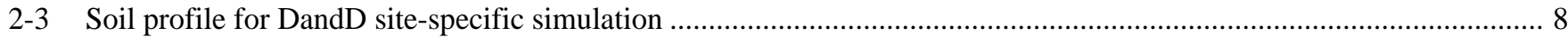

2-4 Plan views of contaminated area and soil profile for the in situ and excavation test cases ...................................... 11

2-5 Total dose as a function of time from the base case RESRAD simulations for the excavation and in situ cases ........... 13

3-1 Spreadsheet calculation of the RESRAD dilution factors and advective travel time for the in situ test case.................. 16

3-2 Histogram and empirical cdf of peak dose and the time of the peak dose for the in situ test case .............................. 20

3-3 Scatter plots of peak dose versus parameter values for the in situ test case ............................................................ 22

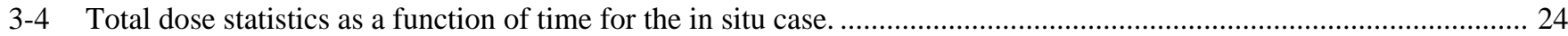

3-5 Histogram and empirical cdf of the peak dose and the time of the peak dose for the excavation test case................... 25

3-6 Scatter plots of peak dose versus parameter values for the excavation test case Monte Carlo simulation..................... 27

3-7 Total dose as a function of parameter values from Monte Carlo simulations with one parameter varying at a time...... 28

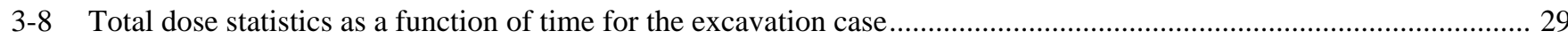

3-9 Prior and updated probability distributions of the saturated zone hydraulic conductivity for the excavation case ......... 30

3-10 Prior and updated probability distributions of the peak dose for the excavation case ................................................ 30

\section{Tables}

1-1 Hydrologic flow and transport parameters of DandD, RESRAD, and MEPAS for residential farmer scenario, groundwater pathway

2-1 Soil concentrations for the source term of the hypothetical test cases ...........................................................................5

2-2 Physical parameters of DandD modified to reflect the hypothetical test case site ......................................................9

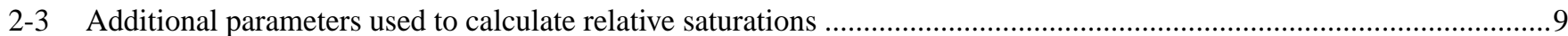

2-4 Radionuclide distribution coefficients modified for the hypothetical test case ….........................................................10

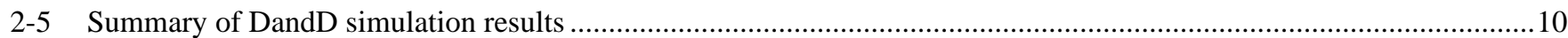




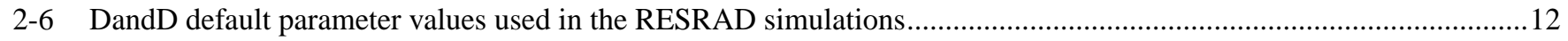

2-7 RESRAD physical parameter values modified from their default values .............................................................. 12

3-1 Parameter distributions used in the hypothetical test case applications ...........................................................17

3-2 Deterministic sensitivity results about the base case parameter values for the in situ case ......................................18

3-3 Deterministic sensitivity results about the conservative parameter values for the in situ case ..................................... 19

3-4 Statistical sensitivity measures for the in situ case (peak total dose) as calculated by RESRAD v. 6.0 .......................23

3-5 Statistical sensitivity measures for the excavation case (peak total dose) as calculated by RESRAD v. 6.0.................26

A-1 Recommended parameters of normal distributions for bulk density ................................................................ A-1

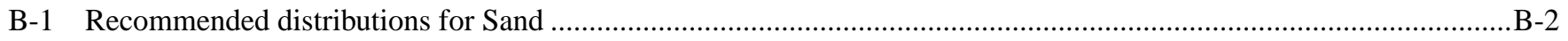

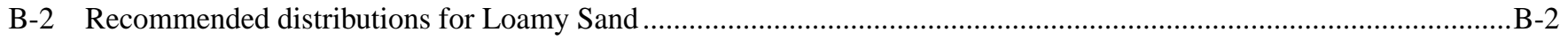

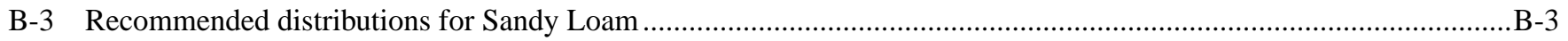

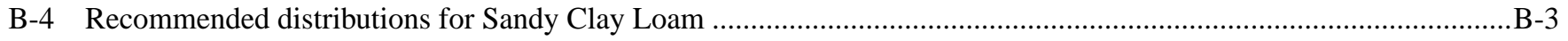

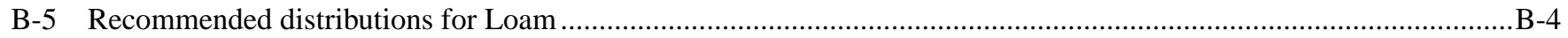

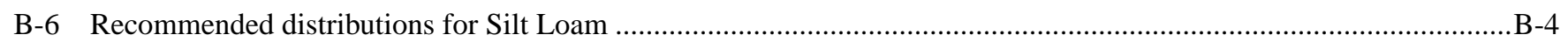

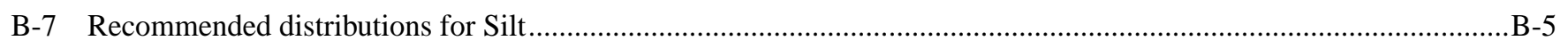

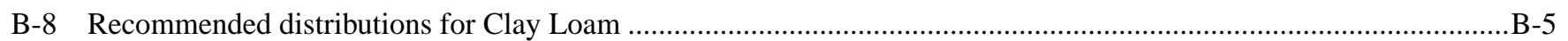

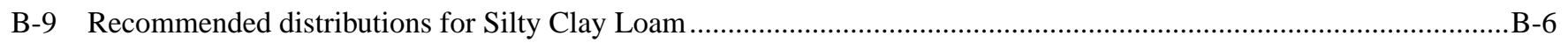

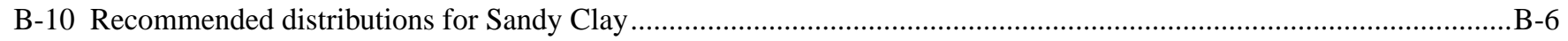

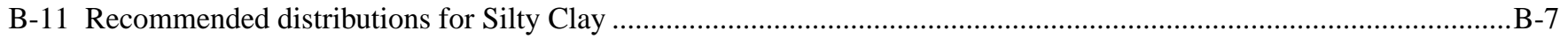

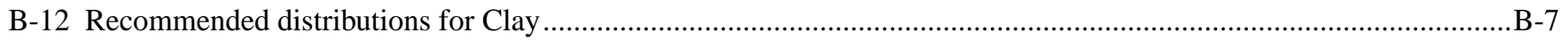

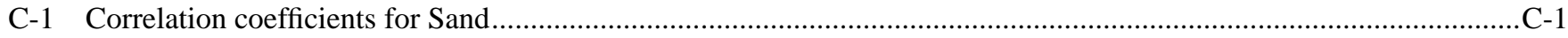

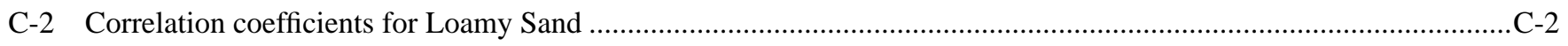

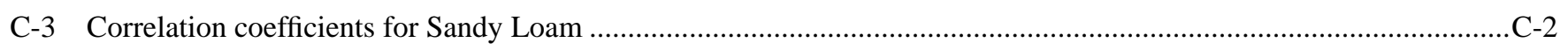

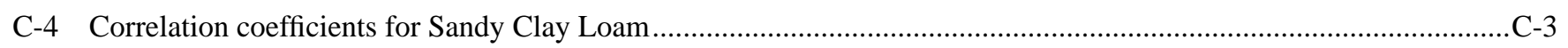

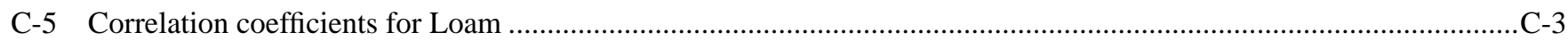

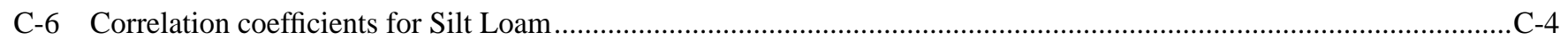

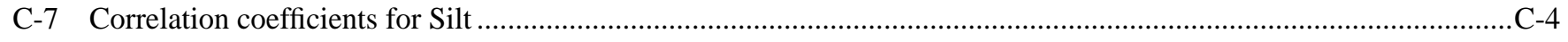

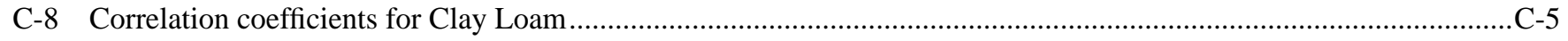

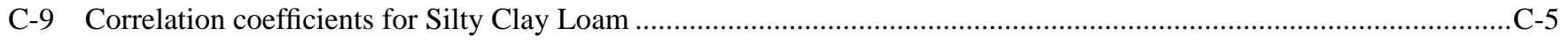

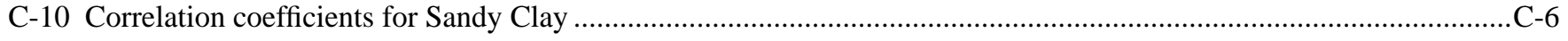

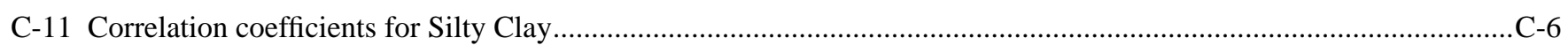

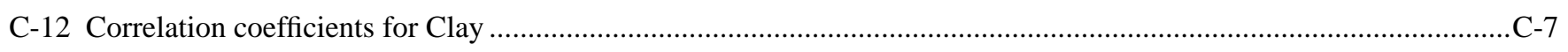





\section{Executive Summary}

This report illustrates the application of an uncertainty assessment methodology for decommissioning analyses previously presented in NUREG/CR-6656. Hypothetical decommissioning test cases are used to illustrate the methods. These test cases are based on source term and scenario information provided by NRC staff and on the physical setting of a site in Arizona at which NRC-sponsored field studies have been carried out. Basic soil and climate information provided by University of Arizona staff were used in the application. Other regional information was obtained from electronic sources. For those aspects of the site without reliable data sources, national databases were used to estimate site characteristics.

A series of deterministic simulations were carried out using the codes DandD v. 1.0 and RESRAD v. 6.0. Simplifications to the conceptual model of the site were made to match the conceptual models embodied in the simulation codes. Following the framework described in NUREG-1549, a DandD screening simulation was executed with the test case source term and all default parameter values. This screening case resulted in a peak dose of $829 \mathrm{mrem} / \mathrm{yr}$. The DandD code was subsequently run with parameter values more representative of the test case site. A peak dose of $285 \mathrm{mrem} / \mathrm{yr}$ was obtained with most of the physical hydrologic parameters modified to reflect site-specific conditions. With default hydrologic parameters and modified distribution coefficients, the peak dose was 198 mrem/yr. With both hydrologic parameters and distribution coefficients modified, the peak dose from DandD was $70 \mathrm{mrem} / \mathrm{yr}$.

Deterministic and probabilistic simulations of the test cases were carried out with RESRAD. An in situ case modeled the waste in its original buried location and assumed that a cover was in place. The in situ case resulted in a peak dose of $115 \mathrm{mrem} / \mathrm{yr}$. An excavation case was also simulated in which the waste was assumed to have been excavated for construction of a house, mixed with clean soil from the excavation, and widely spread about in a surface layer. This case more closely resembled the DandD conceptual model. The RESRAD excavation base case resulted in a peak dose of $16 \mathrm{mrem} / \mathrm{yr}$.

Deterministic sensitivity analyses applied to the in situ test case included use of a simplified model implemented in a spreadsheet and standard sensitivity calculations applied to the base case parameter values and to a set of conservative parameter values. The various sensitivity measures were largely in agreement. For the in situ case, these analyses indicated that the evapotranspiration coefficient, the uranium distribution coefficients, and the well pumping rate were the most important parameters contributing to the uncertainty in peak dose. Soil hydraulic parameters were much less important for this case. Deterministic sensitivity analyses were not carried out for the excavation case.

Probabilistic analyses were carried out for the in situ and excavation cases using the Monte Carlo simulation capability of RESRAD. Histograms and cumulative distributions for the peak total dose and the time of the peak dose were derived. Statistics for the total dose as a function of time, used to obtain the peak of the mean dose, were also presented. The results can be used to compare the estimated site performance to the regulatory measures with consideration of parameter uncertainties.

Probabilistic measures of sensitivity presented were scatter plots of peak dose versus parameter values, statistical sensitivity measures calculated by RESRAD, and single-parameter Monte Carlo simulations used to clarify the relationships between dose and critical parameter values. No single measure was a reliable indicator of the relative importance of the parameters. For the in situ case, the evapotranspiration coefficient, the well pumping rate, and the uranium distribution coefficients were of greatest importance. These results were consistent with the deterministic results. For the excavation case, the saturated zone hydraulic conductivity was the most important parameter followed by the uranium distribution coefficients. The applications illustrate the value of applying a variety of uncertainty analysis methods and understanding the behavior of the simulation code.

A method to update parameter probability distributions was also applied to the excavation test case using the saturated zone hydraulic conductivity. Because site-specific measurements were not available for this parameter, data were generated using four measurements of physical properties from the deepest samples available at the test case site. Updating the saturated zone hydraulic conductivity distribution with the site-specific data had its greatest effect on the standard deviation of the peak dose, which was significantly reduced. The percentage of realizations exceeding $25 \mathrm{mrem} / \mathrm{yr}$ was reduced from $13 \%$ to $2 \%$. 



\section{Foreword}

This technical contractor report, NUREG/CR-6695, was prepared by Pacific Northwest National Laboratory ${ }^{1}$ (PNNL) under their DOE Interagency Work Order (JCN W6933) with the Radiation Protection, Environmental Risk and Waste Management Branch, Division of Risk Analysis and Applications, Office of Nuclear Regulatory Research. The report documents the testing of PNNL's uncertainty assessment methodology (documented in NUREG/CR-6656) using hypothetical test cases provided by the NMSS licensing staff. For these test cases, the PNNL investigators identified the critical hydrologic parameters and evaluated their contribution to dose uncertainty. Results from this work point to the importance of parameter uncertainty, as well as conceptual model uncertainty. The report's appendices provide a listing of the data distributions used in the testing.

The PNNL research study was undertaken to support licensing needs for estimating and reviewing hydrologic parameter distributions and their attendant uncertainties for site-specific dose assessment modeling as outlined in NUREG-1549. The PNNL research focuses on hydrologic parameter uncertainties in the context of dose assessments for decommissioning sites. The information provided in the report supports the NRC staff's efforts in developing dose modeling guidance. Specifically, the report illustrates the use of site-specific data to update parameter distributions used in the dose assessment models. The report demonstrates the application of deterministic sensitivity analyses and probabilistic methods in the PNNL uncertainty assessment methodology. NUREG/CR-6695 is the second report in a series of three contractor reports documenting PNNL's uncertainty assessment methodology, its testing and applications to decommissioning sites.

NUREG/CR-6695 is not a substitute for NRC regulations, and compliance is not required. The approaches and/or methods described in this NUREG/CR are provided for information only. Publication of this report does not necessarily constitute NRC approval or agreement with the information contained herein. Use of product or trade names is for identification purposes only and does not constitute endorsement by the NRC or Pacific Northwest National Laboratory.

Cheryl A. Trottier, Chief

Radiation Protection, Environmental Risk and Waste Management Branch

Division of Risk Analysis and Applications

Office of Nuclear Regulatory Research

1. Pacific Northwest National Laboratory is operated for the U.S. Department of Energy by Battelle Memorial Institute under contract DE-AC06-76RLO 1830. 



\section{Introduction}

The decision-making framework developed by U.S. Nuclear Regulatory Commission (NRC) staff for analyses carried out to comply with NRC regulations on radiological criteria for license termination includes an iterative process of dose assessment, analysis of options, and model revisions (NRC, 1998). It is anticipated that the dose assessment will be conducted using one or more computer codes that model the transport of contaminants from source release to exposure via multiple pathways.

Application of the framework described in NUREG-1549 (NRC, 1998) typically begins with a screening analysis of a site using the DandD code (Beyeler et al., 1999; Kennedy and Strenge, 1992) with default parameter values and pathways and a site-specific source term. The default parameters for DandD were chosen to provide a low probability that application of DandD with the default parameters and pathways would result in a prediction that the site satisfied the license termination criteria when, in reality, it would not. The screening doses calculated by DandD are likely to be overestimates, but not worst-case estimates.

When a site fails the initial screening dose assessment, sitespecific considerations can be used to modify the dose assessment modeling assumptions, parameter values and pathways. Such site-specific considerations may involve additional site characterization and can potentially include remediation activities and restricted use controls to ensure that the dose assessment results meet the criteria for license termination.

The radiological criteria for license termination require the determination of "the peak annual total effective dose equivalent (TEDE) expected within the first 1000 years after decommissioning” [pg. 39088, §20.1401(d), Federal Register, 1997]. Predictions of contaminant transport in the natural environment over such long periods of time are inherently uncertain. This uncertainty arises from a lack of knowledge about the actual exposure scenarios that will occur in the future, from the use of models that are a simplification or misrepresentation of a complex reality, and from uncertainty in the model parameter values used to represent a site. Because of these potentially large uncertainties, the reliability of a decommissioning dose assessment is enhanced when the effect of the uncertainty on the predictions of dose is explicitly explored.

Meyer and Gee (1999) recently provided information that can be used in an assessment of uncertainty at decommissioning sites. The information and methods discussed in their report are intended to be used within the iterative dose assessment component of the decision-making framework described in NRC (1998). Their observations and conclusions are summarized here.

The analysis of Meyer and Gee (1999) was limited to the hydrologic aspects of the dose assessment problem. For buried contaminants, this means the primary pathway of con- cern was that involving infiltration of water at the ground surface, leaching of contaminants, and transport through the subsurface to a point of exposure.

The information provided in Meyer and Gee (1999) primarily addressed parameter uncertainty. Uncertainty in future scenarios was not considered. Conceptual model uncertainty was briefly addressed with respect to three specific codes that can be used in dose assessments: DandD, RESRAD (Yu et al., 1993), and MEPAS (Whelan et al, 1996; Streile et al., 1996). (Limiting the analysis to these three codes was not intended to imply that other codes could not also be used in decommissioning analyses.) The essential conceptual model simplifications held in common by these three codes were identified by Meyer and Gee (1999). Each code uses a relatively simple model for the near-surface water budget to determine the net infiltration rate and assumes steady-state, one-dimensional flow throughout the subsurface. Each code also assumes the site can be modeled using a small number of porous media layers with uniform properties within each layer. Finally, simplified mixing models in the aquifer are used.

It was also noted that although the codes have much in common conceptually, they can nonetheless produce different results when modeling the same problem. This is primarily because of differences in the mathematical implementations used. This observation points out the importance of considering model uncertainties when evaluating overall uncertainty in dose predictions. This includes understanding the underlying conceptual model of the code as well as the mathematical implementation of that conceptual model. A thorough treatment of uncertainty cannot be achieved when a code is treated as a "black box."

The first step in an assessment of parameter uncertainty is to identify the parameters of the code that are potential contributors to the uncertainty in the predicted dose. Meyer and Gee (1999) listed the hydrologic parameters of DandD, RES-

RAD, and MEPAS. Their parameter list is included here as Table 1-1. Near-surface parameters determine the net infiltration flux, that is, the amount of water passing through the subsurface. The parameters of the contaminated zone, in conjunction with the net infiltration flux, determine the release rate from the contaminant source. The unsaturated zone and aquifer parameters determine the transport of contaminants to the exposure point (a well or surface pond).

In general, any estimate of parameter uncertainty is better than none; the level of detail in the characterization of parameter uncertainty depends on the available data. Meyer and Gee (1999) discussed a variety of available data sources that may be useful in providing estimates of uncertainty in parameter values. Such uncertainty can be characterized in a variety of ways, including as bounding values, a mean and variance, and as complete probability distributions, including correlations between parameters. Meyer and Gee (1999) suggest that large national databases and regional informa- 


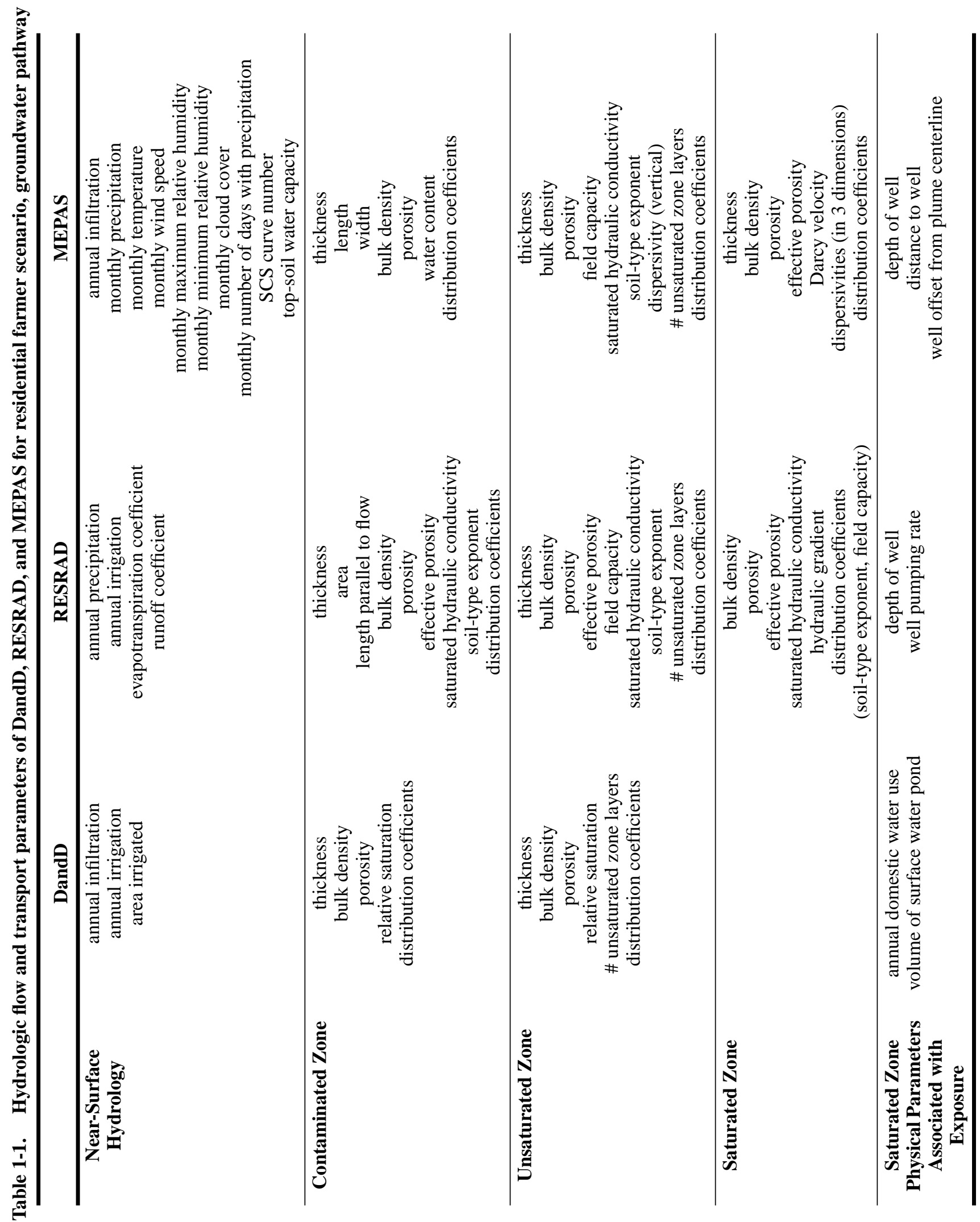


tion sources can be used to provide uncertainty characterizations for the majority of the hydrologic parameters used in DandD, RESRAD, and MEPAS when there are limited sitespecific data. National databases and regional information can also be useful when deriving best-estimate parameter values for deterministic analyses. Meyer et al. (1997) presented a Bayesian updating method for combining limited site-specific data and parameter probability distributions derived from a national database. The resulting updated probability distributions contain information from both national and site-specific data sources and can provide bestestimate parameter values for deterministic analyses as well as parameter probability distributions for probabilistic simulations.

There are two general goals of an uncertainty assessment in decommissioning analyses. One is to determine the uncertainty in the predicted peak dose given the various input uncertainties in parameters, models, and scenarios. Some measure of the dose (such as the mean value) can then be used in regulatory decision making. The other general goal of the uncertainty assessment is to understand the aspects of the problem that contribute the most to uncertainty in the dose. With this understanding it is possible to determine how additional data or revisions in assumptions may affect the regulatory decision. With respect to parameter uncertainty, this means understanding which parameters contrib- ute most significantly to the uncertainty in dose. These parameters might be described as critical. Meyer and Gee (1999) summarize a number of methods using Monte Carlo simulation and sensitivity analysis that are applicable to hydrologic parameter uncertainty assessment for decommissioning analyses. NRC staff are actively developing guidance that will discuss the use of these methods.

This report presents a hypothetical test case application of the information presented in Meyer and Gee (1999). The radionuclide source and scenarios reflect the conditions of an actual decommissioning site. The physical setting of the hypothetical test case is the location of a large-scale field experiment conducted for the NRC in Arizona (Young et al., 1999). Some of the results from this field study were used in this application. Results from the field study are also being used by other researchers in the development of approaches for addressing conceptual model uncertainty.

The following chapter of this report describes the physical and hydrological setting of the hypothetical test case as well as the source term and exposure scenarios. In addition, results from a screening analysis of the site and the initial deterministic analyses are presented. The subsequent chapter presents results and observations from an uncertainty assessment of the site. 



\section{Test Case Descriptions and Initial Deterministic Results}

\subsection{Test Case Descriptions}

\subsubsection{Contaminant Source}

The hypothetical test cases involve the decommissioning of a site at which various unspecified materials contained within approximately 20055 -gallon drums were buried in the 1960s. The buried material was contaminated with natural and enriched uranium and natural thorium. Two scenarios are assumed for the test cases. The in situ case assumes that a soil cover is placed over the waste and that the disposal area remains undisturbed. The excavation case assumes that the entire volume of waste is excavated during construction of a house. Since the volume of the waste is smaller than the assumed excavation, clean soil is excavated along with the waste. The excavated soil and waste are assumed to be uniformly mixed and spread out evenly on adjacent land. In both cases it is assumed that the waste is completely degraded (i.e., that it behaves as a soil) and that the local resident farms the adjacent land, raising crops and animals for personal consumption. Water from a shallow well is assumed to be used for irrigation of crops, watering of animals, and domestic purposes including drinking water.

For the in situ case the waste was assumed to have been buried as a single layer of 55-gallon drums occupying a volume $0.9-\mathrm{m}$ thick and $200-\mathrm{m}^{2}$ in area. For the excavation case the volume excavated for house construction was assumed to be $3-\mathrm{m}$ deep with an area of $210 \mathrm{~m}^{2}$. The average thickness of the excavated soil when spread out on the surrounding land was taken to be $0.15 \mathrm{~m}$, resulting in a contaminated soil area of $4200 \mathrm{~m}^{2}$.

Radionuclide soil concentrations for the two cases are given in Table 2-1. Soil concentrations for the excavation case are lower as a result of the assumption that clean soil is mixed with the excavated contaminated soil. Radionuclides with half lives less than six months are not included.

\subsubsection{Physical Setting}

The test case site is located approximately 25 miles south of Phoenix, Arizona, on the Maricopa Agricultural Center in western Pinal County, Arizona. The site is within one of the broad valleys of the basin and range province of the western United States (US). The valley floor is filled with alluvial deposits eroded from the surrounding mountains. These alluvial deposits can be quite deep and the associated aquifers quite productive. Irrigation using local groundwater sources is common throughout the area. On a regional basis, groundwater levels have been declining due to the extensive pumping for irrigated agriculture (Robson and Banta, 1995). Groundwater levels on the Maricopa Agricultural Center have been rising recently, however, due to the importation of Central Arizona Project water ${ }^{1}$.
Table 2-1. Soil concentrations for the source term of the hypothetical test cases

\begin{tabular}{ccc}
\hline & \multicolumn{2}{c}{ Soil Concentration $(\mathbf{p C i} / \mathbf{g})$} \\
\cline { 2 - 3 } Radionuclide & In Situ & Excavation \\
\hline U-234 & 43.3 & 13.0 \\
Th-230 & $1.21 \times 10^{-2}$ & $3.63 \times 10^{-3}$ \\
Ra-226 & $8.14 \times 10^{-5}$ & $2.44 \times 10^{-5}$ \\
U-235 & 1.75 & 0.526 \\
Pa-231 & $3.61 \times 10^{-4}$ & $1.08 \times 10^{-4}$ \\
Ac-227 & $1.37 \times 10^{-4}$ & $4.11 \times 10^{-5}$ \\
U-238 & 5.42 & 1.63 \\
Th-232 & 4.05 & 1.22 \\
Ra-228 & 3.98 & 1.19 \\
Th-228 & 4.05 & 1.22 \\
\hline
\end{tabular}

The alluvial deposits in the area of the test case site exhibit characteristic depositional variability with textures ranging from clayey to gravelly (Young et al., 1999). A geologic profile derived from a deep borehole on the Maricopa Agricultural Center is shown in Figure 2-1(A). This profile was obtained from University of Arizona staff and is an example of the regional information available from public sources for most locations in the US. The scale of this information does not convey the small-scale variability within the larger scale units shown. Information on the small-scale variability of soil properties is unlikely to be available from public sources at most sites.

A more detailed depiction of the near-surface deposits at the test case site is shown in Figure 2-1(B). This information is derived from boreholes drilled on the actual test case site. The site was the location of two infiltration experiments conducted on a $50-\mathrm{m}$ by $50-\mathrm{m}$ plot. Ten $15-\mathrm{m}$ deep boreholes were drilled on the site for characterization and sampling access. [See Young et al. (1999) for a detailed description of the experiments and monitoring results.] The textural layering shown in Figure 2-1(B) represents an interpretation of data obtained from the 15-m deep boreholes on the site. The site consists of primarily sands and sandy loam above a more clayey unit located about $16 \mathrm{~m}$ below the surface.

Figure 2-1(B) illustrates the presence of small-scale variability that is not depicted in the regional, large-scale profile of Figure 2-1(A). Results from detailed sampling along a $1.5-\mathrm{m}$ deep trench on the site illustrates that variability at the site is present on a smaller scale than that shown in

\footnotetext{
${ }^{1}$ Wenbin Wang, personal communication, Univ. of Arizona, March 28, 2000.
} 
Test Case Descriptions and Initial Deterministic Results

(A)

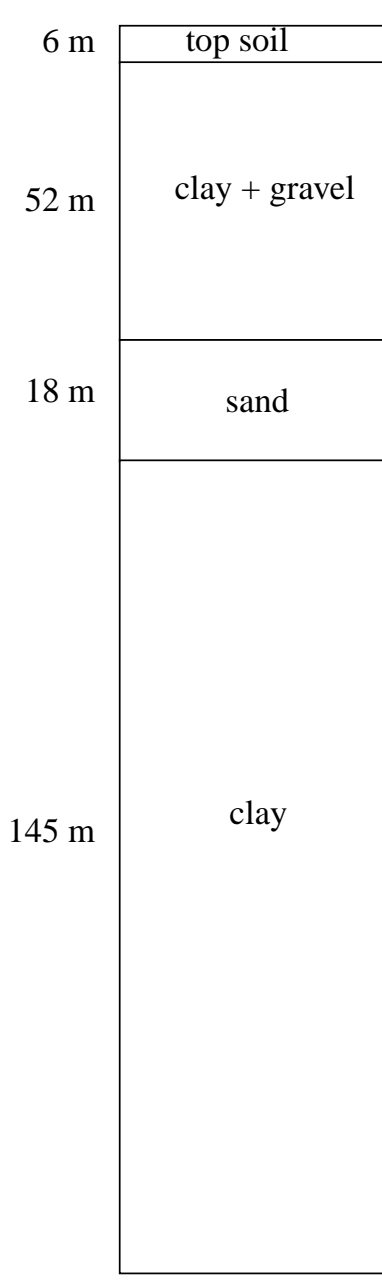

(B) Soil Surface-

\begin{tabular}{|l|}
\hline sandy loam \\
\hline loamy sand \\
\hline gravel, sand \\
\hline sandy loam \\
\hline
\end{tabular}

gravel, sand

$0.75 \mathrm{~m}$

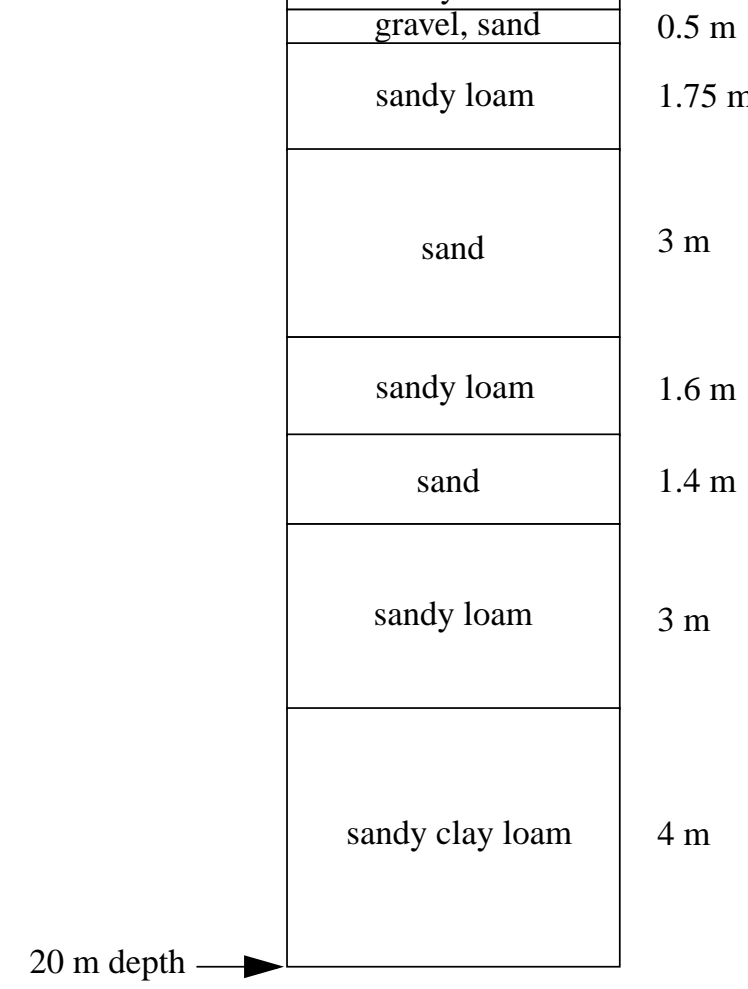

$20 \mathrm{~m}$ depth

Figure 2-1. (A) Geologic characterization from a deep borehole on the Maricopa Agricultural Center, and (B) Nearsurface characterization interpreted from shallow boreholes on the test case site. Both figures are based on information provided by University of Arizona staff.

Figure 2-1(B). Such small-scale variability is typical for natural porous media deposits.

At the test case site, the water table was found at approximately $13 \mathrm{~m}$ below the surface. This is likely to be a perched water table. For the purposes of the test case application, however, it will be assumed that this water table defines the upper boundary of a groundwater source exploited by the resident farmer for domestic, irrigation, and livestock uses. In addition, it is assumed that the clayey sediments located at approximately $16 \mathrm{~m}$ below the surface are relatively impermeable and serve as the lower boundary of the saturated zone.
Meteorological data representing the test case application site was obtained from a weather station located on the Maricopa Agricultural Center. This weather station is at an elevation of $361 \mathrm{~m}$ and is located at a latitude of $33^{\circ} 04^{\prime} 07^{\prime \prime}$ north and a longitude of $111^{\circ} 58^{\prime} 18^{\prime \prime}$ west. Average annual precipitation measured at the Maricopa Agricultural Center was approximately $18 \mathrm{~cm}$ over the period 1988-1998. Distribution of the precipitation throughout the year is shown in Figure 2-2 for the same time period. For many agricultural crops, this relatively small amount of natural precipitation must be supplemented with irrigation. As mentioned previously, the test case application site is in a region where irrigated agriculture using local groundwater sources is common. The Maricopa Agricultural Center is a 770-ha research 
Test Case Descriptions and Initial Deterministic Results

(A)

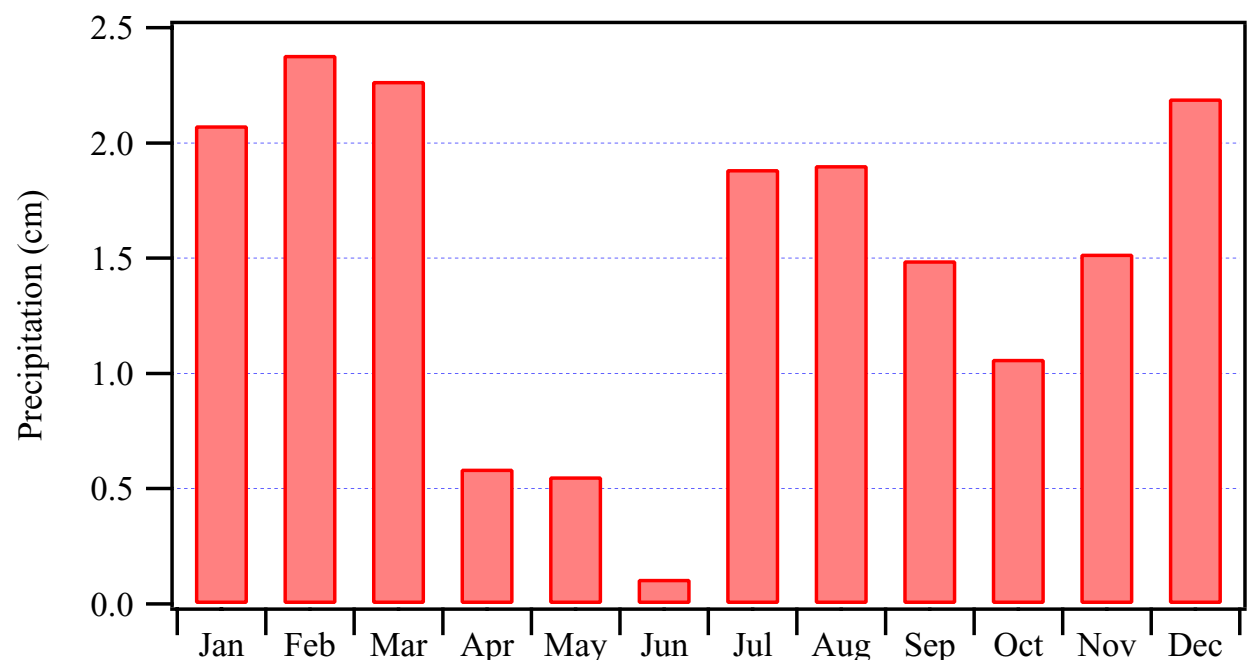

(B)

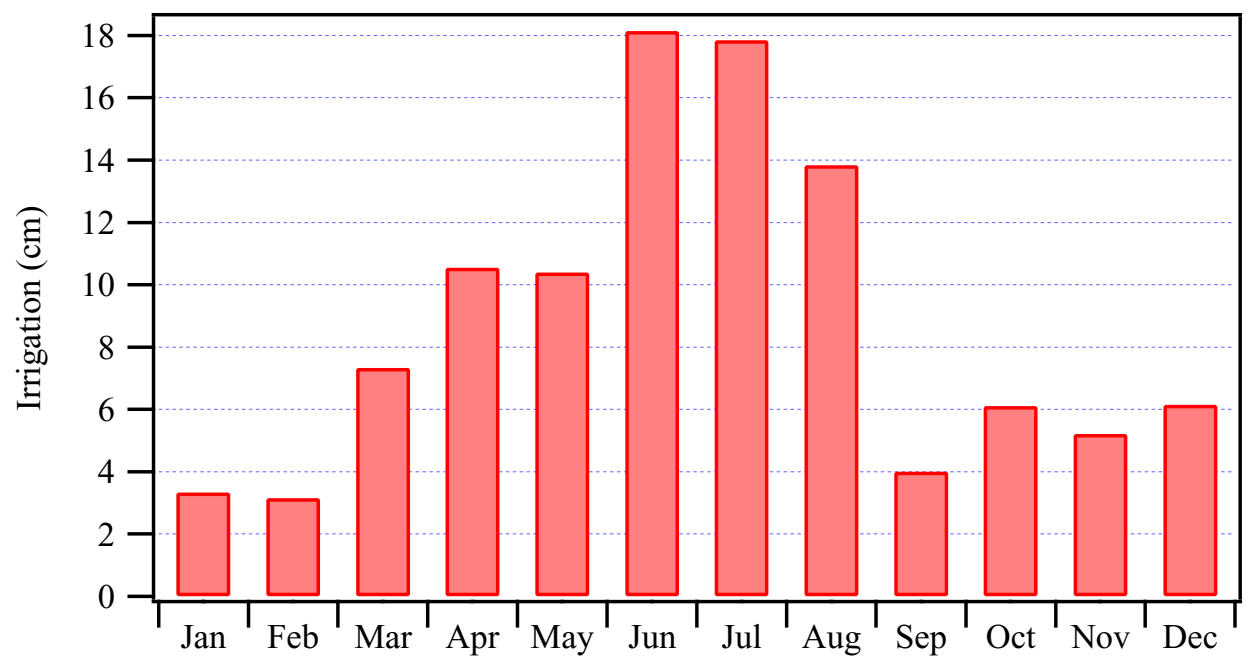

Month

Figure 2-2. Data from the Maricopa Agricultural Center, (A) Average monthly precipitation for the period 1988-1998, (B) Average monthly irrigation for the period 1990-1998

facility on which irrigated crops are grown extensively. Data from the Center indicate that the average annual irrigation from 1989-1998 over 174 ha was approximately $1.1 \mathrm{~m}$. Average monthly irrigation from 1990-1998 is shown in Figure 2-2. The data demonstrate that for the test case site, irrigation contributes significantly more water to the soil profile than natural precipitation. Average monthly irrigation is as high as $18 \mathrm{~cm}$ during the peak summer months when crop water requirements are largest.

\subsection{Initial Deterministic Simulations}

\subsubsection{DandD Screening Simulation}

A screening dose assessment simulation was carried out using the DandD code (v. 1.0) (Wernig et al., 1999) as described in the framework of NUREG-1549 (NRC, 1998). Details of the conceptual model and mathematical implementation of the DandD code can be found in Beyeler et al. (1999) and Kennedy and Strenge (1992). For the DandD screening simulation, the code was run with default parameters and pathways and the initial contaminant source concentrations for the excavation case given in Table 2-1. The 
excavation source concentrations were used because this case corresponds to the conceptual model of DandD, which assumes that all contaminants reside in the upper $15 \mathrm{~cm}$ of soil. This screening analysis resulted in a peak TEDE of 829 mrem during year 4 of the simulation. This peak dose is substantially larger than the 25-mrem regulatory criterion. The primary pathways contributing to the peak dose were irrigation (48\%), aquatic (25\%), and drinking (23\%). The dose via the external pathway was less than $1 \%$ of the total. The peak dose was due almost entirely to the uranium isotopes, with U-234 accounting for $83 \%$ of the peak dose and U-235 (3\%) and U-238 (9\%) contributing to a substantially lesser degree. Th-232 and Ra-228 each contributed about $1.5 \%$ of the peak dose.

\subsubsection{Site-Specific DandD Simulations}

Because the DandD screening simulation resulted in a dose much larger than the regulatory criterion, a site-specific DandD simulation was carried out. Site-specific here refers to the fact that some of the default DandD parameters were modified to reflect site-specific conditions at the test case site. Following the NRC staff guidance presented in the NUREG-1727 (NRC, 2000), modifications were limited to the physical parameters of the DandD code.

The DandD default physical parameters were modified to reflect the site-specific attributes of the test case site as described above. A simplified soil profile for the test case site that is consistent with the conceptual model of DandD is shown in Figure 2-3. The 0.15-m contaminated zone consists of a sandy loam soil. The 11.2-m unsaturated zone has the characteristics of a sand, the principal component of the unsaturated zone at the test case site. The unsaturated zone has homogeneous hydraulic properties (as required by DandD), but is divided into ten computational units as recommended by Cole et al. (1998) to improve the representation of travel time and dispersion. The saturated zone characteristics are fixed by the code. Dilution in the aquifer is determined by the infiltration rate, irrigation rate, and domestic water use parameters (Beyeler et al., 1999).

Physical parameters modified for the site-specific DandD test case simulation are listed in Table 2-2. The irrigation rate was modified to reflect the relatively large irrigation rates that are used on the Maricopa Agricultural Center. As noted above, even larger rates are commonly used at that site. Average annual precipitation was taken to be $25.4 \mathrm{~cm}$, somewhat higher than the observed average over the last 10 years. The infiltration rate reflects the contributions of irrigation and natural precipitation and was calculated with the equation used in the RESRAD code,

$$
\text { Infil. }=\left(1-\mathrm{C}_{\mathrm{e}}\right)\left[\left(1-\mathrm{C}_{\mathrm{r}}\right) \text { Precip. + Irrig. }\right)
$$

where $\mathrm{C}_{\mathrm{e}}$ and $\mathrm{C}_{\mathrm{r}}$ are evapotranspiration and runoff coefficients, respectively. These coefficients were taken to be the
RESRAD default values of $\mathrm{C}_{\mathrm{e}}=0.5$ and $\mathrm{C}_{\mathrm{r}}=0.2$. The resulting infiltration rate of $0.48 \mathrm{~m} / \mathrm{yr}$ is high for the climate of the test case site and more accurate methods of estimating the site-specific infiltration rate could be pursued. A later discussion examines the effect of the infiltration rate on predicted dose.

The bulk densities of the contaminated and unsaturated zones were based on measurements of soil samples from across the US contained in the US Department of Agriculture (USDA) Natural Resources Conservation Service Soil Characterization Database (Soil Survey Staff, 1994). The mean and standard deviation of bulk density for each USDA soil texture from this database are given in Appendix A. The mean sandy loam value was used for the contaminated zone while the unsaturated zone value was taken to be the mean value for sand. These bulk density values fall within the range of observed values at the test case site.

Modified values for the porosities were selected in a similar manner to that used for the bulk density except using the mean values from the appropriate tables in Appendix A of Meyer et al. (1997). These tables list recommended probability distributions for soil hydraulic parameters and are included here in Appendix B. The distributions are based on

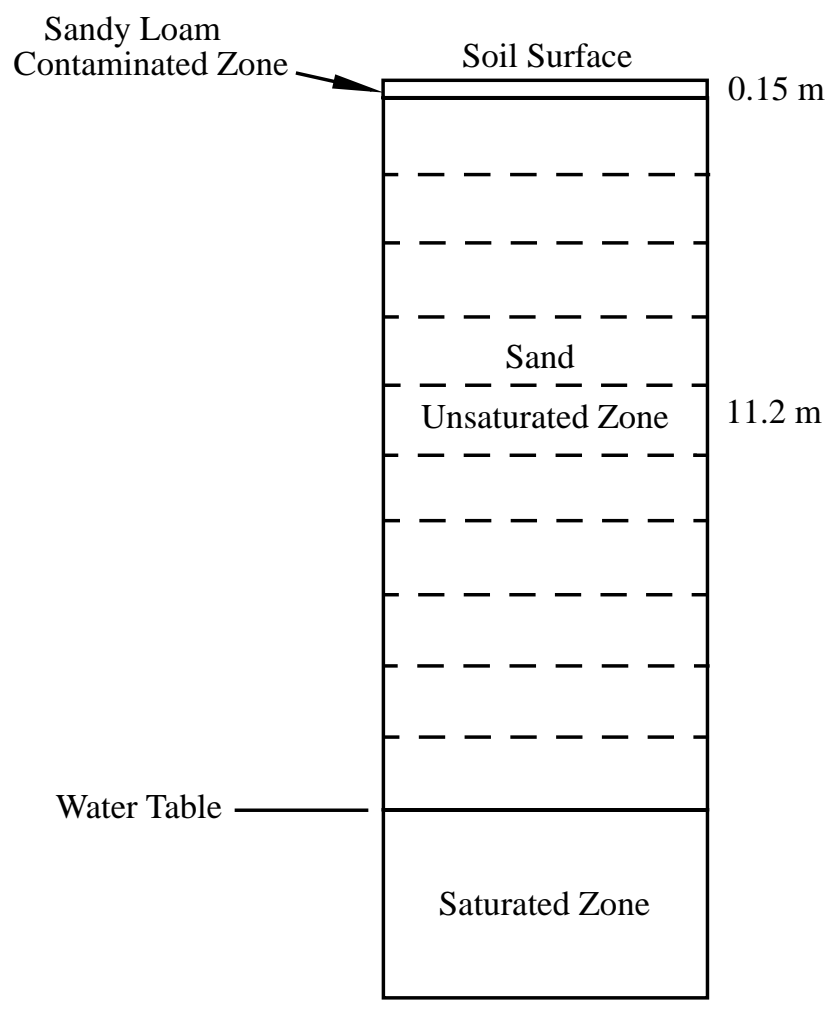

Figure 2-3. Soil profile for DandD site-specific simulation. Dashed lines indicate the unsaturated zone computational layers. 
Table 2-2. Physical parameters of DandD modified to reflect the hypothetical test case site

\begin{tabular}{ccc}
\hline Parameter & $\begin{array}{c}\text { DandD } \\
\text { Default }\end{array}$ & $\begin{array}{c}\text { Modified } \\
\text { Value }\end{array}$ \\
\hline Infiltration $(\mathrm{m} / \mathrm{yr})$ & 0.2526 & 0.48 \\
Irrigation (m/yr) & 0.471 & 0.75 \\
$\mathrm{CZ}^{\mathrm{a}}$ Bulk Density (g/cm $\left.{ }^{3}\right)$ & 1.4312 & 1.46 \\
$\mathrm{CZ}^{\mathrm{a}}$ Porosity & 0.4599 & 0.41 \\
$\mathrm{CZ}^{\mathrm{a}}$ Relative Saturation & 0.1626 & 0.38 \\
$\mathrm{UZ}^{\mathrm{a}}$ Thickness (m) & 1.2288 & 11.2 \\
$\mathrm{UZ}^{\mathrm{a}}$ Bulk Density $\left(\mathrm{g} / \mathrm{cm}^{3}\right)$ & 1.4312 & 1.58 \\
UZ ${ }^{\mathrm{a}}$ Porosity & 0.4599 & 0.43 \\
$\mathrm{UZ}^{\mathrm{a}}$ Relative Saturation & 0.1626 & 0.18 \\
Number of UZ $^{\mathrm{a}}$ Layers & 1 & 10 \\
Domestic Water Use $(\mathrm{L} / \mathrm{yr})$ & 118,000 & 100,000 \\
Cultivated Area (m $\left.{ }^{2}\right)$ & 2400 & 4200 \\
\hline
\end{tabular}

a. CZ - contaminated zone, UZ - unsaturated zone

a national database of soil physical property measurements. The use of national databases to supplement site-specific information on parameter values is part of the uncertainty assessment methods described in Meyer and Gee (1999).

Although the bulk density and porosity values for the sandy loam and sand soils were based on different datasets, they are still consistent with one another, given the potential variation in the (unknown) average particle density. Using the relationship between porosity and bulk density,

$$
\phi=1-\rho_{b} / \rho_{p},
$$

the values chosen for the test case simulation correspond to a particle density of $2.47 \mathrm{~g} / \mathrm{cm}^{3}$ for the sandy loam soil and $2.77 \mathrm{~g} / \mathrm{cm}^{3}$ for the sand soil. In Eq. $2-2 \phi$ is the porosity, $\rho_{\mathrm{b}}$ is the bulk density, and $\rho_{\mathrm{p}}$ is the particle density. Values for either porosity or bulk density could also be selected by assuming a particle density of $2.65 \mathrm{~g} / \mathrm{cm}^{3}$.

Relative saturations for the two zones in the DandD model were calculated using the following equation.

$$
\frac{\theta}{\theta_{s}}=\left(\frac{I}{K_{s}}\right)^{1 /(2 b+3)}
$$

where $\theta / \theta_{s}$ is the relative saturation, $I$ is the infiltration rate, $K_{s}$ is the saturated hydraulic conductivity, and $b$ is a parameter based on soil type. This equation represents the unsaturated hydraulic conductivity using the model of Campbell (1974) and assumes that the unsaturated flow is due to gravity only (the unit gradient assumption). All parameter values for the contaminated and unsaturated zones were selected as the mean values from the distributions given in Meyer et al. (1997) for sandy loam and sand soil textures, respectively. These values are given in Table 2-3.

\begin{tabular}{ccc} 
Table 2-3. & $\begin{array}{c}\text { Additional parameters used to calculate } \\
\text { relative saturations }\end{array}$ \\
\hline & $\mathbf{K}_{\mathbf{s}}(\mathbf{m} / \mathbf{y r})$ & $\mathbf{b}$ \\
\hline Cont. Zone & 369 & 1.96 \\
Unsat. Zone & 2594 & 1.00
\end{tabular}

The number of unsaturated zone layers was set at the maximum value of 10 based on the observations of Cole et al. (1998). They compared transport predictions using the algorithms of the DandD code to analogous numerical models and concluded that the additional unsaturated zone layers resulted in more realistic predictions of travel time and peak dose.

Domestic water use was arbitrarily reduced to $100,000 \mathrm{~L} / \mathrm{yr}$. The cultivated area was increased to $4200 \mathrm{~m}^{2}$ to reflect the conditions of the excavation case as described at the beginning of this chapter. Modification of the irrigation or domestic water use may change the volume of the aquifer and consequently the amount of dilution in the aquifer. In this application, the effect is to increase dilution and therefore decrease the peak dose.

With the modifications to the physical parameters as listed in Table 2-2, DandD predicts a peak dose of $285 \mathrm{mrem}$ at year 17 . Once again the primary pathways contributing to the peak dose are the irrigated (53\%), aquatic (25\%), and drinking (16\%) pathways. The external pathway was slightly less than $2 \%$ of the peak dose. The uranium isotopes were once again the primary contributors, comprising approximately $93 \%$ of the peak dose.

A DandD simulation was also carried out in which all parameters were at the default values except for the radionuclide distribution (partition) coefficients. The modified distribution coefficient values were set to the geometric mean values from Sheppard and Thibault (1990). The uranium value was selected from the table for loam soils; the remaining values were selected from the table for sand soils. DandD default and modified distribution coefficient values are given in Table 2-4.

The DandD simulation using all default parameter values except for the distribution coefficients listed in Table 2-4 resulted in a peak dose of $198 \mathrm{mrem}$ in year 10. Contribution to the peak dose by pathways was similar to the previous simulations with the irrigated, aquatic, and drinking pathways contributing about $84 \%$ of the peak dose. The agricultural (12\%) and the external (4\%) pathways were somewhat more important with the modified distribution coefficients. Similarly, Th-232 (6\%) and Ra-228 (3\%) contributed a somewhat larger share of the peak dose. 
Table 2-4. Radionuclide distribution coefficients modified for the hypothetical test case

\begin{tabular}{ccc}
\hline & \multicolumn{2}{c}{ Distribution Coefficients $(\mathbf{m l} / \mathbf{g})$} \\
\cline { 2 - 3 } Radionuclide & DandD Default & Modified \\
\hline $\mathrm{U}$ & 2.18 & 15 \\
$\mathrm{Th}$ & 119 & 3200 \\
$\mathrm{Ra}$ & 3530 & 500 \\
$\mathrm{~Pa}$ & 4.8 & 550 \\
$\mathrm{Ac}$ & 1730 & 450 \\
\hline
\end{tabular}

A final DandD simulation was carried out using all the modified parameter values listed in Tables 2-2 and 2-4. This simulation resulted in a peak dose of 70 mrem in year 98 . Contribution by pathway was irrigated (35\%), agricultural (28\%), aquatic (16\%), drinking (11\%), and external (9\%). Radionuclides contributing most significantly to the peak dose were U-234 (55\%), Th-232 (15\%), and Ra-228 (8\%).

The results from the DandD simulations are summarized in Table 2-5. As was the intention when the DandD default parameters were derived, their use results in a conservative dose relative to the use of site-specific parameter values. Modification of physical parameter values for the hypothetical test case results in predicted doses that are significantly smaller. In addition, the external pathway and contributions from Th-232 and Ra-228 become somewhat more important for this test case. In spite of the parameter modifications, however, the smallest dose is still larger than the 25 mrem criterion for unrestricted release.

Table 2-5. Summary of DandD simulation results

\begin{tabular}{ccc}
\hline $\begin{array}{c}\text { Physical Parameters } \\
\text { Modified }\end{array}$ & $\begin{array}{c}\text { Peak Dose } \\
(\mathbf{m r e m} / \mathbf{y r})\end{array}$ & $\begin{array}{c}\text { Peak Dose } \\
\text { Time (yr) }\end{array}$ \\
\hline None (Default Values) & 829 & 4 \\
Physical Parameters in \\
Table 2-2 Modified & 285 & 17 \\
$\begin{array}{c}\text { Distribution Coefficients in } \\
\text { Table 2-4 Modified }\end{array}$ & 198 & 10 \\
$\begin{array}{c}\text { Parameters in Tables 2-2 } \\
\text { and 2-4 Modified }\end{array}$ & 70 & 98 \\
\hline
\end{tabular}

\subsubsection{RESRAD Base Case Simulations}

RESRAD v. 6.0 was used to conduct several deterministic simulations as well as the probabilistic simulations discussed in the following chapter. Documentation for the RESRAD code is contained in Yu et al. (1993) and LePoire et al. (2000).

\subsubsection{RESRAD Base Case Parameter Values}

While the DandD code is unable to represent soil layering such as that shown in Figure 2-1(B), RESRAD has this capability. In spite of this, the soil profile layering shown in Figure 2-1(B) may actually be too detailed for a simplified codes such as RESRAD. Difficulties such as excessive computational times may result from the use of too many layers. In addition, representing such small-scale differences in sediments is somewhat inconsistent with the underlying simplified conceptual model of these codes, that of onedimensional, steady-state, unit gradient flow. Because of this, the sediment profile was simplified from Figure 2-1(B) for the RESRAD test case applications.

Figure 2-4 shows this simplified soil profile for the in situ case (on the left side of the figure) and for the excavation case (on the right). For the in situ case, the upper two meters of the profile is a sandy loam soil consisting of a 0.9 m uncontaminated cover layer with a $0.9-\mathrm{m}$ layer of contaminated soil immediately beneath. The remaining $0.2 \mathrm{~m}$ of the upper sandy loam soil is designated as unsaturated zone 1 . There are three additional unsaturated zone layers, all fairly coarse textured. The total unsaturated zone thickness beneath the contaminated zone is $11.2 \mathrm{~m}$. The saturated zone is a 3-m thick layer of sediments with a sandy loam texture. A plan view of the contaminated zone is also shown in Figure 2-4.

The soil profile for the excavation case is identical to the in situ case except that the cover is not present and the contaminated zone is just $0.15-\mathrm{m}$ thick. Note that the distance the contaminants must travel to reach the groundwater is the same for the two cases. A plan view illustrating the relative size of the contaminated zone area for the excavation case (compared to the in situ case) is also shown in Figure 2-4.

Initial deterministic simulations using RESRAD were carried out assuming no site-specific measurements of parameter values were available. These simulations will be referred to as the base case simulations. Following the recommendations contained within NRC (2000) and Meyer and Gee (1999), the best-estimate parameter values for the hydrologic parameters were chosen from (1) default DandD values, (2) default RESRAD values, or (3) arithmetic mean values from parameter probability distributions derived from national databases and site-specific information. The default values used were primarily the behavioral and metabolic parameters as defined in Beyeler et al. (1999) and NRC (2000). The parameters used in the RESRAD simulations that are DandD (v. 1.0) default values are listed in Table 2-6. The remaining behavioral parameters were at RESRAD default values.

The majority of the physical parameters for the RESRAD simulations were modified from their default values to reflect the site-specific conditions described earlier in this chapter. The modified parameters are listed in Table 2-7. 
Test Case Descriptions and Initial Deterministic Results
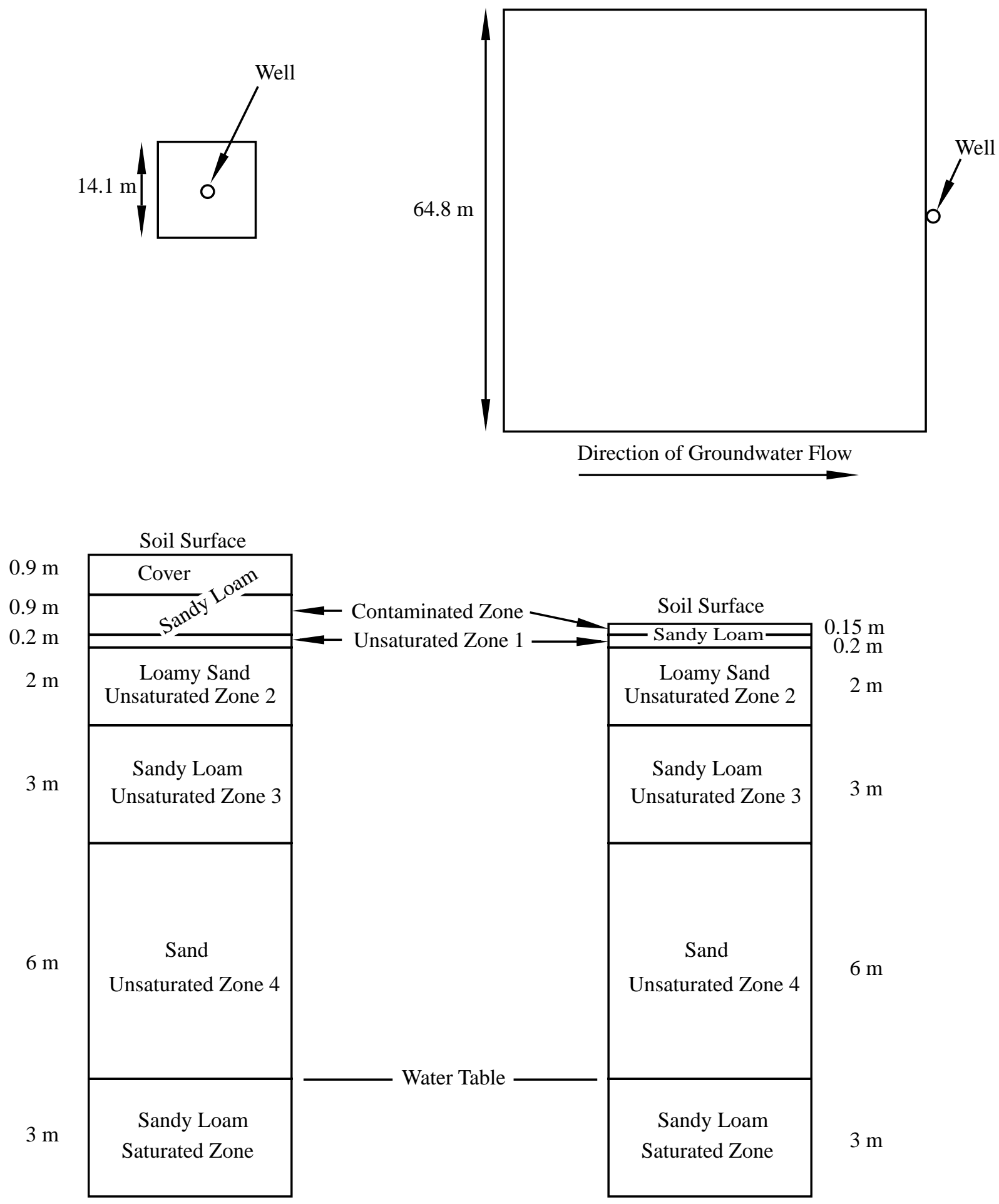

Figure 2-4. Plan views of contaminated area (top) and soil profile (bottom) for the in situ (left) and excavation (right) test cases 
Test Case Descriptions and Initial Deterministic Results

Table 2-6. DandD default parameter values used in the RESRAD simulations

\begin{tabular}{|c|c|c|}
\hline & Parameter & Value \\
\hline & Inhalation Rate $\left(\mathrm{m}^{3} / \mathrm{yr}\right)$ & 11690 \\
\hline & Mass Loading for Inhalation $\left(\mathrm{g} / \mathrm{m}^{3}\right)$ & $3.14 \times 10^{-6}$ \\
\hline & External Gamma Shielding Factor & 0.5512 \\
\hline & Indoor Time Fraction & 0.6571 \\
\hline & Outdoor Time Fraction & 0.1101 \\
\hline \multirow{5}{*}{ 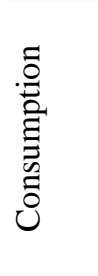 } & Fruit, vegetable, and grain $(\mathrm{kg} / \mathrm{yr})$ & 112 \\
\hline & Leafy vegetable $(\mathrm{kg} / \mathrm{yr})$ & 21.4 \\
\hline & Milk (L/yr) & 233 \\
\hline & Meat and poultry $(\mathrm{kg} / \mathrm{yr})$ & 65.1 \\
\hline & Fish (kg/yr) & 20.6 \\
\hline \multirow{4}{*}{ 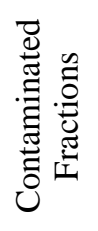 } & Aquatic food & 1 \\
\hline & Plant food & 1 \\
\hline & Meat & 1 \\
\hline & Milk & 1 \\
\hline \multirow{4}{*}{ 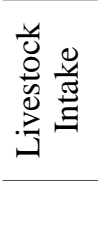 } & Fodder for meat (kg/day) & 27.1 \\
\hline & Fodder for milk (kg/day) & 63.25 \\
\hline & Water for milk (L/day) & 60 \\
\hline & Livestock fodder storage time (day) & 1 \\
\hline
\end{tabular}

(CZ, UZ, and SZ indicate the contaminated, unsaturated, and saturated zones, respectively, in this table. Values separated by a backslash are for the in situ/excavation cases.) Thicknesses of the various layers are given in Figure 2-4. Irrigation and infiltration rates are the same as those used in the DandD simulations. Because the site and surrounding area are quite flat, erosion rates were assumed to be zero. A rooting depth of $0.8 \mathrm{~m}$ is representative of deep rooted plants that may be grown on the site for food or forage. The dimensions of the contaminated zone for the in situ and excavation cases were discussed in Section 2.1.1.

Soil parameters were taken from the recommended distributions presented in Meyer et al. (1997), reproduced here in Appendix B. Mean values were used as the best estimates. The hydraulic gradient was estimated from water table measurements obtained at the site in May 1999. The well pumping rate was arbitrarily chosen. A rate of $625 \mathrm{~m}^{3} / \mathrm{yr}$ is sufficient to supply the estimated domestic water needs (100,000 L/yr) and enough water to irrigate $700 \mathrm{~m}^{2}$ at an average rate of $0.75 \mathrm{~m} / \mathrm{yr}$.

Initial radionuclide concentrations and distribution coefficients for the RESRAD simulations are listed in Tables 2-1
Table 2-7. RESRAD physical parameter values modified from their default values

\begin{tabular}{|c|c|c|}
\hline & Parameter & Value \\
\hline & Precipitation $(\mathrm{m} / \mathrm{yr})$ & 0.254 \\
\hline & Irrigation (m/yr) & 0.75 \\
\hline & Root Depth (m) & 0.8 \\
\hline \multirow{3}{*}{ 宛 } & Thickness (m) & $0 / 0.9$ \\
\hline & Bulk density $\left(\mathrm{g} / \mathrm{cm}^{3}\right)$ & 1.46 \\
\hline & Erosion rate $(\mathrm{m} / \mathrm{yr})$ & 0 \\
\hline \multirow{4}{*}{ 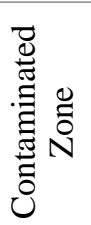 } & Area $\left(\mathrm{m}^{2}\right)$ & $4200 / 200$ \\
\hline & Thickness (m) & $0.15 / 0.9$ \\
\hline & Length parallel to aquifer flow (m) & $65 / 14$ \\
\hline & Erosion rate (m/yr) & 0 \\
\hline \multirow{6}{*}{ 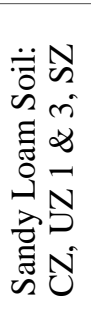 } & Bulk density $\left(\mathrm{g} / \mathrm{cm}^{3}\right)$ & 1.46 \\
\hline & Total porosity & 0.41 \\
\hline & Effective porosity & 0.346 \\
\hline & Field capacity & 0.12 \\
\hline & Sat. Hydraulic Conductivity (m/yr) & 369 \\
\hline & Soil-type 'b' parameter & 1.96 \\
\hline \multirow{6}{*}{ 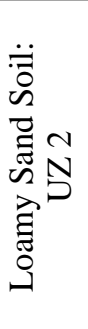 } & Bulk density $\left(\mathrm{g} / \mathrm{cm}^{3}\right)$ & 1.52 \\
\hline & Total porosity & 0.41 \\
\hline & Effective porosity & 0.353 \\
\hline & Field capacity & 0.08 \\
\hline & Sat. Hydraulic Conductivity (m/yr) & 1259 \\
\hline & Soil-type 'b' parameter & 1.4 \\
\hline \multirow{6}{*}{ 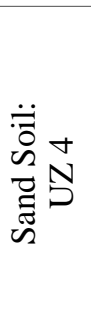 } & Bulk density $\left(\mathrm{g} / \mathrm{cm}^{3}\right)$ & 1.58 \\
\hline & Total porosity & 0.43 \\
\hline & Effective porosity & 0.383 \\
\hline & Field capacity & 0.06 \\
\hline & Sat. Hydraulic Conductivity (m/yr) & 2594 \\
\hline & Soil-type 'b' parameter & 1.0 \\
\hline \multirow{4}{*}{ 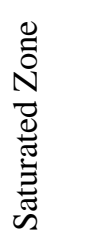 } & Hydraulic gradient & 0.007 \\
\hline & Water table drop rate $(\mathrm{m} / \mathrm{yr})$ & 0 \\
\hline & $\begin{array}{l}\text { Well pump intake depth below } \\
\text { water table }(\mathrm{m})\end{array}$ & 0.9 \\
\hline & Well pumping rate $\left(\mathrm{m}^{3} / \mathrm{yr}\right)$ & 625 \\
\hline
\end{tabular}

and 2-4 with the following change: the distribution coefficients for the uranium isotopes are $15 \mathrm{ml} / \mathrm{g}$ in the sandy loam soil and $35 \mathrm{ml} / \mathrm{g}$ in the loamy sand and sand soils. 
Test Case Descriptions and Initial Deterministic Results

These are the geometric mean values for loam and sand soils, respectively, from Sheppard and Thibault (1990).

Those parameters not listed in Table 2-7 or discussed here were set at the RESRAD default values.

The inhalation, soil ingestion, and radon pathways were turned off for the RESRAD simulations. The mass balance transport model was used for the in situ case while the nondispersion transport model was used for the excavation case. The RESRAD documentation (Yu et al., 1993) states that the mass balance model is usually used when the contaminated area is less than $1000 \mathrm{~m}^{2}$. The mass balance model assumes that all of the contaminant that arrives at the water table gets withdrawn through the well and that mixing in the aquifer is instantaneous. Dilution in the well for this model depends only on the amount of water passing through the contaminated zone and the well pumping rate. The nondispersion model calculates travel time through the saturated zone (along the length of the contaminated zone) and bases the dilution in the well on additional factors such as the flow rate in the aquifer and the depth of the well.

\subsubsection{RESRAD Base Case Results}

The RESRAD in situ base case simulation results in a peak dose of $115 \mathrm{mrem} / \mathrm{yr}$ at 939 years. This dose occurs primarily through the drinking water pathway $(58 \%)$ and the water-dependent plant (33\%) and milk (8\%) pathways. (The water-dependent pathways involve the contaminated irrigation water.) The peak dose is due almost entirely to the uranium isotopes with U-234 (86\%) contributing the largest share and U-238 (10\%) and U-235 (3\%) contributing relatively small amounts. (Note that daughter products of the radionuclides are included in the peak dose contributions reported here, but their contribution is less than $1 \%$ in this case.)

Since the in situ base case cover thickness is greater than the rooting depth and there is no cover erosion, the relative contribution of water-independent pathways is minimized. Only $3 \%$ of the total peak dose is due to direct plant uptake of Th232. This pathway would be more significant if the rooting depth were greater than the cover thickness, as is the case for the excavation scenario.

The excavation base case simulation results in a peak dose of $16 \mathrm{mrem} / \mathrm{yr}$ at year 973 . The drinking water pathway is once again the largest contributor (39\%) with the external (25\%) and the water-dependent plant (23\%) pathways contributing the majority of the remaining dose. U-234 still contributes the largest share of the total peak dose (58\%) with Th-232 contributing most of the remainer (32\%).

The total dose as a function of time for the two base case RESRAD simulations is shown in Figure 2-5. (Note that the two cases are plotted at different scales for the dose.) In both cases, the peak dose is due to the uranium isotopes and the peaks are fairly sharp. This behavior indicates that the uranium is released from the source over a relatively short period of time. In fact, after 100 years the soil concentration of uranium in the contaminated zone has dropped to approximately $10 \%$ of its initial value for the in situ case and to far less than $1 \%$ of the initial value for the excavation case.

Because of the sharp peak that occurs in total dose, lengthening the travel time slightly (less than $10 \%$ in the excavation test case) will produce a result that satisfies the regulatory criterion by moving the peak dose pulse shown in Figure 2-5 to a point beyond 1000 years. Such a result demonstrates the importance of considering the uncertainty in parameter values. This result also emphasizes the importance of considering uncertainty in the time at which the peak dose occurs, in addition to uncertainty in the magnitude of the peak.

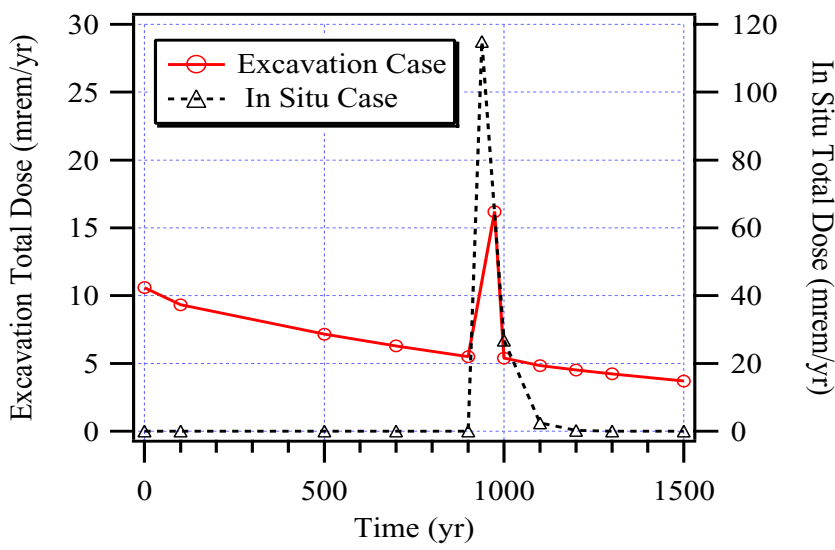

Figure 2-5. Total dose as a function of time from the base case RESRAD simulations for the excavation and in situ cases 



\section{Sensitivity Analyses and Probabilistic Simulation Results}

As discussed in the introduction, there are two general goals of an uncertainty assessment in decommissioning analyses. The first is to determine the uncertainty in the predicted peak dose given the various input uncertainties in parameters, models, and scenarios. For model and scenario uncertainty, this is generally done by separately evaluating alternative scenarios or models. This type of analysis requires a relatively small number of simulations (depending on the number of alternatives considered) and provides an estimate of the range in predicted dose as a result of the scenario or model uncertainty.

For parameter uncertainty, methods are available to translate probability distributions of parameter values (which represent parameter uncertainty) into a probability distribution of dose. (For a description of the most commonly used methods, see Morgan and Henrion, 1990). The expected value of the dose distribution (or some other statistical measure) can then be used in regulatory decision making. The Monte Carlo simulation method is used here to derive probability distributions of dose since this method is implemented in RESRAD (and is relatively easy to implement for other codes). Kozak et al. (1993) presented an approach for lowlevel waste performance assessment that combined scenario, model, and parameter uncertainty. In that approach a Monte Carlo simulation for parameter uncertainty is carried out for each of the scenario/model alternatives. Such an approach is also applicable to decommissioning analyses.

The other general goal of an uncertainty assessment for decommissioning analyses is to understand the aspects of the problem that contribute the most to uncertainty in the dose. With this understanding it is possible to determine how additional data or revisions in assumptions may affect the regulatory decision. Note that this includes those aspects related to scenario and model uncertainty as well as parameter uncertainty. Limiting the analysis to parameter uncertainty, this goal can be restated as the identification of critical parameters: that is, those parameters that contribute most significantly to the uncertainty in dose. One of the common techniques for identifying critical parameters is sensitivity analysis (Morgan and Henrion, 1990; Helton, 1993; NRC, 1999).

An informal analysis of the RESRAD code and identification of potentially critical parameters is carried out in the following section. Using the results of this analysis, probability distributions for the RESRAD test case parameters are defined. Deterministic sensitivity measures are then applied to the test cases. The chapter concludes with the application of probabilistic methods to the in situ and excavation test cases.

\subsection{Informal Analysis of RESRAD Parameters}

The subsurface hydrologic transport model in RESRAD is quite simplified and it is instructive to examine the basic behavior of the code by extracting this piece of the transport model and simplifying it a bit more to allow some of the features of the code to be displayed in a single spreadsheet page. Figure 3-1 is a spreadsheet that illustrates the calculation of the infiltration rate and the dilution factors for the mass balance (MB) and nondispersion (ND) models of RESRAD using the methods described in Yu et al. (1993). The in situ case is shown in Figure 3-1. A calculation of advective travel times through the various layers of the test case site (with consideration of linear equilibrium adsorption) is also shown in this figure. With simple tools such as these spreadsheets it is easy to see the value of some important intermediate parameters of the code (such as the dilution factors and the travel times). By altering parameter values it is also easy to immediately see the effect of parameter changes on basic measures of the performance of the site with respect to the regulatory criteria.

For the test case application, the results of the spreadsheet calculations are fairly accurate. Referring back to Section 2.2.3.2, one can see that the travel times for the mass balance model (given as total breakthrough time in Figure 3-1) and the nondispersion model (given as time to peak dose) are similar to the base case results (939 years for the in situ case and 973 years for the excavation case). This similarity occurs because the peak dose is due to the transport of long-lived uranium isotopes in the groundwater.

Although the spreadsheet closely reflects the behavior of RESRAD for the hypothetical test case, this may not be the case for other sites or other contaminants (for example, a primary contaminant that had a much shorter half-life than U-234). In addition, the spreadsheet is a simplification of RESRAD and may not reflect the parameters of greatest interest at another site (for instance, if the primary pathway was the water-independent plant pathway).

Manipulation of the parameter values on the spreadsheet model (changing one parameter at a time) demonstrates that the values of the contaminated area and the well pumping rate have a significant influence on the dilution factors. Additional parameters influence the nondispersion model dilution factor but not that of the mass balance model. The advective travel time calculations show that transport in unsaturated zone 4 comprises the majority of the travel time. The field capacity, saturated hydraulic conductivity, and soil-type exponent have minimal or no effect on the travel time through this layer. 
Sensitivity Analyses and Probabilistic Simulation Results

$\begin{array}{lc}\text { Precipitation } & 0.254 \mathrm{~m} / \mathrm{y} \mathrm{r} \\ \text { Irrigation } & 0.75 \mathrm{~m} / \mathrm{y} \mathrm{r} \\ \text { Evapotranspiration Coefficient } & 0.5 \\ \text { Runoff Coefficient } & 0.2 \\ \text { Infiltration Rate } & 0.48 \mathrm{~m} / \mathrm{y} \mathrm{r} \\ & \\ & \\ \text { Calculation of RESRAD Dilution Factor } & \\ & \\ \text { Contaminated Zone Area } & 200 \mathrm{~m}^{\wedge} 2 \\ \text { Length of Cont. Zone II hydraulic gradient } & 14.1 \mathrm{~m} \\ \text { Contaminated Zone Thickness } & 0.9 \mathrm{~m} \\ \text { Well Pumping Rate } & 625 \mathrm{~m} \wedge 3 / \mathrm{yr} \\ \text { Well Intake Depth below Water Table } & 0.9 \mathrm{~m} \\ \text { Aquifer Saturated Hyd. Conductivity } & 369 \mathrm{~m} / \mathrm{y} \mathrm{r} \\ \text { Aquifer Hydraulic Gradient } & 0.007 \mathrm{~m} / \mathrm{m} \\ \text { Water Flow Rate in the Aquifer } & 2.6 \mathrm{~m} / \mathrm{y} \mathrm{r} \\ \text { Effective Pumping Diameter } & 268.9 \mathrm{~m} \\ \text { Depth below wat. tbl. of contamination } & 2.6 \mathrm{~m} \\ \text { Area/length of cont. Zone } & 14.1 \mathrm{~m} \\ & \\ \text { Dilution Factor for MB model } & 0.15 \\ \text { Dilution Factor for ND model } & 0.05\end{array}$

$\begin{array}{lr}\text { Zone Properties } & \\ \text { thickness }(\mathrm{m}) & 1.46 \\ \text { bulk density }\left(\mathrm{g} / \mathrm{cm}^{\wedge} 3\right) & 0.41 \\ \text { total porosity } & \\ \text { effective porosity } & 0.12 \\ \text { field capacity } & 369 \\ \text { saturated hyd. Conductivity (m/yr) } & 1.96 \\ \text { soil-type exponent } & 15 \\ \text { distribution coefficient (cm^3/g) } & 0.16 \\ \text { water content } & 141 \\ \text { Retardation factor } & \\ \text { travel time in unsat zone }(\mathrm{yr}) & \\ \text { travel time along length of cont. Zone (yr) } & \\ & \\ \text { Total breakthrough time } & 939 \mathrm{y} \mathrm{r} \\ \text { Rise time } & 42 \mathrm{y} \mathrm{r} \\ \text { Time to peak dose } & 981 \mathrm{y} \mathrm{r}\end{array}$

Figure 3-1. Spreadsheet calculation of the RESRAD dilution factors (top) and advective travel time of a conservative solute (bottom) for the in situ test case

\subsection{Parameter Distributions}

As mentioned earlier, characterizations of parameter uncertainty can take a number of forms ranging from bounding values to a complete probability distribution (density function). In this analysis, probability distributions are used. For the soil hydraulic parameters, these distributions are based on national databases of estimated parameters for sim- ilar soil textures. When a mean and variance of a parameter could be estimated, the normal distribution was used. Uniform distributions were used for those parameters whose uncertainty was best characterized by bounding values.

One of the important decisions in a parameter uncertainty analysis is deciding which parameters to include in the analysis. In general, all parameters whose values are not well known should be included. From a practical standpoint, 
however, some parameters can often be eliminated. Because the simplified model analysis discussed in Section 3.1 showed that travel times through unsaturated zones 1 and 3 were relatively short, the parameters for these zones were not considered in this test case application. Since this analysis is limited to the hydrologic parameters only, this eliminated a number of other parameters as well.

The parameters for which probability distributions were assigned for the test case are shown in Table 3-1. All soil hydraulic parameter distributions were taken from Meyer et al. (1997) for the appropriate soil types (loamy sand for unsaturated zone 2, sand for unsaturated zone 4, and sandy loam for the contaminated and saturated zones). These tables of parameter distributions are reproduced here in Appendix B. (Definitions of parameters listed in Appendix B can be found in Appendix D.) Bulk densities were taken from Appendix A of this report.

Distributions for the two cover parameters listed were intended to represent reasonable ranges. The evapotranspiration coefficient is used, along with other parameters, to calculate the infiltration rate (see Eq. 2-1). These other parameters are all constant in the test case applications so the variation in the infiltration rate is entirely due to the evapotranspiration coefficient distribution. The resulting distribution of infiltration rates varies from 0.19 to 0.76 $\mathrm{m} / \mathrm{yr}$.
Because the uranium isotopes were the primary contributors to the peak dose in the base case simulation, only the distribution coefficients $\left(\mathrm{K}_{\mathrm{d}}\right)$ for uranium were included in the uncertainty assessment. The probability distribution given in Table 3-1 for the uranium $\mathrm{K}_{\mathrm{d}}$ in the sandy loam layers (the contaminated zone, unsaturated zones 1 and 3 , and the saturated zone) was chosen to give a fairly wide range of possible values. The uranium $\mathrm{K}_{\mathrm{d}}$ in unsaturated zones 2 and 4 was held at a constant value.

The mean values given in Table 3-1 are the base case values with the exception of the cover erosion rate, which has a base case value of $0 \mathrm{~m} / \mathrm{yr}$, and the well pump intake depth, which has a base case value of $3 \mathrm{~m}$.

Correlations between soil hydraulic parameters were taken from Meyer et al. (1997), reproduced here in Appendix C. Only correlation coefficients greater than 0.6 were assigned. A large positive correlation coefficient (0.99) was assigned between total porosity and effective porosity. A large negative correlation coefficient (-0.99) was assigned between total porosity and bulk density. These large correlations attempted to enforce fixed relationships between these parameters. For example, porosity is often calculated from a measurement of bulk density; effective porosity must be less than or equal to total porosity. A large correlation coefficient was also used with the distribution coefficients in an attempt to have similar values in all zones composed of sandy loam.

Table 3-1. Parameter distributions used in the hypothetical test case applications

\begin{tabular}{|c|c|c|c|c|c|c|}
\hline Parameter & Alias & Distribut. & Mean* & Std.Dev & Min & $\operatorname{Max}$ \\
\hline Source Cover Depth (m) & COVER0 & normal & 0.9 & 0.2 & 0.282 & 1.518 \\
\hline Cover Erosion Rate $(\mathrm{m} / \mathrm{yr})$ & VCV & loguniform & 0.00021 & 0.00025 & 0.00001 & 0.001 \\
\hline Evapotranspiration Coefficient & EVAPTR & normal & 0.5 & 0.168 & 0.2 & 0.8 \\
\hline Contaminated Zone Bulk Density $\left(\mathrm{g} / \mathrm{cm}^{\wedge} 3\right)$ & DENSCZ & normal & 1.46 & 0.268 & 0.63 & 2 \\
\hline Contaminated Zone Total Porosity (fraction) & TPCZ & normal & 0.41 & 0.09 & 0.132 & 0.688 \\
\hline Vadose Zone 2 Total Porosity (fraction) & TPUZ(2) & normal & 0.41 & 0.09 & 0.132 & 0.688 \\
\hline Vadose Zone 2 Sat. Hyd. Conductivity (m/yr) & HCUZ(2) & lognormal & 1259 & 1000 & 12 & 4229 \\
\hline Vadose Zone 2 Bulk Density $\left(\mathrm{g} / \mathrm{cm}^{\wedge} 3\right)$ & DENSUZ(2) & normal & 1.52 & 0.262 & 0.71 & 2 \\
\hline Vadose Zone 2 Effective Porosity (fraction) & EPUZ(2) & normal & 0.353 & 0.078 & 0.112 & 0.594 \\
\hline Vadose Zone 2 Soil-Type Exponent & BUZ(2) & lognormal & 1.4 & 0.397 & 0.61 & 3.01 \\
\hline Vadose Zone 4 Total Porosity (fraction) & TPUZ(4) & normal & 0.43 & 0.06 & 0.245 & 0.615 \\
\hline Vadose Zone 4 Sat. Hyd. Conductivity (m/yr) & $\operatorname{HCUZ(4)}$ & lognormal & 2594 & 1385 & 110 & 5870 \\
\hline Vadose Zone 4 Bulk Density $\left(\mathrm{g} / \mathrm{cm}^{\wedge} 3\right)$ & DENSUZ(4) & normal & 1.58 & 0.158 & 1.09 & \\
\hline Vadose Zone 4 Effective Porosity (fraction) & EPUZ(4) & normal & 0.383 & 0.05 & 0.23 & 0.54 \\
\hline Vadose Zone 4 Soil-Type Exponent & BUZ(4) & lognormal & 0.998 & 0.226 & 0.501 & 1.9 \\
\hline Saturated Zone Total Porosity (fraction) & TPSZ & normal & 0.41 & 0.09 & 0.132 & 0.688 \\
\hline Saturated Zone Effective Porosity (fraction) & EPSZ & normal & 0.346 & 0.076 & 0.27 & 0.422 \\
\hline Saturated Zone Sat. Hyd. Conduct & HCSZ & lognormal & 369 & 432 & 3 & 10950 \\
\hline Uranium Kd in Sandy Loam $\left(\mathrm{cm}^{\wedge} 3 / \mathrm{g}\right)$ & DCACT*(U) & normal & 15 & 4.5 & 1.1 & 28.9 \\
\hline Well Pump Intake Depth (m) & DWIBWT & uniform & 1.75 & 0.72 & 0.5 & 3 \\
\hline Well Pumping Rate $\left(\mathrm{m}^{\wedge} 3 / \mathrm{yr}\right)$ & UW & normal & 625 & 125 & 240 & 1010 \\
\hline
\end{tabular}

*Basecase erosion rate is $0 \mathrm{~m} / \mathrm{yr}$; Basecase well pump intake depth is $3 \mathrm{~m}$ 
[Note, however, that the code used by RESRAD to generate realizations of parameter values (Iman and Shortencarier, 1984) may modify these correlations for computational reasons.]

\subsection{Deterministic Sensitivity Measures}

The simplest measure of the sensitivity of peak dose, $D$, to the value of a parameter, $x$, is

$$
S=\left.\frac{\partial D}{\partial x}\right|_{A}
$$

where $A$ is the nominal set of parameters at which the sensitivities are evaluated. The partial derivative can be estimated from the nominal dose by modifying the value of $x$ by a small amount and making a second calculation of dose. To make relative comparisons between parameters meaningful, the sensitivity is usually normalized,

$$
S_{n}=\left.\frac{x_{A}}{D_{A}} \cdot \frac{\partial D}{\partial x}\right|_{A}
$$

where $x_{A}$ and $D_{A}$ are the nominal values of the parameter and the peak dose. An additional measure of sensitivity that includes the magnitude of the variation in the parameters is obtained by multiplying Eq. 3-1 by the standard deviation of the parameter.

$$
S_{\sigma}=\left.\sigma_{x} \cdot \frac{\partial D}{\partial x}\right|_{A}
$$

Note that Eq. 3-3 was referred to in Meyer and Gee (1999) as a measure of the importance of the parameter to uncertainty in dose and can be used to define critical parameters.

\subsubsection{Base Case Sensitivity Results}

Sensitivity of the peak total dose evaluated at the base case parameter values was determined by slightly modifying the base case parameter values one at a time (for those parameters listed in Table 3-1) and running RESRAD to determine the resulting change in the dose. In most cases, the base case parameter values were modified by increasing them by approximately one-fourth of the difference between the base case and maximum values. Deterministic sensitivities were calculated for the in situ case only.

The base case sensitivities, calculated according to Eqs. 3-1 to 3-3, are listed in Table 3-2. The peak dose is most sensitive to the evapotranspiration coefficient, the uranium distribution coefficient in the sandy loam soils, and the well pumping rate. The peak dose is much less sensitive to the remaining parameters, although the cover erosion rate and the bulk density/total porosity/effective porosity of the unsaturated zones are more important than the remaining parameters. These results are consistent with the conclusions of Meyer and Gee (1999) in their general assessment

Table 3-2. Deterministic sensitivity results about the base case parameter values for the in situ case

\begin{tabular}{lrrr}
\hline Parameter & S & S n & S· $\sigma$ \\
\hline Evapotranspiration Coefficient & -252.00 & -1.10 & -42.34 \\
Uranium Kd in Sandy Loam $\left(\mathrm{cm}^{\wedge} 3 / \mathrm{g}\right)$ & -5.70 & -0.74 & -25.65 \\
Well Pumping Rate $\left(\mathrm{m}^{\wedge} 3 / \mathrm{yr}\right)$ & -0.16 & -0.86 & -19.87 \\
Cover Erosion Rate $(\mathrm{m} / \mathrm{yr})$ & 18000.00 & 0.00 & 4.50 \\
Vadose Zone 4 Effective Porosity (fraction) & 50.96 & 0.17 & 2.55 \\
Vadose Zone 2 Bulk Density $\left(\mathrm{g} / \mathrm{cm}^{\wedge} 3\right)$ & -7.50 & -0.10 & -1.97 \\
Vadose Zone 4 Total Porosity (fraction) & 30.00 & 0.11 & 1.80 \\
Vadose Zone 4 Bulk Density (g/cm^3) & 8.33 & 0.11 & 1.32 \\
Vadose Zone 2 Effective Porosity (fraction) & 10.64 & 0.03 & 0.83 \\
Contaminated Zone Bulk Density (g/cm^3) & 2.22 & 0.03 & 0.60 \\
Vadose Zone 4 Soil-Type Exponent & 1.15 & 0.01 & 0.26 \\
Contaminated Zone Total Porosity (fraction) & -2.88 & -0.01 & -0.26 \\
Vadose Zone 4 Sat. Hyd. Conductivity (m/yr) & 0.00 & 0.00 & -0.24 \\
Vadose Zone 2 Sat. Hyd. Conductivity (m/yr) & 0.00 & 0.00 & -0.22 \\
Vadose Zone 2 Soil-Type Exponent & 0.34 & 0.00 & 0.13 \\
Source Cover Depth (m) & -0.50 & 0.00 & -0.10 \\
Vadose Zone 2 Total Porosity (fraction) & 0.00 & 0.00 & 0.00 \\
Saturated Zone Total Porosity (fraction) & 0.00 & 0.00 & 0.00 \\
Saturated Zone Effective Porosity (fraction) & 0.00 & 0.00 & 0.00 \\
Saturated Zone Sat. Hyd. Conductivity (m/yr) & 0.00 & 0.00 & 0.00 \\
Well Pump Intake Depth (m) & 0.00 & 0.00 & 0.00 \\
\hline
\end{tabular}


of the sensitivity of simplified dose assessment codes (such as DandD, RESRAD, and MEPAS). Note that dose is insensitive to the saturated zone parameters as a consequence of using the mass balance transport model of RESRAD.

The results in Table 3-2 show that Eqs. 3-2 and 3-3 provide similar estimates of the relative sensitivity of dose to the parameters. Eq. 3-3 may be preferred since it includes a measure of the magnitude of each parameter's uncertainty and it avoids the situation that occurs here with the cover erosion rate. The sensitivity to the cover erosion rate is underestimated using Eq. 3-2 (because the nominal value is zero for this parameter). Nonetheless, the relative importance of the parameters is consistent using Eqs. 3-2 and 3-3 for this application.

\subsubsection{Conservative Case Sensitivity Results}

As discussed in Meyer and Gee (1999) as well as other sources, one of the problems with a deterministic sensitivity analysis is it considers changes in only one parameter at a time and potentially evaluates the sensitivities about a single point (the base case in this application). In a study for the high-level radioactive waste repository performance assessment (NRC, 1999), these problems were addressed, in part, by performing a set of deterministic sensitivity analyses with the evaluation occurring about five points: a base case, a case with all parameters at their 90th percentile val- ues, a case with all parameters at their 10th percentile values, and two cases with parameter values chosen at random.

For the in situ test case application, a similar, but limited approach was taken. A second deterministic sensitivity analysis was carried out with all parameters set to reasonably conservative values. For most parameters, the conservative values were (approximately) either the 25th or 75th percentiles of the distributions given in Table 3-1. Which of these two values was used was determined from physical understanding of the models used in RESRAD or from the sensitivities evaluated at the base case parameter values (Table 3-2). A conservative set of parameters was chosen instead of, for example, a 90th percentile set because it was felt that evaluating the sensitivities with all parameters at conservative values would reveal any possible impact of parameter interactions in the region of concern (i.e., the region of large peak doses). Setting all parameters at large values (or small values) could result in a cancellation of sensitivities if one parameter has a negative effect on dose and another has a positive effect. Note that in choosing conservative values, physical conditions, such as the total porosity always being greater than or equal to the effective porosity, were maintained.

The results of the sensitivity measures evaluated at the conservative parameter values are presented in Table 3-3. Note that the peak dose using the conservative parameter values was $398 \mathrm{mrem} / \mathrm{yr}$ and occurred at 516 years. As measured by Eq. 3-3, the largest sensitivity was to the uranium distri-

Table 3-3. Deterministic sensitivity results about the conservative parameter values for the in situ case

\begin{tabular}{|c|c|c|c|c|c|}
\hline Parameter & Basecase & Conserv. & $\mathbf{S}$ & Sn & $\mathbf{S} \cdot \sigma$ \\
\hline Uranium Kd in Sandy Loam $\left(\mathrm{cm}^{\wedge} 3 / \mathrm{g}\right)$ & 15 & 9 & -35.90 & -0.81 & -161.55 \\
\hline Evapotranspiration Coefficient & 0.5 & 0.28496 & -470.61 & -0.34 & -79.06 \\
\hline Well Pumping Rate $\left(\mathrm{m}^{\wedge} 3 / \mathrm{yr}\right)$ & 625 & 465 & -0.46 & -0.54 & -57.50 \\
\hline Vadose Zone 4 Bulk Density $\left(\mathrm{g} / \mathrm{cm}^{\wedge} 3\right)$ & 1.58 & 1.78224 & 122.63 & 0.55 & 19.38 \\
\hline Vadose Zone 2 Bulk Density $\left(\mathrm{g} / \mathrm{cm}^{\wedge} 3\right)$ & 1.52 & 1.85536 & 63.22 & 0.29 & 16.56 \\
\hline Vadose Zone 2 Effective Porosity (fraction) & 0.353 & 0.45284 & 172.28 & 0.20 & 13.44 \\
\hline Vadose Zone 4 Effective Porosity (fraction) & 0.383 & 0.447 & 206.25 & 0.23 & 10.31 \\
\hline Vadose Zone 4 Total Porosity (fraction) & 0.43 & 0.45 & -165.00 & -0.19 & -9.90 \\
\hline Source Cover Depth (m) & 0.9 & 0.1 & -29.50 & -0.01 & -5.90 \\
\hline Cover Erosion Rate (m/yr) & 0 & 0.0005 & 21600.00 & 0.03 & 5.40 \\
\hline Vadose Zone 4 Sat. Hyd. Conductivity (m/yr) & 2594 & 1205.322 & 0.00 & 0.00 & -2.18 \\
\hline Contaminated Zone Bulk Density $\left(\mathrm{g} / \mathrm{cm}^{\wedge} 3\right)$ & 1.46 & 1.80304 & 7.00 & 0.03 & 1.88 \\
\hline Vadose Zone 4 Soil-Type Exponent & 0.998 & 1.295941 & 7.32 & 0.02 & 1.66 \\
\hline Vadose Zone 2 Sat. Hyd. Conductivity (m/yr) & 1259 & 402.75 & 0.00 & 0.00 & -1.51 \\
\hline Contaminated Zone Total Porosity (fraction) & 0.41 & 0.2948 & -6.94 & -0.01 & -0.63 \\
\hline Vadose Zone 2 Soil-Type Exponent & 1.4 & 1.922789 & 1.36 & 0.01 & 0.54 \\
\hline Vadose Zone 2 Total Porosity (fraction) & 0.41 & 0.45 & 0.00 & 0.00 & 0.00 \\
\hline Saturated Zone Total Porosity (fraction) & 0.41 & 0.2948 & 0.00 & 0.00 & 0.00 \\
\hline Saturated Zone Effective Porosity (fraction) & 0.346 & 0.24872 & 0.00 & 0.00 & 0.00 \\
\hline Saturated Zone Sat. Hyd. Conductivity (m/yr) & 369 & 787.1481 & 0.00 & 0.00 & 0.00 \\
\hline Well Pump Intake Depth (m) & 3 & 3 & 0.00 & 0.00 & 0.00 \\
\hline
\end{tabular}


bution coefficient value in the sandy loam soils. This sensitivity is due almost entirely to the distribution coefficient of the uranium isotopes in the contaminated zone only. The contaminated zone distribution coefficient determines the release of uranium from the source, which has a large impact on the peak dose for the test case application.

In addition to the distribution coefficient of uranium in the contaminated zone, the peak dose at the conservative parameter values is highly sensitive to the evapotranspiration coefficient and the well pumping rate. Peak dose is also sensitive to the porosities and bulk densities in the unsaturated zone layers, but to a lesser degree. These results are comparable to the sensitivities evaluated at the base case solution and indicate that the critical hydrologic parameters are consistent for both parameter sets.

\subsection{Probabilistic Analyses}

Probabilistic simulation of dose can be used to provide quantitative estimates of the uncertainty in dose due to parameter uncertainty. These estimates may be derived as a probability distribution of dose or as a mean and variance, depending on the method used. Probabilistic simulation
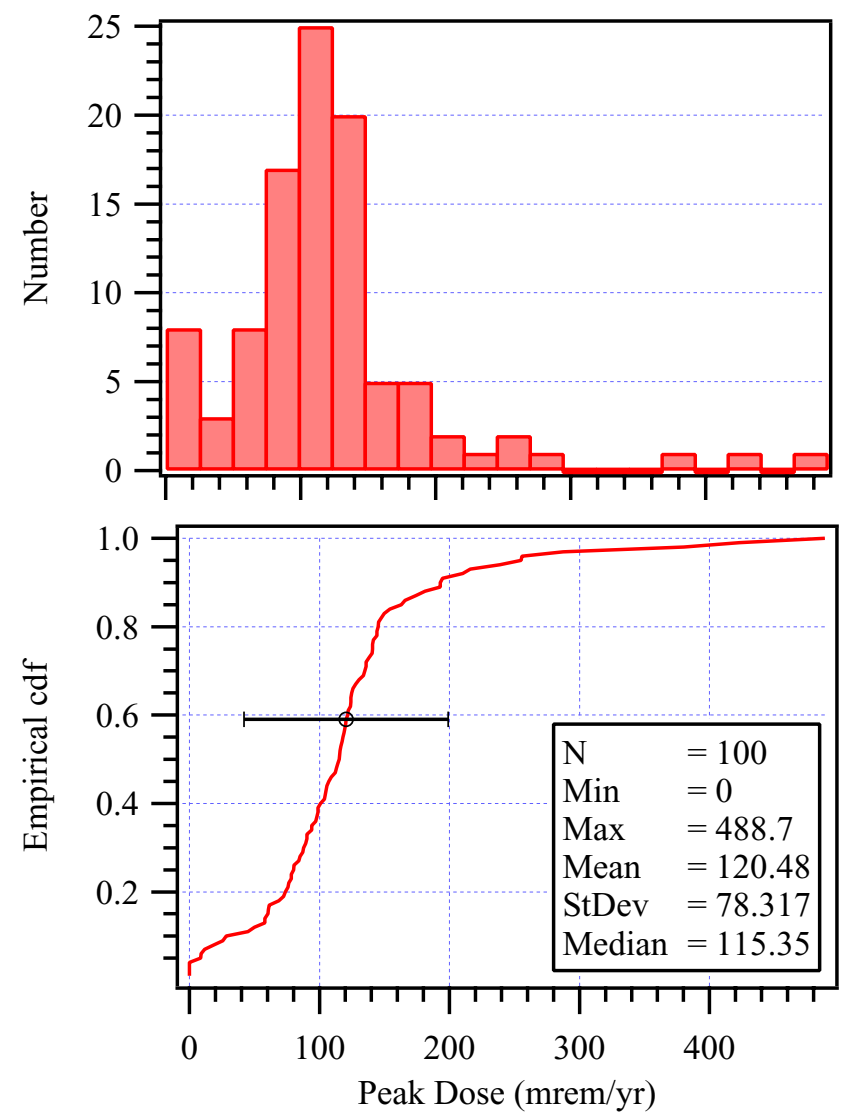

results can also be used to evaluate the sensitivity of dose to parameter values. The statistical sensitivity measures calculated by RESRAD v. 6.0 are the partial (rank) correlation coefficients and partial (rank) regression coefficients. Multiple linear regression with stepwise addition or deletion of variables has also been used to determine parameter importance (e.g., NRC, 1999), but is not implemented in RESRAD.

For the hypothetical test cases, Monte Carlo simulation was used to derive the probability distribution of dose. The parameter distributions from Table 3-1 were input to the uncertainty analysis component of RESRAD v. 6.0 along with the parameter correlations discussed in Section 3.2. For the excavation case, the cover parameters were not used since there is no cover for this case. 100 realizations were used in each Monte Carlo simulation.

\subsubsection{In Situ Case Results}

The distributions of peak total dose from all pathways and the time of the peak dose for the Monte Carlo simulation of the in situ case are shown in Figure 3-2. The distributions are shown as a histogram and as an empirical cumulative
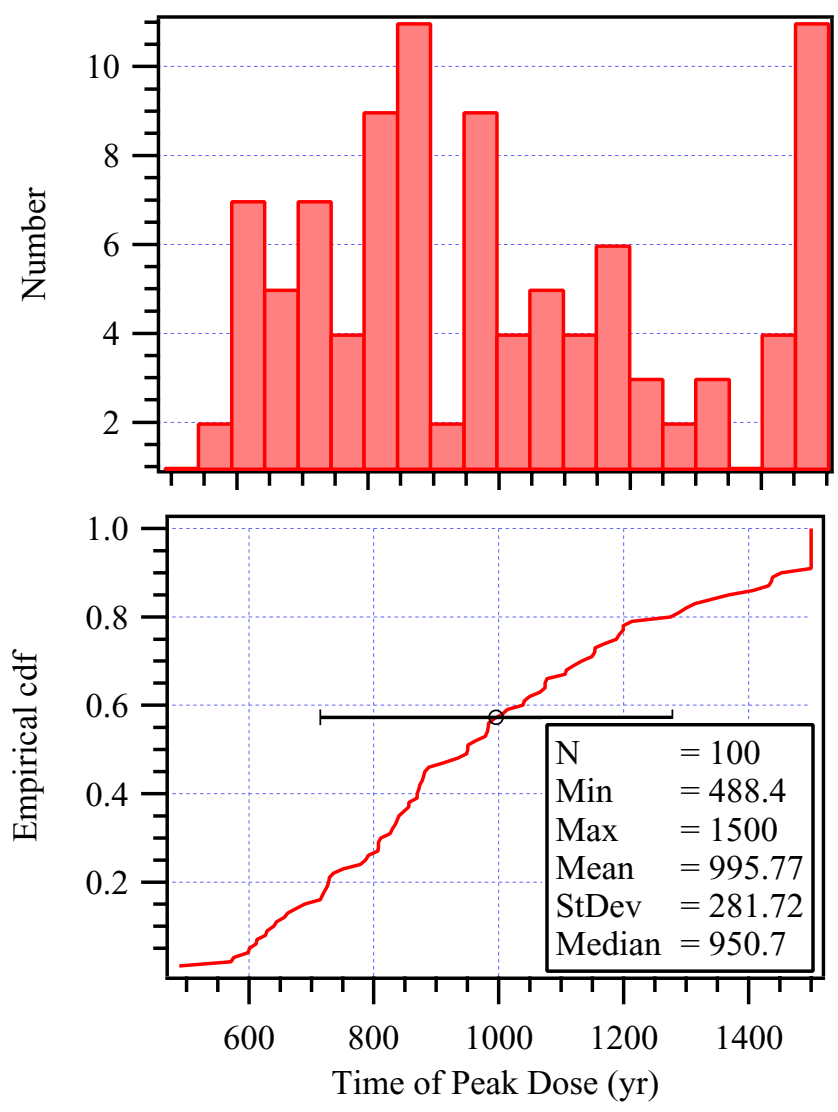

Figure 3-2. Histogram (top) and empirical cdf (bottom) of peak dose (left) and the time of the peak dose (right) for the in situ test case Monte Carlo simulation 
Sensitivity Analyses and Probabilistic Simulation Results

distribution function (cdf). Summary statistics are listed as well. The circular mark with error bars in the cdf plot indicates the mean dose/time plus and minus one standard deviations. The mean peak dose for this case $(120 \mathrm{mrem} / \mathrm{yr})$ is very similar to the base case peak dose (115 mrem/yr). This result cannot be expected in every case as the relationship between the peak dose and parameter values is often nonlinear and parameter distributions are frequently skewed. The standard deviation of peak dose ( $78 \mathrm{mrem} / \mathrm{yr})$ is relatively large, resulting in a coefficient of variation of 0.65 . The modeled parameter uncertainty thus is a significant contributor to uncertainty in the peak dose for this case. Given the fact that the mean dose is almost five times the regulatory criterion, this level of uncertainty would deserve further investigation.

The histogram and cdf for the time to peak dose (shown in Figure 3-2) demonstrate that the uncertainty in this result is also significant. The mean time to peak (996 yr) is just under the regulatory criterion of $1000 \mathrm{yr}$. Since approximately $10 \%$ of the 100 realizations had an actual peak dose that occurred later than 1500 years (the limit of this simulation), the mean time to peak (and the mean peak dose) would have been larger had the simulation been carried out for a sufficiently long time to reach each realization's peak dose. Similarly, if this simulation had been limited to a 1000-year duration, the average peak dose would have been less than that given in Figure 3-2 since $40 \%$ of the parameter realizations resulted in a peak dose greater than 1000 years.

The deterministic analysis described in Section 3.3 evaluated sensitivities at a single point (the base case or conservative case) and varied the parameters one at a time. Scatter plots of peak dose versus the parameter values used in the Monte Carlo simulation can reveal sensitivities over the entire range of parameter variation and can include the combined impact of multiple parameters on dose. A selection of scatter plots for the in situ case are shown in Figure 3-3. Of the parameters in the Monte Carlo simulation, the three that exhibited the most significant deterministic sensitivity were the evapotranspiration coefficient, the contaminated zone U234 distribution coefficient, and the well pumping rate (see Tables 3-2 and 3-3). Relatively strong correlations with peak dose result from the Monte Carlo simulation results for these three parameters as well. Scatter plots for the cover erosion rate and bulk density of unsaturated zone 4 are also shown in Figure 3-3. These parameters had sensitivity coefficients that were small relative to the three dominant parameters, but were larger than for the other parameters. As seen in Figure 3-3, the cover erosion rate and the unsaturated zone 4 bulk density do not produce a significant correlation with peak dose.

The statistical sensitivity measures calculated by RESRAD v.6.0 use the Monte Carlo results to estimate the impact on the dose of each individual parameter. These sensitivity measures are reproduced in Table 3-4 for the peak total (all pathways) dose. The coefficient of determination for the partial correlation coefficient (PCC) and the standardized regression coefficient (SRC) was 0.79. For the measures using ranks (PRCC and SRRC), the coefficient of determination was 0.84 . The parameters are listed in Table 3-4 by rank according to the PRCC measure. The PRCC could reasonably be expected to best represent the importance of parameters because of the nonlinearities and parameter correlations in the simulation.

Three of the four statistical correlation measures show the evapotranspiration coefficient to be the most important parameter. There is little agreement between the various measures on the relative importance of the remaining parameters, however. The uranium distribution coefficients in the contaminated zone are ranked highly by the SRC measure, but not by the others (although the U-234 $\mathrm{K}_{\mathrm{d}}$ in the contaminated zone is ranked third by the SRRC measure). The well pumping rate received a relatively low ranking from the regression coefficients. The cover depth is highly ranked by the PRCC measure only, but as shown in Figure 3-3 the peak dose does not appear to be strongly related to the cover depth. For this application it appears that, while the statistical correlation measures are useful in determining the relative importance of parameters, additional analyses are required to be able to specify the critical parameters.

There are multiple measures of dose that could be used for comparison to the regulatory standard when probabilistic simulations are used in decommissioning analyses. One could use a statistic (such as the mean or the 50th percentile) of the distribution of peak dose. Peak dose as used here refers to the total (all pathways) dose occurring in the first 1000 years after decommissioning. This is the quantity used in Figures 3-2 and 3-3 (albeit without the 1000 year limit). An alternative measure of dose discussed in NRC (2000) is the peak of the mean dose, where the mean dose is calculated as a function of time by averaging over all Monte Carlo realizations for each year of the simulation.

The mean total dose as a function of time is presented in Figure 3-4(A) for the in situ case. The median and 90th percentile doses are shown in this figure as well. The base case dose as a function of time is presented for comparison. For the in situ test case, the mean dose at any time during the simulation is significantly less than the base case peak dose. This result occurs because of the sharp peak in the dose as a function of time and the fact that the parameter variation results in the time of the peak varying significantly. At any particular time, in fact, the fraction of realizations that have a dose greater than the $25 \mathrm{mrem} / \mathrm{yr}$ limit is quite small. Figure 3-4(B) illustrates this at times 500, 700, and 1000 years after decommissioning. At 1000 years, approximately $20 \%$ of the realizations result in a dose greater than 25 mrem. Figure $3-4(C)$ is a plot of peak dose versus the time 

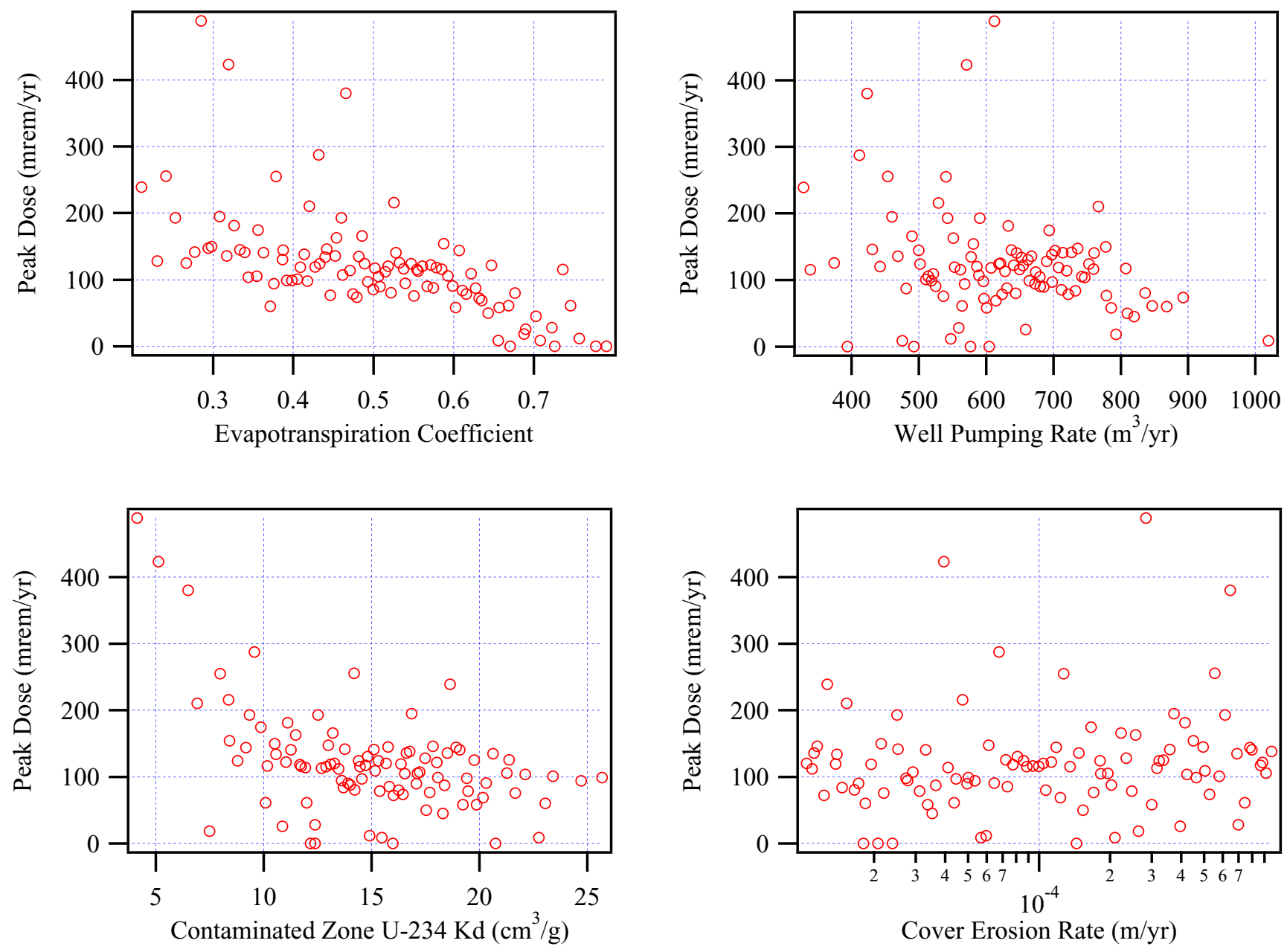

Cover Erosion Rate (m/yr)
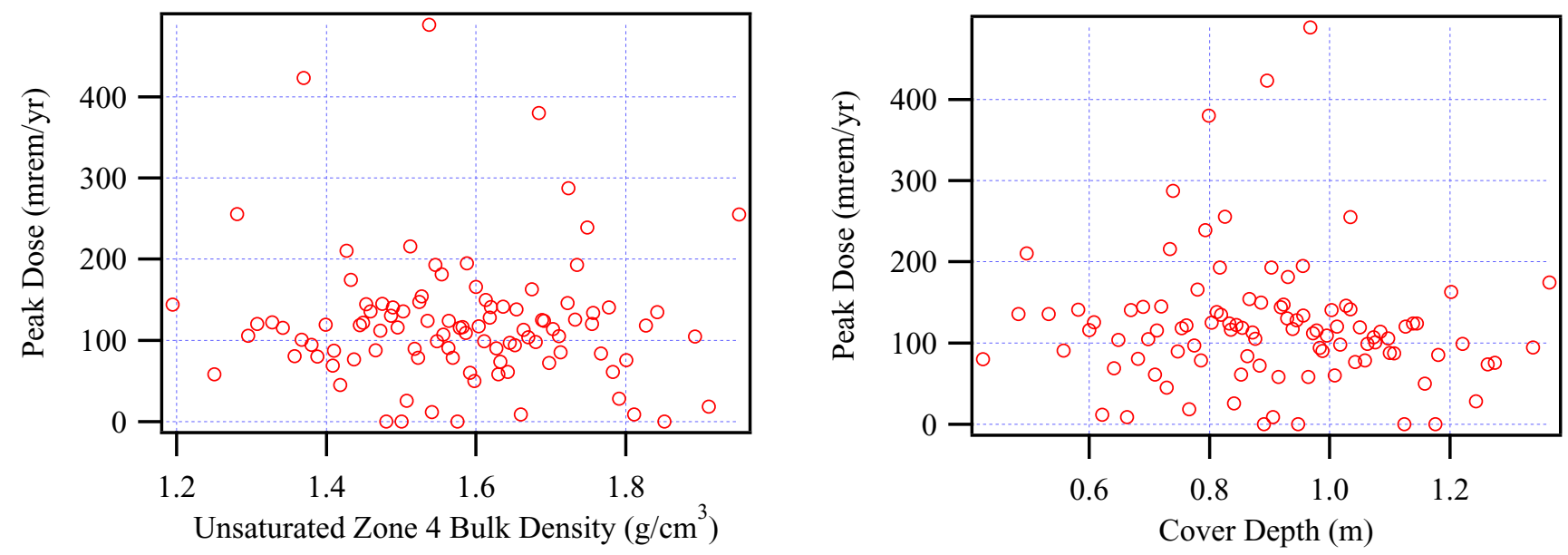

Figure 3-3. Scatter plots of peak dose versus parameter values for the in situ test case Monte Carlo simulation 
Sensitivity Analyses and Probabilistic Simulation Results

Table 3-4. Statistical sensitivity measures for the in situ case (peak total dose) as calculated by RESRAD v. 6.0

\begin{tabular}{|c|c|c|c|c|c|c|c|c|}
\hline Parameter & Rank & PCC & Rank & SRC & Rank & PRCC & Rank & SRRC \\
\hline Evapotranspiration coefficient & 1 & -0.8 & 4 & -0.63 & 1 & -0.87 & 1 & -0.74 \\
\hline Well pumping rate & 2 & -0.51 & 17 & -0.29 & 2 & -0.61 & 7 & -0.32 \\
\hline Cover depth & 6 & -0.24 & 24 & -0.12 & 3 & -0.39 & 11 & -0.17 \\
\hline Density of Unsaturated zone 4 & 21 & -0.11 & 15 & -0.31 & 4 & -0.26 & 4 & -0.4 \\
\hline Effective Porosity of Unsaturated zone 4 & 28 & 0.08 & 19 & 0.21 & 5 & 0.24 & 5 & 0.38 \\
\hline Cover erosion rate & 27 & 0.08 & 30 & 0.04 & 6 & 0.24 & 17 & 0.1 \\
\hline Total Porosity of Unsaturated zone 4 & 25 & -0.09 & 10 & -0.37 & 7 & -0.23 & 2 & -0.55 \\
\hline $\mathrm{Kd}$ of U-234 in Contaminated Zone & 8 & -0.24 & 2 & -0.86 & 8 & -0.23 & 3 & -0.46 \\
\hline Well pump intake depth & 29 & -0.06 & 31 & -0.03 & 9 & -0.17 & 20 & -0.07 \\
\hline $\mathrm{Kd}$ of U-238 in Unsaturated Zone 1 & 16 & -0.14 & 13 & -0.34 & 10 & 0.11 & 13 & 0.14 \\
\hline Saturated zone hydraulic conductivity & 19 & -0.12 & 28 & -0.06 & 11 & -0.11 & 25 & -0.05 \\
\hline Saturated zone effective porosity & 15 & -0.15 & 11 & -0.35 & 12 & -0.11 & 6 & -0.32 \\
\hline Density of Unsaturated zone 2 & 26 & 0.08 & 21 & 0.17 & 13 & -0.1 & 12 & -0.16 \\
\hline Kd of U-238 in Saturated Zone & 14 & -0.15 & 9 & -0.38 & 14 & 0.1 & 15 & 0.13 \\
\hline $\mathrm{Kd}$ of U-238 in Contaminated Zone & 11 & 0.17 & 3 & 0.83 & 15 & -0.09 & 8 & -0.21 \\
\hline Kd of U-234 in Saturated Zone & 22 & 0.11 & 18 & 0.21 & 16 & 0.07 & 18 & 0.08 \\
\hline Density of contaminated zone & 32 & 0.02 & 29 & 0.05 & 17 & -0.06 & 9 & -0.19 \\
\hline Hydraulic Conductivity of Unsaturated zone 4 & 30 & -0.04 & 32 & -0.02 & 18 & 0.06 & 27 & 0.03 \\
\hline Saturated zone total porosity & 18 & 0.13 & 16 & 0.3 & 19 & 0.06 & 10 & 0.18 \\
\hline Total Porosity of Unsaturated zone 2 & 23 & 0.11 & 12 & 0.34 & 20 & -0.06 & 14 & -0.14 \\
\hline $\mathrm{Kd}$ of U-235 in Unsaturated Zone 3 & 7 & -0.24 & 8 & -0.46 & 21 & -0.06 & 23 & -0.05 \\
\hline $\mathrm{Kd}$ of U-234 in Unsaturated Zone 3 & 24 & 0.1 & 22 & 0.17 & 22 & -0.05 & 24 & -0.05 \\
\hline $\mathrm{Kd}$ of U-238 in Unsaturated Zone 3 & 10 & -0.2 & 7 & -0.5 & 23 & 0.05 & 22 & 0.06 \\
\hline Effective Porosity of Unsaturated zone 2 & 13 & -0.15 & 14 & -0.33 & 24 & 0.05 & 19 & 0.07 \\
\hline $\mathrm{Kd}$ of U-234 in Unsaturated Zone 1 & 20 & 0.11 & 20 & 0.21 & 25 & 0.05 & 26 & 0.05 \\
\hline $\mathrm{Kd}$ of U-235 in Contaminated Zone & 5 & 0.27 & 1 & $1.01^{*}$ & 26 & 0.04 & 21 & 0.07 \\
\hline Contaminated zone total porosity & 31 & 0.03 & 27 & 0.07 & 27 & -0.04 & 16 & -0.11 \\
\hline Hydraulic Conductivity of Unsaturated zone 2 & 17 & 0.13 & 26 & 0.08 & 28 & 0.03 & 29 & 0.02 \\
\hline b Parameter of Unsaturated zone 4 & 9 & -0.21 & 23 & -0.13 & 29 & 0.03 & 30 & 0.02 \\
\hline Kd of U-235 in Saturated Zone & 4 & -0.28 & 5 & -0.58 & 30 & -0.03 & 28 & -0.03 \\
\hline b Parameter of Unsaturated zone 2 & 12 & 0.16 & 25 & 0.1 & 31 & -0.03 & 31 & -0.02 \\
\hline Kd of U-235 in Unsaturated Zone 1 & 3 & -0.3 & 6 & -0.57 & 32 & -0.01 & 32 & -0.01 \\
\hline
\end{tabular}

P(R)CC: Partial (Rank) Correlation Coefficient

S(R)RC: Standardized (Rank) Regression Coefficient

* Large, spurious SRC values will be generated by RESRAD v. 6.0 when strong correlations exist between input parameters (LePoire et al., 2000). 
(A)

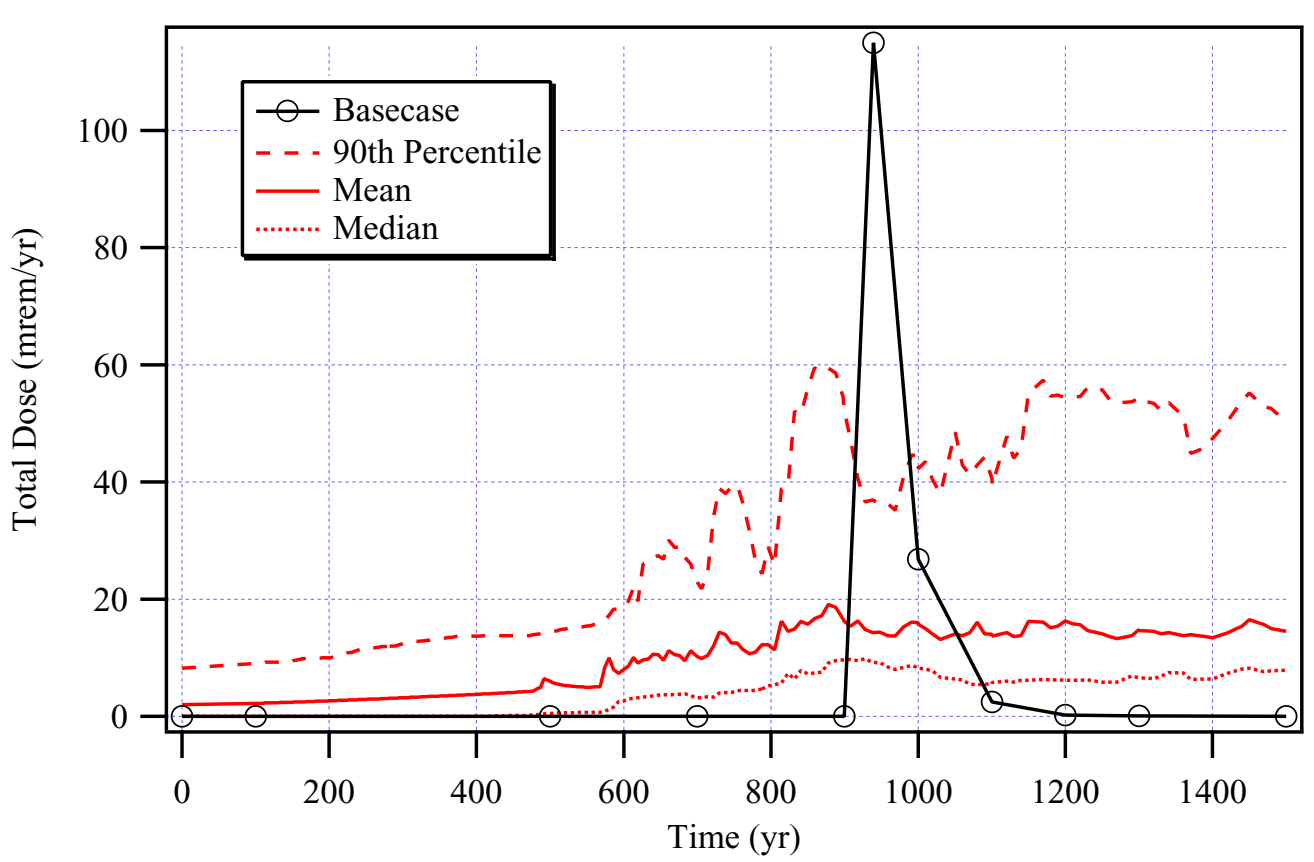

(B)
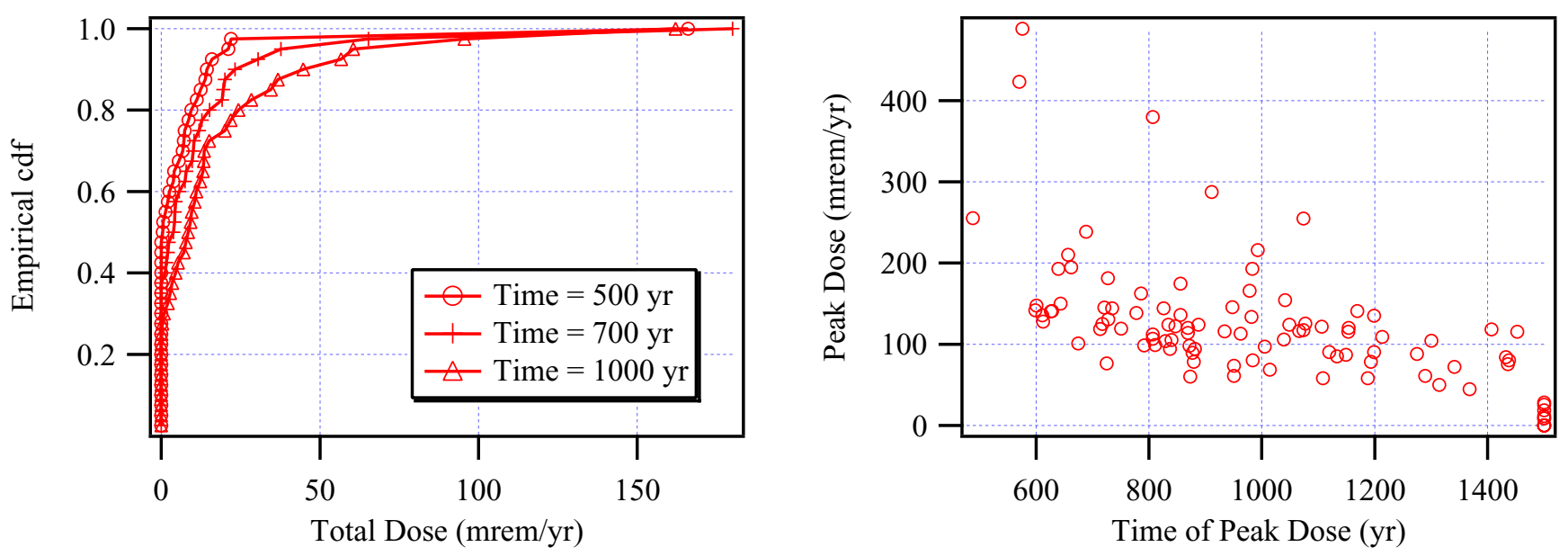

Figure 3-4. (A) Total dose statistics as a function of time; (B) Total dose distributions at specified times; and (C) Peak dose vs. time of peak dose. All plots are for the in situ case.

at which the peak occurs and illustrates the fact that the peak dose for the various realizations occurs over a broad range of times. (This result is also seen in Figure 3-2.)

\subsubsection{Excavation Case Results}

Probabilistic results for the excavation case are presented in a similar manner to those presented in the previous section for the in situ case. Figure 3-5 contains plots of the histograms and cumulative distribution functions for the peak dose and the time of the peak dose. The distributions for this case are more highly skewed than for the in situ case, with a large number of realizations resulting in a peak dose near 11 $\mathrm{mrem} / \mathrm{yr}$ that occurs at the beginning of the simulation. For these realizations, the peak dose is due to the external and water-independent pathways. Larger doses that occur later in time result from the transport of uranium isotopes through the groundwater. Approximately $20 \%$ of the realizations have a peak dose that occurs more than 1000 years after decommissioning. The mean dose is $15 \mathrm{mrem} / \mathrm{yr}$ with $13 \%$ of the realizations resulting in a peak dose greater than the 

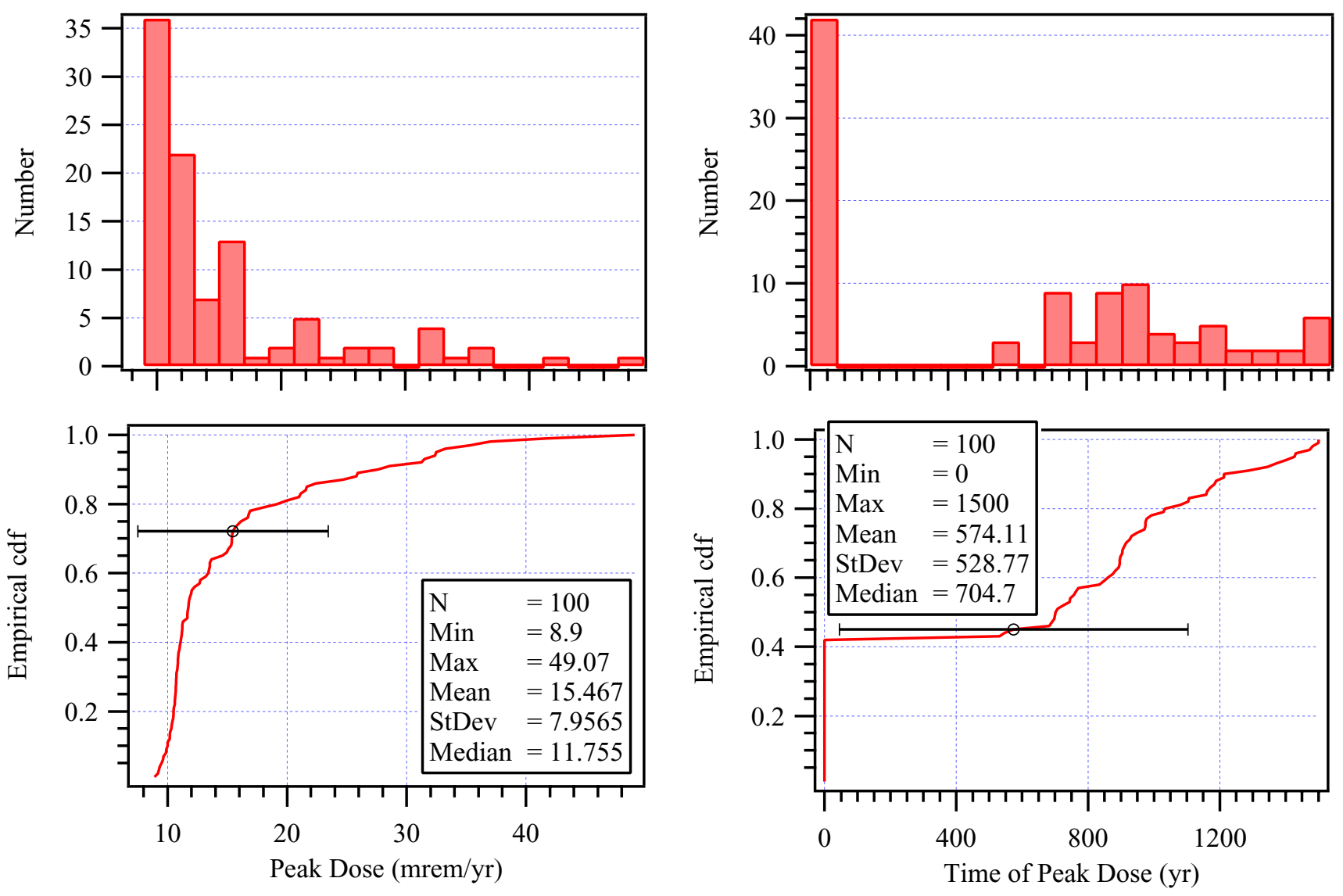

Figure 3-5. Histogram (top) and empirical cdf (bottom) of the peak dose (left) and the time of the peak dose (right) for the excavation test case Monte Carlo simulation

$25 \mathrm{mrem} / \mathrm{yr}$ regulatory standard. The coefficient of variation for the peak dose is $51 \%$. As with the in situ case, there is a significant amount of uncertainty in the peak dose and the time of the peak due to the modeled parameter uncertainty.

Statistical sensitivity measures as calculated by RESRAD v.6.0 are presented in Table 3-5 for the excavation case. These results were calculated using the peak total (all pathways) dose. The coefficient of determination for the PCC and SRC measures was 0.80 and for the measures using ranks it was 0.81 . As with the in situ case, the parameters are ordered in Table 3-5 by the magnitude of the partial rank correlation coefficient. The PRCC could reasonably be expected to best represent the importance of parameters because of the nonlinearities and parameter correlations in the simulation. As for the in situ case, however, the statistical correlation measures do not provide a definitive ranking of the importance of parameters.

The saturated zone saturated hydraulic conductivity is highly ranked by each of the statistical correlation measures and appears to have the greatest impact on peak dose. The evapotranspiration coefficient is highly ranked by the correlation coefficients, but not by the regression coefficients. The U-234 distribution coefficient in the contaminated zone is highly ranked by the regression coefficients. The importance of the well pumping rate is estimated to be comparatively low.

Scatter plots of peak dose as a function of parameter values are shown in Figure 3-6. The parameters chosen for plotting are the most sensitive parameters as measured by the statistical correlation measures. The dependence of peak dose on the saturated zone hydraulic conductivity is clear. A nonlinear relationship is implied. The scatter plots suggest a nonlinear relationship between the peak dose and the U-234 distribution coefficient in the contaminated zone, although the relationship does not appear as strong, perhaps due to the confounding effect of other parameters (most notably the saturated zone hydraulic conductivity). From the remaining plots in Figure 3-6 it does not appear that the peak dose is very sensitive to the evapotranspiration coefficient and the contaminated zone bulk density. 
Sensitivity Analyses and Probabilistic Simulation Results

Table 3-5. Statistical sensitivity measures for the excavation case (peak total dose) as calculated by RESRAD v. 6.0

\begin{tabular}{|c|c|c|c|c|c|c|c|c|}
\hline Parameter & Rank & PCC & Rank & SRC & Rank & PRCC & Rank & SRRC \\
\hline Saturated zone hydraulic conductivity & 1 & 0.84 & 1 & 0.76 & 1 & 0.81 & 2 & 0.64 \\
\hline Evapotranspiration coefficient & 2 & -0.38 & 17 & -0.19 & 2 & -0.27 & 13 & -0.13 \\
\hline $\mathrm{Kd}$ of U-234 in Unsaturated Zone 1 & 10 & 0.16 & 11 & 0.33 & 3 & 0.26 & 6 & 0.36 \\
\hline Density of contaminated zone & 7 & 0.19 & 5 & 0.56 & 4 & 0.25 & 1 & 0.74 \\
\hline $\mathrm{Kd}$ of U-234 in Contaminated Zone & 9 & -0.17 & 2 & -0.68 & 5 & -0.22 & 3 & -0.58 \\
\hline $\mathrm{Kd}$ of U-238 in Saturated Zone & 11 & -0.16 & 12 & -0.33 & 6 & 0.19 & 7 & 0.25 \\
\hline Hydraulic Conductivity of Unsaturated zone 2 & 22 & 0.04 & 24 & 0.02 & 7 & 0.16 & 16 & 0.11 \\
\hline $\mathrm{Kd}$ of U-234 in Unsaturated Zone 3 & 18 & 0.11 & 14 & 0.23 & 8 & 0.15 & 8 & 0.21 \\
\hline $\mathrm{Kd}$ of U-238 in Contaminated Zone & 8 & 0.17 & 3 & 0.67 & 9 & -0.15 & 5 & -0.39 \\
\hline $\mathrm{Kd}$ of U-238 in Unsaturated Zone 1 & 15 & -0.14 & 13 & -0.28 & 10 & 0.14 & 9 & 0.2 \\
\hline Contaminated zone total porosity & 13 & 0.15 & 8 & 0.44 & 11 & 0.14 & 4 & 0.41 \\
\hline Density of Unsaturated zone 4 & 30 & 0 & 30 & 0 & 12 & -0.11 & 10 & -0.18 \\
\hline b Parameter of Unsaturated zone 2 & 28 & 0.01 & 29 & 0 & 13 & 0.11 & 19 & 0.09 \\
\hline Well pumping rate & 14 & -0.15 & 19 & -0.07 & 14 & -0.1 & 27 & -0.04 \\
\hline $\mathrm{Kd}$ of U-234 in Saturated Zone & 24 & 0.01 & 23 & 0.02 & 15 & -0.08 & 18 & -0.1 \\
\hline $\mathrm{Kd}$ of U-235 in Unsaturated Zone 1 & 17 & 0.11 & 15 & 0.2 & 16 & 0.07 & 21 & 0.08 \\
\hline Density of Unsaturated zone 2 & 26 & -0.01 & 26 & -0.01 & 17 & 0.07 & 15 & 0.11 \\
\hline b Parameter of Unsaturated zone 4 & 25 & -0.01 & 28 & -0.01 & 18 & 0.07 & 23 & 0.06 \\
\hline $\mathrm{Kd}$ of U-235 in Contaminated Zone & 12 & -0.15 & 6 & -0.55 & 19 & -0.07 & 11 & -0.16 \\
\hline $\mathrm{Kd}$ of U-238 in Unsaturated Zone 3 & 5 & -0.2 & 9 & -0.4 & 20 & 0.07 & 20 & 0.09 \\
\hline Effective Porosity of Unsaturated zone 2 & 20 & 0.05 & 18 & 0.09 & 21 & 0.06 & 17 & 0.11 \\
\hline Well pump intake depth & 16 & -0.14 & 20 & -0.06 & 22 & -0.05 & 28 & -0.02 \\
\hline $\mathrm{Kd}$ of U-235 in Saturated Zone & 6 & 0.2 & 10 & 0.35 & 23 & 0.05 & 26 & 0.05 \\
\hline $\mathrm{Kd}$ of U-235 in Unsaturated Zone 3 & 19 & 0.11 & 16 & 0.19 & 24 & 0.05 & 25 & 0.05 \\
\hline Total Porosity of Unsaturated zone 4 & 29 & 0 & 27 & 0.01 & 25 & -0.05 & 14 & -0.11 \\
\hline Saturated zone total porosity & 3 & 0.25 & 4 & 0.59 & 26 & 0.04 & 12 & 0.14 \\
\hline Effective Porosity of Unsaturated zone 4 & 27 & 0.01 & 25 & 0.02 & 27 & 0.04 & 22 & 0.06 \\
\hline Hydraulic Conductivity of Unsaturated zone 4 & 21 & -0.04 & 22 & -0.02 & 28 & 0.03 & 29 & 0.02 \\
\hline Total Porosity of Unsaturated zone 2 & 23 & -0.02 & 21 & -0.05 & 29 & 0.02 & 24 & 0.06 \\
\hline Saturated zone effective porosity & 4 & -0.23 & 7 & -0.55 & 30 & 0 & 30 & -0.01 \\
\hline
\end{tabular}

P(R)CC: Partial (Rank) Correlation Coefficient

S(R)RC: Standardized (Rank) Regression Coefficient

Scatter plots such as those in Figure 3-6 include the effect of varying multiple parameters at the same time. As a result, it is not easy to observe relatively weak relationships between peak dose and specific parameters. The saturated hydraulic conductivity in the saturated zone is the only parameter in this test case that has a sufficiently strong effect on peak dose to be obvious in the scatter plots. Statistical measures such as the partial (rank) correlation coefficient attempt to isolate the effect of individual parameters. As has been shown, however, these measures do not always agree and they may not make clear the relative importance of parameters. One additional analytical tool available is to examine the functional relationship between dose and a particular parameter using Monte Carlo simulation with a single parameter varying. This can be conveniently accomplished using the built-in capabilities of RESRAD v. 6.0 (as well as other codes).

Examples of the results from single parameter Monte Carlo simulations are shown in Figure 3-7 for the saturated zone hydraulic conductivity, the evapotranspiration coefficient, and the U-234 distribution coefficient in the contaminated and saturated zones. These results were obtained with all parameters except for one at the excavation base case values. These plots can be compared with those in Figure 3-6. The results provide additional evidence that the saturated zone hydraulic conductivity is much more important than the other parameters. In addition, it appears that the satu- 


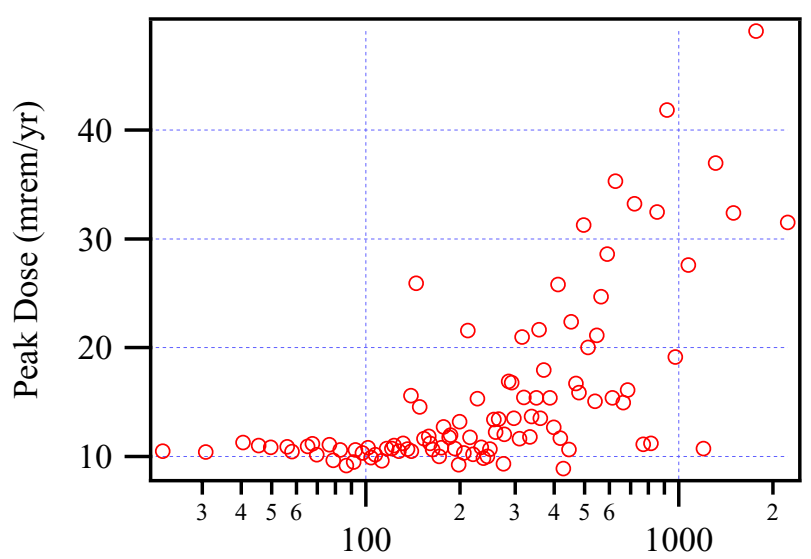

Saturated Zone Sat. Hydraulic Conductivity (m/yr)

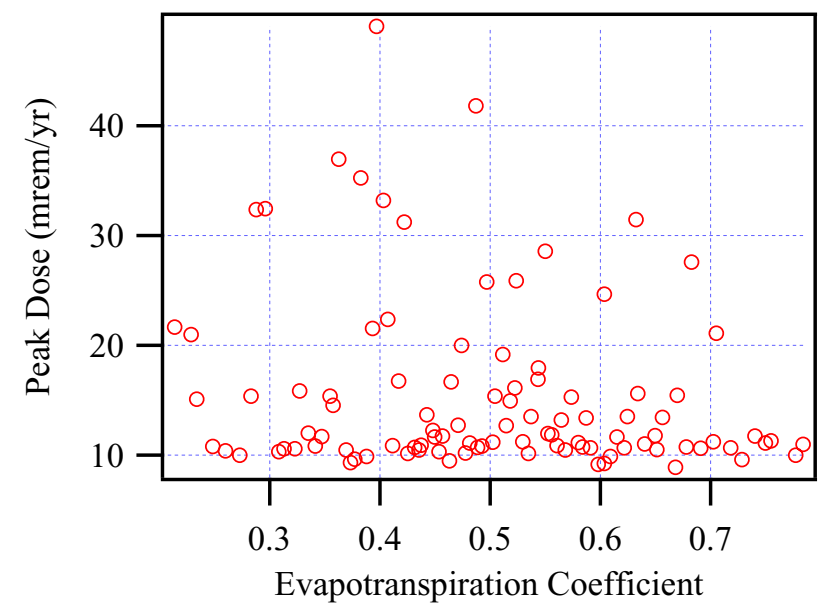

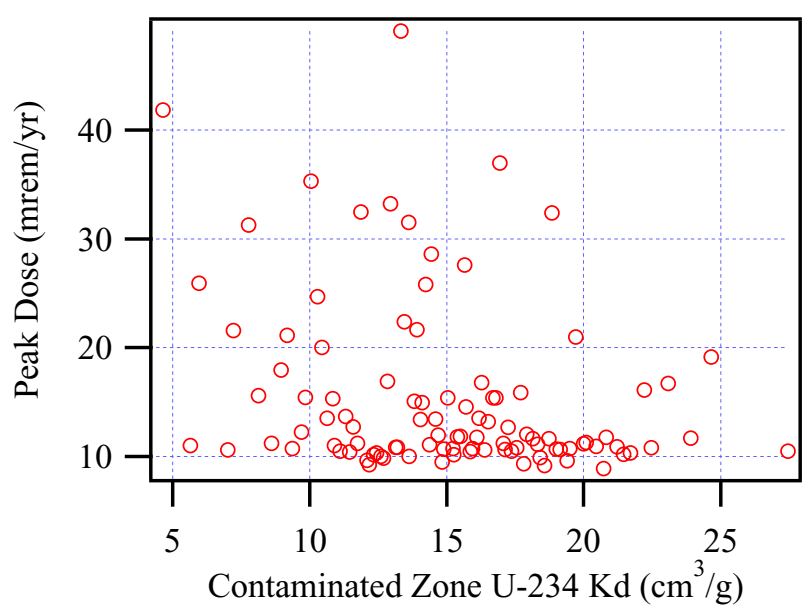

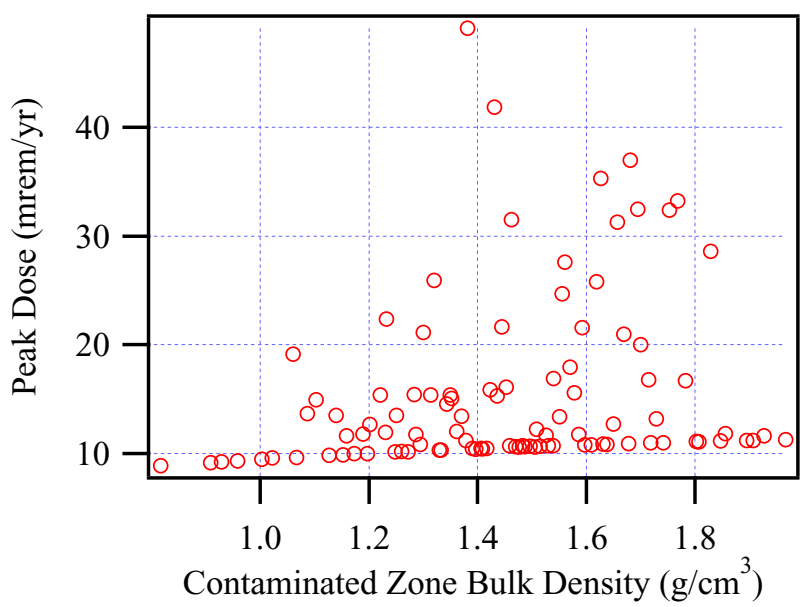

Figure 3-6. Scatter plots of peak dose versus parameter values for the excavation test case Monte Carlo simulation

rated zone hydraulic conductivity has a threshold value, below which the dose is essentially constant and above which the dose is linearly related to the conductivity. With the remaining parameters at their base case values, that threshold is approximately $200 \mathrm{~m} / \mathrm{yr}$. This relationship compares well with the Monte Carlo results shown in Figure 3-6.

The evapotranspiration coefficient and the U-234 distribution coefficient in the contaminated zone, two parameters that were highly ranked by the statistical measures, exhibit little influence on the peak dose with the remaining parameters at their base case values. In contrast, the U-234 distribution coefficient in the saturated zone was not highly ranked by any of the statistical measures, but has a relatively large impact on peak dose according to Figure 3-7. It is possible that the combinations of parameter values used in the Monte Carlo simulation render this parameter less significant than indicated here, but that determination would require additional analyses.

Total dose statistics as a function of time are shown in Figure 3-8. The mean, median, and 90th percentile of total dose are shown along with the excavation base case dose as a function of time. As with the in situ case, the peak of the mean dose is less than the peak of the base case results, although for the excavation case they are both less than the regulatory standard. The interpretation of these results is similar to that for the in situ case. Peak doses for individual realizations that result from the transport of uranium isotopes in groundwater are (1) larger than the mean dose at any particular time and (2) occur at different times for different realizations [see Figures 3-8(B) and 3-8(C)]. 

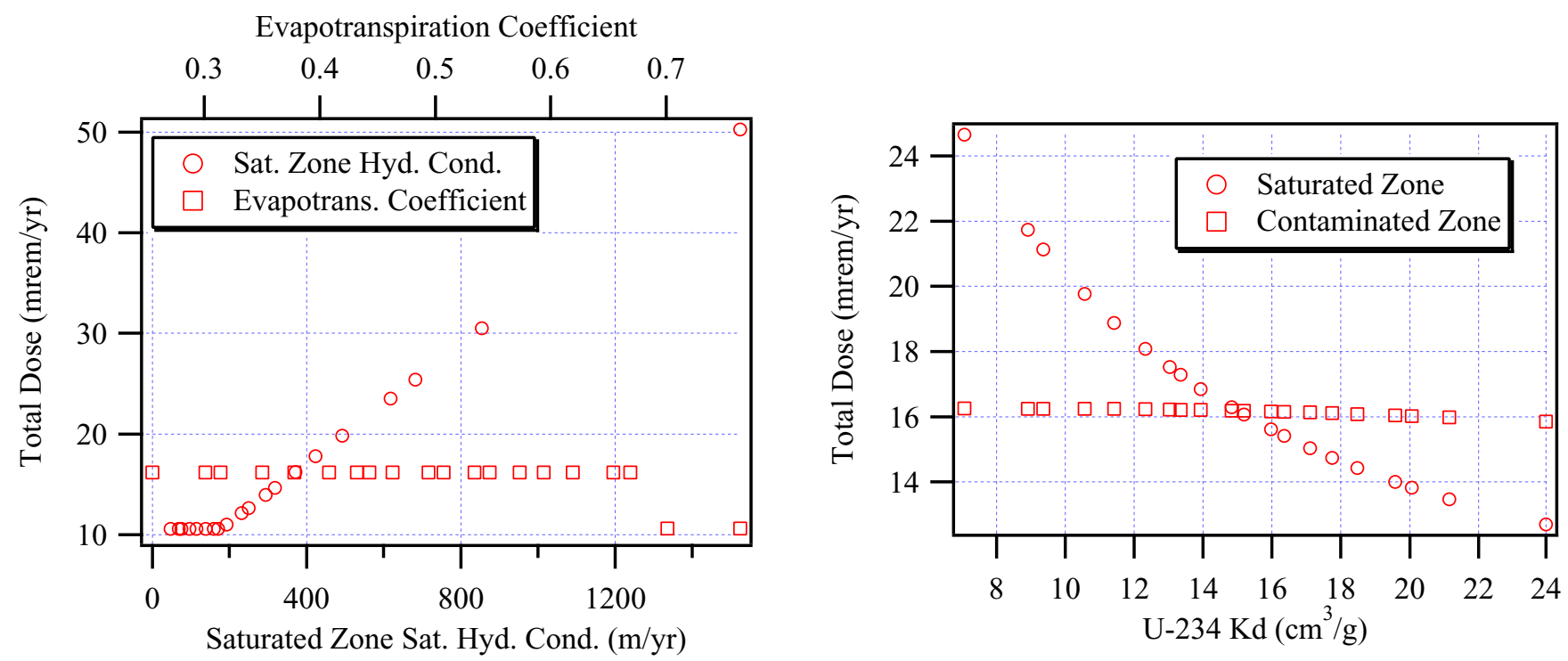

Figure 3-7. Total dose as a function of parameter values from Monte Carlo simulations with one parameter varying at a time: saturated zone saturated hydraulic conductivity and evapotranspiration coefficient (left) and U234 distribution coefficient in the saturated and contaminated zones (right). Both plots are for the excavation case.

\subsubsection{Updating Distributions}

For some decommissioning sites, the initial distributions used in probabilistic analyses are likely to be based largely on prior judgement and national or regional data instead of on site-specific data. Yet some amount of site-specific data is likely to be available or to become available as the site investigation progresses. Meyer et al. (1997) presented a method, based on Bayesian updating, to combine prior distributions with limited site-specific data. The issues involved in the application of this method to decommissioning analyses were summarized in Meyer and Gee (1999). An example application of the method to the excavation test case is presented here.

Based on the analyses presented in Section 3.4.2, the saturated zone hydraulic conductivity is the parameter for which site-specific information has the greatest potential to reduce the uncertainty in the peak dose. The saturated zone hydraulic conductivity distribution in the excavation case was based on a national database of soil physical property measurements as documented in Meyer et al. (1997). Since it is clearly a critical parameter, site-specific data on the saturated zone hydraulic conductivity seems warranted. If the site-specific values were on the high end of the prior distribution, the predicted peak dose would potentially exceed the regulatory criterion.

Actual site-specific values of saturated hydraulic conductivity from the upper saturated zone of the test case site were not available at the time this report was prepared. There were, however, four samples obtained from a depth of at least $13 \mathrm{~m}$ on which the percentages of sand, silt, and clay were measured. These measurements were used with the Rosetta code (Schaap, 1999) to estimate the saturated hydraulic conductivity of the samples. Rosetta v. 1.1 uses neural network methods to estimate hydraulic parameters from soil physical measurements. The resulting estimates contain a significant degree of uncertainty, but for the purposes of this test case it was assumed that the derived hydraulic conductivity values were precise measurements.

The prior conductivity distribution (from Table 3-1) and the hypothetical site-specific data values were combined using the updating method described in Meyer et al. (1997). A simple spreadsheet calculation was used to determine the updated distribution of saturated zone hydraulic conductivity: a lognormal distribution with a mean value of $246 \mathrm{~m} / \mathrm{yr}$ and a standard deviation of $43 \mathrm{~m} / \mathrm{yr}$. This can be compared to the prior distribution based on the national database with a mean of $369 \mathrm{~m} / \mathrm{yr}$ and a standard deviation of $432 \mathrm{~m} / \mathrm{yr}$. The remaining parameter distributions were identical to those in Table 3-1.

The relationship between the prior distribution, the assumed site-specific data, and the updated distribution are shown in Figure 3-9 (as empirical cumulative distribution functions). As discussed in Meyer and Gee (1999), the prior and updated distributions represent the effective value of saturated zone conductivity over the entire site. For this example, it is assumed that the effective value can be represented by the geometric mean value. The prior distribution is so 
(A)

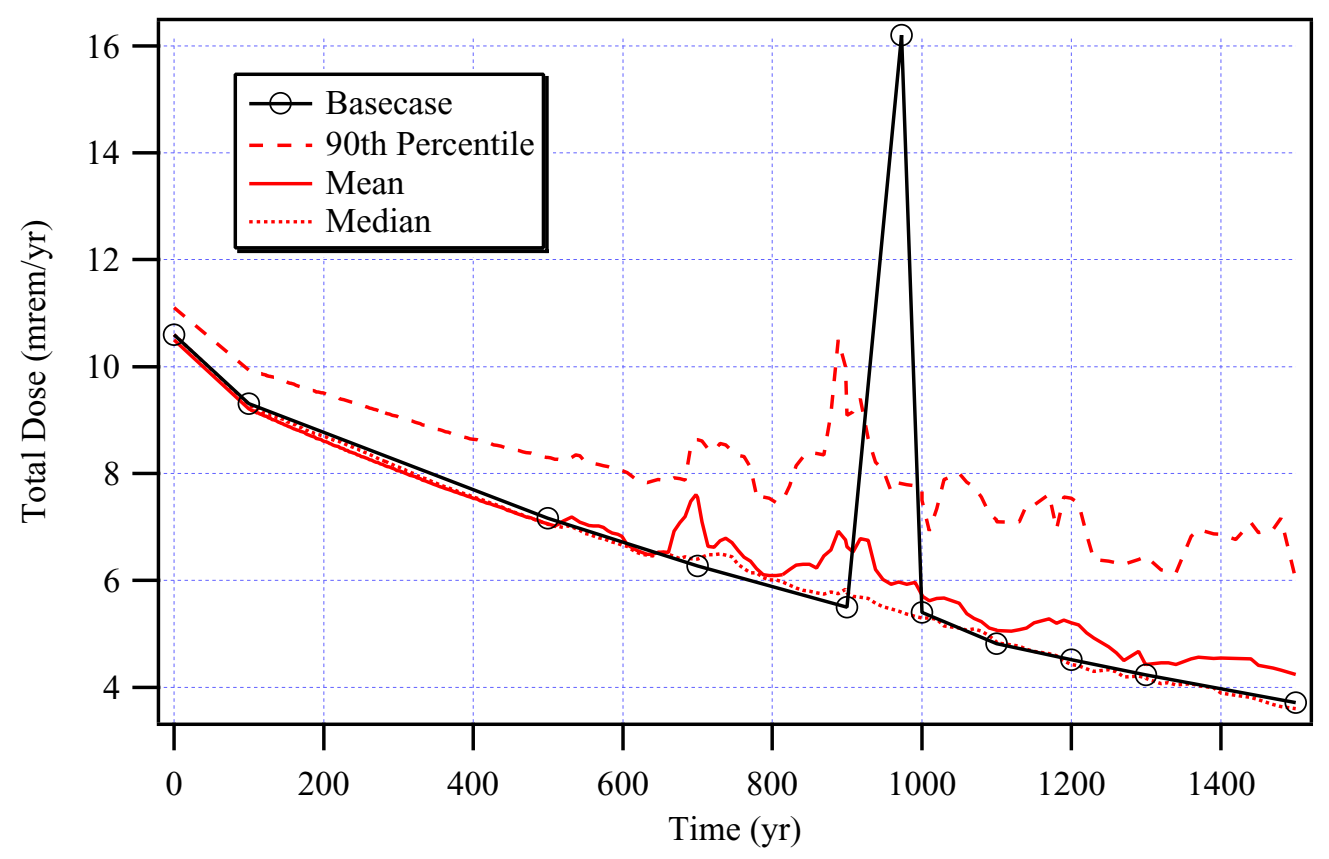

(B)
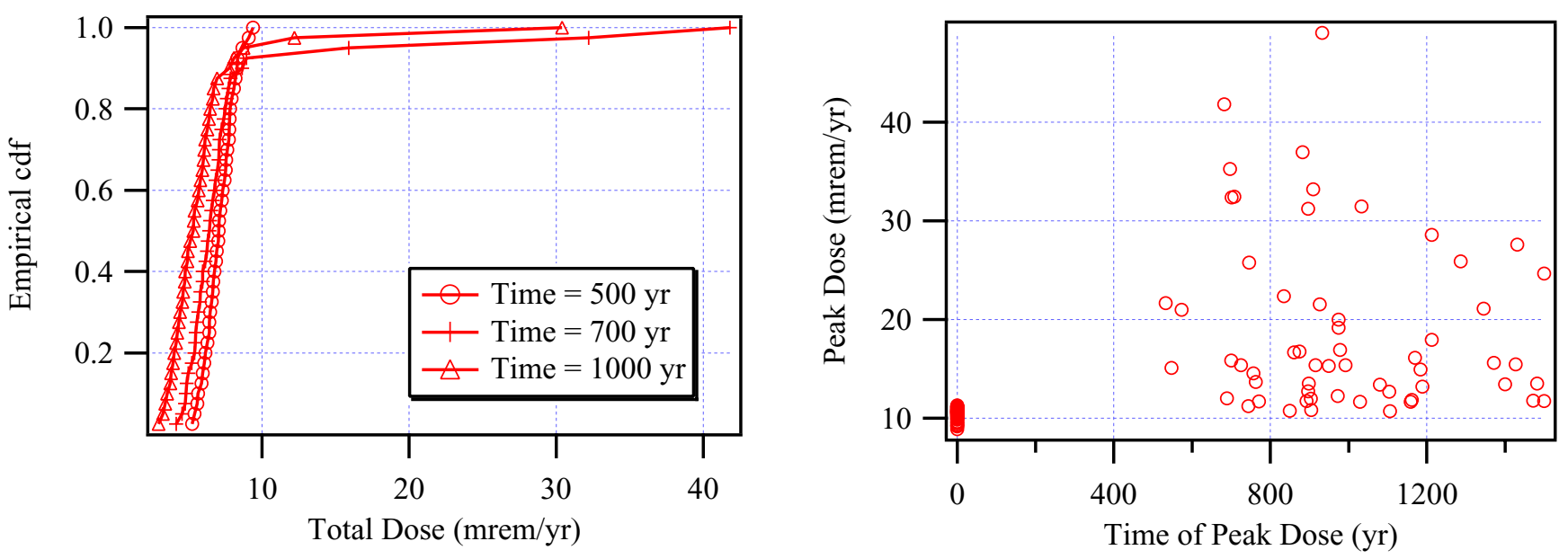

(C)

Figure 3-8. (A) Total dose statistics as a function of time; (B) Total dose distributions at specified times; and (C) Peak dose vs. time of peak dose. All plots are for the excavation case.

much broader than the updated distribution because it assumes that there is no information at the site about the saturated zone hydraulic conductivity other than the textural characterization. As shown by the error bars in Figure 3-9 (representing plus or minus one standard deviation about the arithmetic mean value), the presence of actual site-specific measurements significantly reduces the uncertainty in the mean (effective) hydraulic conductivity. As a result of the reduction of the standard deviation, the arithmetic mean of the updated conductivity distribution is significantly smaller. The updated geometric mean, however, is little changed.
The effect of the updated saturated zone hydraulic conductivity on the peak dose was determined by repeating the Monte Carlo simulation with the new (updated) hydraulic conductivity distribution. The resulting cumulative distribution functions for the peak dose are shown in Figure 3-10. As a result of the smaller average hydraulic conductivity, there is a small reduction in the mean of the updated peak dose. More significantly, the coefficient of variation of the peak dose is reduced from $51 \%$ to $33 \%$ and the percentage of realizations exceeding $25 \mathrm{mrem} / \mathrm{yr}$ is reduced from $13 \%$ to $2 \%$. There were only minor changes in the distribution of the time of the peak dose. 
The observed decrease in the variance of the peak dose as a result of updating the input parameter distribution(s) with site-specific data is a general result that can be expected to occur unless the updated parameter distribution has a larger variance than the prior distribution. The observed decrease in the mean of the updated peak dose distribution, on the other hand, is a particular result of this test case application and should not be construed as a general conclusion. Had the site-specific hydraulic conductivity values used in the updating procedure been larger, the mean of the updated peak dose distribution could easily have been larger than the prior mean value.

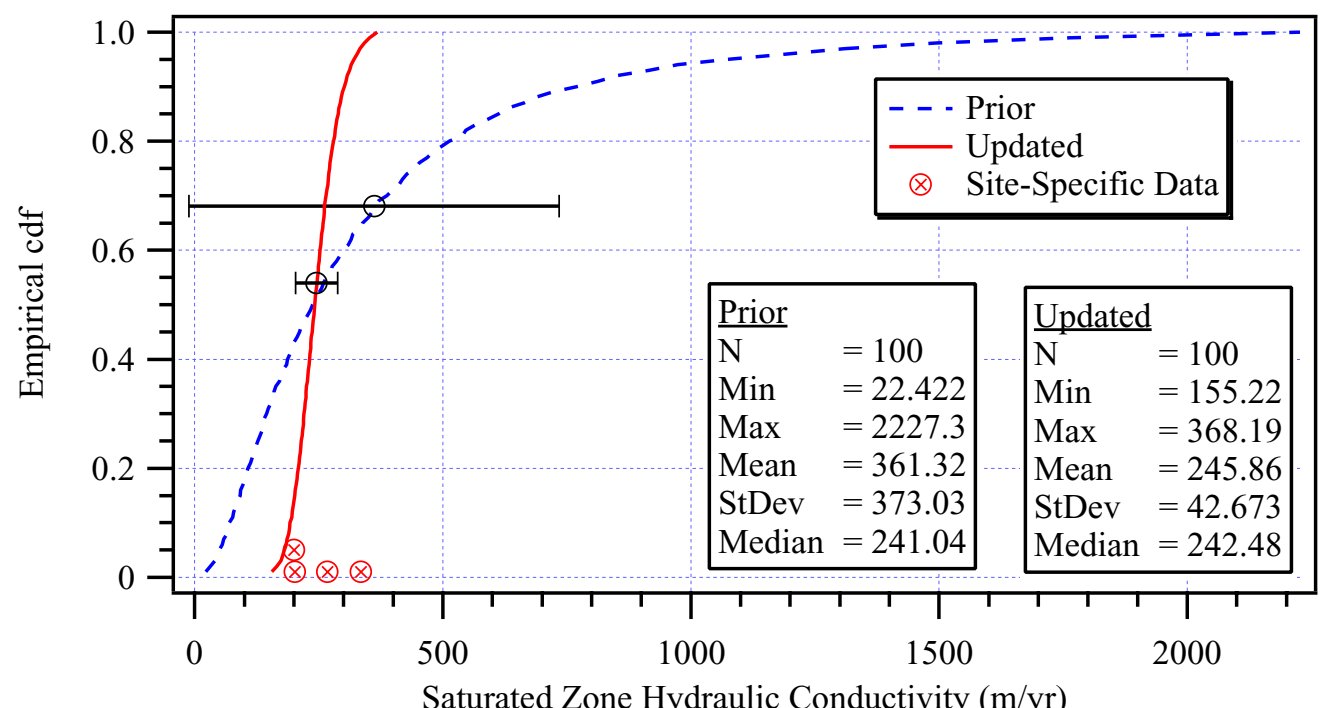

Figure 3-9. Prior and updated probability distributions of the saturated zone hydraulic conductivity for the excavation case. Site-specific data values used in the updating procedure are shown as well.

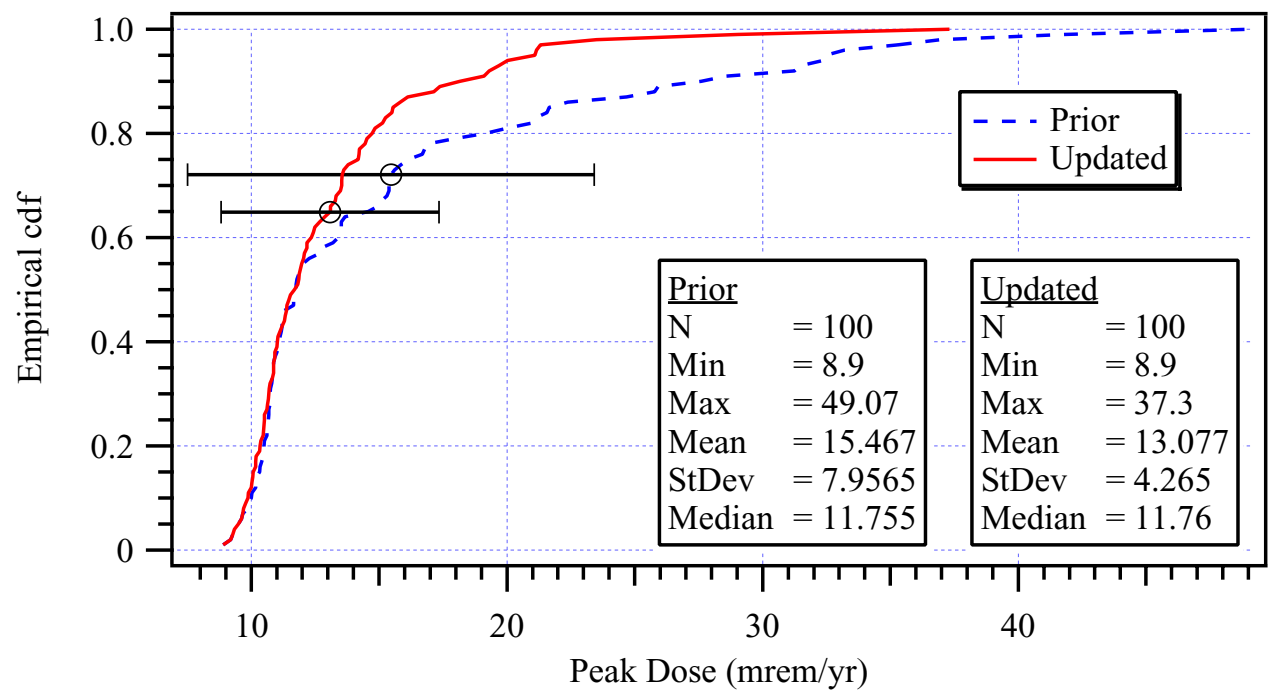

Figure 3-10. Prior and updated probability distributions of the peak dose for the excavation case. The updated distribution uses the updated saturated zone hydraulic conductivity distribution with the remaining parameter distributions taken from Table 3-1. 


\section{Conclusions}

This report is a follow-on report to NUREG/CR-6656 (Meyer and Gee, 1999) and has illustrated the application of many of the methods discussed there using hypothetical decommissioning test cases. The source term and scenarios for the test cases were based on an actual decommissioning case and the physical setting was based on the site of a field experiment carried out in Arizona. Basic soil and climate information from the site were used in the application. The soil profile was simplified from the site-specific information to reduce the computational requirements of the simulations and to fit the simplified conceptual models of the codes used.

A series of deterministic simulations were carried out using the codes DandD v. 1.0 and RESRAD v. 6.0. DandD was executed with the test case source term and all default parameter values. This screening case resulted in a peak dose of $829 \mathrm{mrem} / \mathrm{yr}$. The DandD code was also run with site-specific parameters. A peak dose of $285 \mathrm{mrem} / \mathrm{yr}$ was obtained with most of the physical hydrologic parameters modified to reflect site-specific conditions. With default hydrologic parameters and modified distribution coefficients, the peak dose was $198 \mathrm{mrem} / \mathrm{yr}$. With site-specific hydrologic parameters and modified distribution coefficients, the peak dose from DandD was $70 \mathrm{mrem} / \mathrm{yr}$.

Several deterministic simulations using RESRAD were carried out also using best-estimate (base case) parameter values. The base case parameters were based on national databases and information from the site in Arizona. The in situ case modeled the waste in its original buried location and assumed that a cover was in place. The in situ case resulted in a peak dose of $115 \mathrm{mrem} / \mathrm{yr}$. An excavation case was also simulated in which the waste was assumed to have been excavated and widely spread about in a surface soil mixture. This case more closely resembled the DandD conceptual model. The RESRAD excavation base case resulted in a peak dose of $16 \mathrm{mrem} / \mathrm{yr}$.

A variety of deterministic sensitivity analyses were applied to the test cases, including a simplified model implemented in a spreadsheet, standard sensitivity measures, and application of sensitivity analysis to the base case and a conservative parameter case. For the in situ test case, these analyses indicated that the evapotranspiration coefficient and the uranium distribution coefficients were the most important parameters contributing to the uncertainty in peak dose. The well pumping rate was also important. Soil hydraulic parameters were much less important. Deterministic sensitivity analyses were not carried out for the excavation case.

Probabilistic analyses were carried out for the in situ and excavation test cases using the Monte Carlo simulation capability of RESRAD. Results were presented as distributions for the peak total dose and the time of the peak dose. Statistics for the total dose as a function of time were also presented. Uncertainties in the peak dose and the time of the peak dose were significant with the coefficient of variation for the peak dose exceeding 50\% in both cases. Several measures of sensitivity based on the probabilistic results were also discussed. These included scatter plots of peak dose versus parameter values, statistical sensitivity measures calculated by RESRAD, and single-parameter Monte Carlo simulations to clarify the relationship between dose and critical parameter values. No single measure was a reliable indicator of the relative importance of the parameters. The greatest value from an uncertainty analysis can be obtained by using multiple analytical methods and graphical presentations.

The Monte Carlo simulation results were also used to obtain the mean total dose as a function of time. The peak of this mean is an alternative comparative measure being considered for decommissioning analyses. For the test cases considered here, the mean dose at any time during the simulation was significantly less than the base case peak doses (and significantly less than the mean of the peak dose distributions). This result occurred because of the sharp peak in the dose as a function of time and the fact that the parameter variation resulted in the time of the peak varying significantly.

A method to update parameter probability distributions was applied to the excavation test case. Based on the statistical sensitivity analyses, the saturated zone hydraulic conductivity was the most critical parameter for this case. Because site-specific measurements were not available for this parameter, data was generated using four measurements of physical properties from the deepest samples available at the test case site. The standard deviation of the saturated zone hydraulic conductivity was significantly reduced by including the site-specific values. When the updated saturated zone hydraulic conductivity distribution was applied to the excavation case, the geometric mean of the peak dose was little changed, but the coefficient of variation of the peak dose was reduced from $51 \%$ to $33 \%$ and the percentage of realizations exceeding $25 \mathrm{mrem} / \mathrm{yr}$ was reduced from $13 \%$ to $2 \%$. It was noted that the updating procedure makes a number of assumptions about the distributions involved and also assumes that the site-specific data is error-free, an assumption that underestimates parameter uncertainty. Additional research is needed to establish general guidance for application of the updating method to decommissioning analyses. 



\section{References}

Beyeler, W. E., W. A. Hareland, F. A Duran, T. J. Brown, E. Kalinina, D. P. Gallegos, and P. A. Davis, "Residual Radioactive Contamination from Decommissioning: Parameter Analysis," Draft Report for Comment, NUREG/CR-5512, Vol. 3, October, 1999, Sandia National Laboratories, Albuquerque, NM, 1999.

Campbell, G. S., "A simple method for determining unsaturated conductivity from moisture retention data," Soil Sci., 117:311-314, 1974.

Cole, C. R., M. D. Williams, W. A. Perkins, M. D. White, and P. D. Meyer, "Groundwater Models in Support of NUREG/CR-5512," NUREG/CR-5621, U.S. Nuclear Regulatory Commission, Washington, DC, 1998.

Kennedy, J.D., and D.L. Strenge, "Residual Radioactive Contamination from Decommissioning: Technical Basis for Translating Contamination Levels to Annual Total Effective Dose Equivalent," NUREG/CR-5512, (PNL-7994), U.S. Nuclear Regulatory Commission, Washington, D.C., 1992.

Federal Register, " 10 CFR Part 20 et al., Radiological Criteria for License Termination; Final Rule," Vol. 62, No. 139, Monday, July 21, pp. 39058-39092, 1997.

Helton, J. C., "Uncertainty and Sensitivity Analysis Techniques for Use in Performance Assessment for Radioactive Waste Disposal," Reliability Engineering and System Safety, 42:327-367, 1993.

Iman, R. L. and M. J. Shortencarier, "A FORTRAN 77 Program and User's Guide for the Generation of Latin Hypercube and Random Samples for Use with Computer Models," NUREG/CR-3624, SAND83-2365, U.S. Nuclear Regulatory Commission, Washington, D.C., 1984

Kennedy, J.D., and D.L. Strenge, "Residual Radioactive Contamination from Decommissioning: Technical Basis for Translating Contamination Levels to Annual Total Effective Dose Equivalent," NUREG/CR-5512, (PNL-7994), U.S. Nuclear Regulatory Commission, Washington, D.C., 1992.

Kozak, M. W., N.E. Olague, R. R. Rao, and J. T. McCord, "Evaluation of a Performance Assessment Methodology for Low-Level Radioactive Waste Disposal Facilities," NUREG/CR-5927, Vol. 1, U. S. Nuclear Regulatory Commission, Washington, D.C., 1993.

LePoire, D., J. Arnish, E. Gnanapragasam, S. Kamboj, B. M. Biwer, J.-J. Cheng, C. Yu, and S. Y. Chen, "Probabilistic Modules for the RESRAD and RESRAD-BUILD Computer Codes," NUREG/CR-6692, U.S. Nuclear Regulatory Commission, Washington, D.C., 2000.

Meyer, P. D. and G. W. Gee, "Information on Hydrologic Conceptual Models, Parameters, Uncertainty Analysis, and Data Sources for Dose Assessments at Decommissioning Sites," NUREG/CR-6656, U.S. Nuclear Regulatory Commission, Washington, D.C., 1999.
Meyer, P.D., M.L. Rockhold, and G.W. Gee, "Uncertainty Analyses of Infiltration and Subsurface Flow and Transport for SDMP Sites," NUREG/CR-6565, U.S. Nuclear Regulatory Commission, Washington, DC, 1997.

Morgan, M. G. and M. Henrion, Uncertainty: A Guide to Dealing with Uncertainty in Quantitative Risk and Policy Analysis, Cambridge University Press, New York, 332 pp., 1990.

NRC, "Standard Review Plan for Decommissioning," NUREG-1727, U.S. Nuclear Regulatory Commission, Washington, D.C., 2000.

NRC, "NRC Sensitivity and Uncertainty Analyses for a Proposed HLW Repository at Yucca Mountain, Nevada, Using TPA 3.1," NUREG-1668, Vol. 2, U.S. Nuclear Regulatory Commission, Washington, D.C., 1999.

NRC, "Decision Methods for Dose Assessments to Comply with Radiological Criteria for License Termination," Draft NUREG-1549, U.S. Nuclear Regulatory Commission, Washington, D.C., February 3, 1998.

Robson, S. G. and E. R. Banta, "Groundwater Atlas of the United States, Segment 2: Arizona, Colorado, New Mexico, Utah," Hydrologic Investigations Atlas 730-C, U.S. Geological Survey, 1995.

Schaap, M., Rosetta Version 1.1, 1999. Available at http://www.ussl.ars.usda.gov.

Sheppard, M. I. and D. H. Thibault, "Default Soil Solid/Liquid Partition Coefficients, $\mathrm{K}_{\mathrm{d}} \mathrm{s}$, for Four Major Soil Types: A Compendium," Health Physics, 59(4):471-482, 1990.

Soil Survey Staff, National Characterization Data, Soil Survey Laboratory, National Soil Survey Center, Natural Resources Conservation Service, Lincoln, NE, 1994.

Streile, G. P., K.D. Shields, J. L. Stroh, L. M. Bagaasen, G. Whelan, J. P. McDonald, J. G. Droppo, and J. W. Buck, "The Multimedia Environmental Pollutant Assessment System (MEPAS): Source-Term Release Formulations," PNNL11248, Pacific Northwest National Laboratory, Richland, WA, 1996.

Wernig, M. A., A. M. Tomasi, F. A Duran, and C. D. Updegraff, "Residual Radioactive Contamination from Decommissioning, User's Manual, Draft Report," NUREG/CR5512, Volume 2 (Draft), Sandia National Laboratories, May, 1999.

Whelan, G., J. P. McDonald, and C. Sato, "Multimedia Environmental Pollutant Assessment System (MEPAS): Groundwater Pathway Formulations," PNNL-10907, Pacific Northwest National Laboratory, Richland, WA, 1996.

Young, M. H., P. J. Wierenga, A. W. Warrick, L. L. Hofmann, S. A. Musil, M. Yao, C. J. Mai, Z. Zou, and B. R. Scanlon, "Results of Field Studies at the Maricopa Environ- 
mental Monitoring Site, Arizona," NUREG/CR-5694, U.S. Nuclear Regulatory Commission, Washington, D.C., 1999.

Yu, C., A. J. Zielen, J.-J. Cheng, Y. C. Yuan, L. G. Jones, D. J. LePoire, Y.Y Wang, C. O. Loureiro, E. Gnanapragasam, E. Faillace, A. Wallo III, W. A. Williams, and H. Peterson, "Manual for Implementing Residual Radioactive Material Guidelines Using RESRAD, Version 5.0," ANL/EAD/LD-2, Argonne National Laboratory, Argonne, IL, 1993. 


\section{Appendix A: Recommended Soil Bulk Density Distributions}

Dry soil bulk density data were obtained from the U.S. Natural Resources Conservation Service Soil Characterization Database, dated May 1994. The data were divided according to USDA soil textural class based on the sand, silt, and clay percentages. The distribution of these data over textural classes can be seen in Figure 5-5 of NUREG/CR-6656 (Meyer and Gee, 1999).

For each textural class, the Kolmogorov-Smirnov D-statistic was calculated using hypothetical normal and lognormal distributions. The parameters for the hypothetical normal and lognormal distributions were based on the data. In all cases the D-statistic from the normal distribution was smaller than that from the lognormal distribution. In addition, plots of the bulk density histogram for each soil texture were examined and appeared to better fit a normal distribution. For these reasons, the normal distribution is recommended for modeling bulk density.

The mean and standard deviation of the bulk density data are given in the table below. These values reflect the elimination of outliers from the dataset for each textural class.

Outliers were defined as those points outside the mean plus or minus four times the standard deviation, where the mean and standard deviation were calculated as the sample mean and sample standard deviation with the potential outliers eliminated. The upper and lower limits given in the table are the actual limits of the data extracted from the Soil Characterization Database. Samples with a bulk density less than $0.5 \mathrm{~g} / \mathrm{cm} 3$ or greater than $2.0 \mathrm{~g} / \mathrm{cm} 3$ were not included in the analysis.

Bulk density is highly correlated to saturated water content and effective porosity with correlations generally between -0.95 and -0.99 .

\section{A.1 References}

Meyer, P.D. and G.W. Gee, "Information on Hydrologic Conceptual Models, Parameters, Uncertainty Analysis, and Data Sources for Dose Assessments at Decommissioning Sites," NUREG/CR-6656, U.S. Nuclear Regulatory Commission, Washington, DC, 1999.

Table A-1. Recommended parameters of normal distributions for bulk density

\begin{tabular}{cccccc}
\hline Soil Texture & Number of Samples & Mean & Std. Deviation & Lower Limit & Upper Limit \\
\hline Sand & 811 & 1.578 & 0.158 & 1.0 & 1.99 \\
Loamy Sand & 1889 & 1.515 & 0.262 & 0.5 & 2.0 \\
Sandy Loam & 7195 & 1.461 & 0.268 & 0.5 & 2.0 \\
Sandy Clay Loam & 2189 & 1.518 & 0.186 & 0.76 & 2.0 \\
Loam & 5198 & 1.418 & 0.240 & 0.54 & 1.99 \\
Silt Loam & 6411 & 1.366 & 0.227 & 0.5 & 1.99 \\
Silt & 195 & 1.330 & 0.202 & 0.63 & 1.74 \\
Clay Loam & 3396 & 1.410 & 0.197 & 0.63 & 2.0 \\
Silty Clay Loam & 3139 & 1.405 & 0.148 & 0.8 & 1.91 \\
Sandy Clay & 386 & 1.491 & 0.177 & 0.87 & 1.94 \\
Silty Clay & 2165 & 1.37 & 0.154 & 0.73 & 1.82 \\
Clay & 4539 & 1.292 & 0.177 & 0.58 & 1.9 \\
\hline
\end{tabular}





\section{Appendix B: Recommended Soil Parameter Distributions}

Probability distributions of three types (normal, lognormal, and beta) were used to approximate the soil hydraulic parameter distributions generated from the Carsel and Parrish (1988) statistics. This appendix provides a summary of these distributions and presents tables of recommended distributions for selected soil hydraulic parameters. The information provided in Sections B.1 - B.3 can be found in many good probability or statistics textbooks (e.g., Ang and Tang, 1975). Definitions of parameters can be found in Appendix D.

This appendix was originally presented in NUREG/CR6565 (Meyer et al., 1997).

\section{B.1 The Normal Distribution}

The normal distribution has a density function given by

$$
f(x)=\frac{1}{\sqrt{2 \pi} \sigma^{\prime}} \exp \left[\frac{1}{2}\left(\frac{x-\mu^{\prime}}{\sigma^{\prime}}\right)^{2}\right]
$$

where $x$ is the soil parameter being modeled and $\mu^{\prime}$ and $\sigma^{\prime}$ are the parameters of the distribution. The mean, $\mu$, and the variance, $\sigma^{2}$, are related to the parameters of the normal distribution as follows.

$$
\begin{aligned}
\mu & =\mu^{\prime} \\
\sigma^{2} & =\sigma^{\prime 2}
\end{aligned}
$$

Although the normal distribution is unbounded, soil parameters modeled by a normal distribution often have physical limits. These limits can be enforced by specifying that the soil parameter values fall between given quantiles of the normal distribution. In the tables below, the lower $(A)$ and upper $(B)$ limits of each normal distribution are the 0.001 and 0.999 quantiles calculated as follows.

$$
A=\mu^{\prime}-3.09 \sigma^{\prime} \quad B=\mu^{\prime}+3.09 \sigma^{\prime}
$$

\section{B.2 The Lognormal distribution}

The lognormal distribution has a density function given by

$$
f(x)=\frac{1}{\sqrt{2 \pi} \zeta x} \exp \left[\frac{1}{2}\left(\frac{\ln (x)-\gamma}{\zeta}\right)^{2}\right]
$$

where $\gamma$ and $\zeta$ are the parameters of the distribution. The mean and variance of the lognormal distribution are related to the parameters as follows.

$$
\begin{aligned}
\mu & =\exp \left(\gamma+\frac{1}{2} \zeta^{2}\right) \\
\sigma^{2} & =\mu^{2}\left[\exp \left(\zeta^{2}\right)-1\right]
\end{aligned}
$$

These relationships can also be inverted.

$$
\begin{gathered}
\gamma=\ln \mu-\frac{1}{2} \zeta^{2} \\
\zeta=\sqrt{\ln \left(\frac{\sigma^{2}}{\mu^{2}}+1\right)}
\end{gathered}
$$

The lognormal distribution is thus completely specified by either its parameters or its mean and variance.

The lognormal distribution is bounded below by zero, but has no upper bound. In the tables below, the lower and upper bound for the lognormal distributions are the 0.001 and 0.999 quantiles calculated as follows.

$$
A=\exp (\gamma-3.09 \zeta) \quad B=\exp (\gamma+3.09 \zeta)
$$

\section{B.3 The Beta Distribution}

The beta distribution has a density function given by

$$
f(x)=\frac{1}{\beta(q, r)} \frac{(x-A)^{q-1}(B-x)^{r-1}}{(B-A)^{q+r-1}}
$$

where $q$ and $r$ are parameters controlling the shape of the distribution and $A$ and $B$ are the lower and upper limits of the distribution. $\beta(q, r)$ is the beta function, calculated through its relationship to the gamma function.

$$
\beta(q, r)=\frac{\Gamma(q) \Gamma(r)}{\Gamma(q+r)}
$$

where $\Gamma($ ) indicates the gamma function.

The mean and variance of the beta distribution are related to the parameters as follows.

$$
\begin{gathered}
\mu=A+\frac{q}{q+r}(B-A) \\
\sigma^{2}=\frac{q r}{(q+r)^{2}(q+r+1)}(B-A)^{2}
\end{gathered}
$$

With some algebraic manipulation, these relationships can be inverted to provide the shape parameters as a function of the mean, variance, and limits.

$$
\begin{gathered}
q=\left(\frac{(B-\mu)(\mu-A)}{\sigma^{2}}-1\right)\left(\frac{\mu-A}{B-A}\right) \\
r=q\left(\frac{B-\mu}{\mu-A}\right)
\end{gathered}
$$

The beta distribution can thus be completed specified by its lower and upper limits and either its mean and variance or its shape parameters.

In the tables below, the lower and upper limits for the beta distributions are the actual limits, $A$ and $B$. 


\section{B.4 Recommended Probability Distributions for Soil Hydraulic Parameters by Soil Texture}

Tables B-1 to B-12 contain the recommended distributions for the selected soil hydraulic parameters. Each table represents a particular USDA soil textural classification. Observed correlations between parameters are given in Appendix B.

Table B-1. Recommended distributions for Sand

\begin{tabular}{cccccc}
\hline Parameter & Distribution & Mean & Std. Deviation & Lower Limit $^{2}$ & Upper Limit $^{2}$ \\
\hline$\theta_{\mathrm{S}}$ & Normal & 0.430 & 0.0600 & 0.245 & 0.615 \\
$\theta_{\mathrm{r}}$ & $\mathrm{LN}(-3.09,0.224)^{*}$ & 0.0466 & 0.0106 & 0.0228 & 0.0907 \\
$p_{e}$ & Normal & 0.383 & 0.0610 & 0.195 & 0.572 \\
$f_{c}$ & $\mathrm{LN}(-2.83,0.241)$ & 0.0607 & 0.0150 & 0.0280 & 0.124 \\
$w_{p}$ & $\mathrm{LN}(-3.09,0.224)$ & 0.0466 & 0.0106 & 0.0227 & 0.0907 \\
$a w c$ & $\mathrm{LN}(-4.34,0.387)$ & 0.0141 & $6.12 \mathrm{E}-03$ & $3.95 \mathrm{E}-03$ & 0.0431 \\
$\alpha\left[\mathrm{cm}^{-1}\right]$ & Normal & 0.147 & 0.0255 & 0.0687 & 0.226 \\
$n$ & $\mathrm{LN}(0.978,0.0998)^{*}$ & 2.67 & 0.267 & 1.95 & 3.62 \\
$h_{b}$ & $\mathrm{LN}(1.93,0.183)$ & 7.02 & 1.38 & 3.92 & 12.1 \\
$\lambda$ & $\mathrm{LN}(0.502,0.161)$ & 1.67 & 0.267 & 1.00 & 2.72 \\
$b$ & $\mathrm{LN}(-0.0253,0.216)$ & 0.998 & 0.226 & 0.501 & 1.90 \\
$K_{s}[\mathrm{~cm} / \mathrm{s}]$ & $\mathrm{Beta}(1.398,1.842)$ & $8.22 \mathrm{E}-03$ & $4.39 \mathrm{E}-03$ & $3.50 \mathrm{E}-04$ & 0.0186 \\
\hline
\end{tabular}

Table B-2. Recommended distributions for Loamy Sand

\begin{tabular}{cccccc}
\hline Parameter & Distribution & Mean & Std. Deviation & Lower Limit $^{2}$ & Upper Limit $^{2}$ \\
\hline$\theta_{\mathrm{s}}$ & Normal & 0.410 & 0.0900 & 0.132 & 0.688 \\
$\theta_{\mathrm{r}}$ & Normal & 0.0569 & 0.0145 & 0.0121 & 0.102 \\
$p_{e}$ & Normal & 0.353 & 0.0913 & 0.0711 & 0.635 \\
$f_{c}$ & $\mathrm{LN}(-2.55,0.281)$ & 0.0809 & 0.0224 & 0.0327 & 0.186 \\
$w_{p}$ & Normal & 0.0570 & 0.0146 & 0.0119 & 0.102 \\
$a w c$ & $\mathrm{LN}(-3.85,0.491)$ & 0.0239 & 0.0125 & $4.65 \mathrm{E}-03$ & 0.0966 \\
$\alpha\left[\mathrm{cm}^{-1}\right]$ & Normal* & 0.125 & 0.0404 & $2.03 \mathrm{E}-04$ & 0.250 \\
$n$ & $\mathrm{LN}(0.816,0.0910)$ & 2.27 & 0.209 & 1.71 & 3.00 \\
$h_{b}$ & $\mathrm{LN}(2.15,0.401)$ & 9.58 & 8.59 & 2.48 & 29.5 \\
$\lambda$ & $\mathrm{LN}(0.226,0.164)$ & 1.27 & 0.209 & 0.756 & 2.08 \\
$b$ & $\mathrm{LN}(0.305,0.258)$ & 1.40 & 0.397 & 0.610 & 3.01 \\
$K_{s}[\mathrm{~cm} / \mathrm{s}]$ & $\mathrm{Beta}(0.7992,1.910)$ & $3.99 \mathrm{E}-03$ & $3.17 \mathrm{E}-03$ & $3.90 \mathrm{E}-05$ & 0.0134 \\
\hline
\end{tabular}


Table B-3. Recommended distributions for Sandy Loam

\begin{tabular}{cccccc}
\hline Parameter & Distribution & Mean & Std. Deviation & Lower Limit $^{2}$ & Upper Limit $^{2}$ \\
\hline$\theta_{\mathrm{s}}$ & Normal & 0.410 & 0.0899 & 0.132 & 0.688 \\
$\theta_{\mathrm{r}}$ & Beta(2.885,2.304) & 0.0644 & 0.0169 & 0.0173 & 0.102 \\
$p_{e}$ & Normal & 0.346 & 0.0915 & 0.0629 & 0.628 \\
$f_{c}$ & $\mathrm{LN}(-2.21,0.314)$ & 0.116 & 0.0369 & 0.0417 & 0.291 \\
$w_{p}$ & Normal & 0.0659 & 0.0179 & 0.0106 & 0.121 \\
$a w c$ & $\mathrm{LN}(-3.12,0.489)$ & 0.0498 & 0.0256 & $9.75 \mathrm{E}-03$ & 0.200 \\
$\alpha\left[\mathrm{cm}^{-1}\right]$ & $\mathrm{Beta}(1.816,3.412)$ & 0.0757 & 0.0368 & $8.72 \mathrm{E}-03$ & 0.202 \\
$n$ & $\mathrm{LN}(0.634,0.0818)^{*}$ & 1.89 & 0.155 & 1.46 & 2.43 \\
$h_{b}$ & $\mathrm{LN}(2.71,0.538)$ & 17.7 & 12.0 & 2.85 & 79.4 \\
$\lambda$ & Normal & 0.892 & 0.155 & 0.412 & 1.37 \\
$b$ & $\mathrm{LN}(0.632,0.282)$ & 1.96 & 0.597 & 0.786 & 4.50 \\
$K_{s}[\mathrm{~cm} / \mathrm{s}]$ & $\mathrm{LN}(-7.46,1.33)$ & $1.17 \mathrm{E}-03$ & $1.37 \mathrm{E}-03$ & $9.62 \mathrm{E}-06$ & 0.0347 \\
\hline
\end{tabular}

Table B-4. Recommended distributions for Sandy Clay Loam

\begin{tabular}{cccccc}
\hline Parameter & Distribution & Mean & Std. Deviation & Lower Limit $^{2}$ & Upper Limit $^{2}$ \\
\hline$\theta_{\mathrm{s}}$ & Normal & 0.390 & 0.0700 & 0.174 & 0.606 \\
$\theta_{\mathrm{r}}$ & Beta(2.202,2.010) & 0.101 & $6.09 \mathrm{E}-03$ & 0.0860 & 0.114 \\
$p_{e}$ & Normal & 0.289 & 0.0703 & 0.0723 & 0.507 \\
$f_{c}$ & $\mathrm{LN}(-1.59,0.254)$ & 0.212 & 0.0568 & 0.0933 & 0.449 \\
$w_{p}$ & $\mathrm{LN}(-2.14,0.158)$ & 0.120 & 0.0214 & 0.0724 & 0.193 \\
$a w c$ & $\mathrm{Beta}(1.890,3.817)$ & 0.0920 & 0.0393 & 0.0204 & 0.237 \\
$\alpha\left[\mathrm{cm}^{-1}\right]$ & $\mathrm{LN}(-3.04,0.639)$ & 0.0572 & 0.0337 & $6.62 \mathrm{E}-03$ & 0.343 \\
$n$ & $\mathrm{LN}(0.388,0.0858)^{*}$ & 1.48 & 0.127 & 1.13 & 1.92 \\
$h_{b}$ & $\mathrm{LN}(3.04,0.639)$ & 26.2 & 21.3 & 2.92 & 151. \\
$\lambda$ & Normal & 0.479 & 0.127 & 0.0865 & 0.872 \\
$b$ & $\mathrm{LN}(1.41,0.275)$ & 4.27 & 1.39 & 1.75 & 9.57 \\
$K_{s}[\mathrm{~cm} / \mathrm{s}]$ & $\mathrm{LN}(-9.30,1.75)$ & $3.23 \mathrm{E}-04$ & $5.98 \mathrm{E}-04$ & $4.12 \mathrm{E}-07$ & 0.0202 \\
\hline
\end{tabular}


Recommended Soil Parameter Distributions

Table B-5. Recommended distributions for Loam

\begin{tabular}{cccccc}
\hline Parameter & Distribution & Mean & Std. Deviation & Lower Limit $^{2}$ & Upper Limit $^{2}$ \\
\hline$\theta_{\mathrm{s}}$ & Normal & 0.430 & 0.0998 & 0.122 & 0.738 \\
$\theta_{\mathrm{r}}$ & Beta(3.639,2.652) & 0.0776 & 0.0127 & 0.0374 & 0.107 \\
$p_{e}$ & Normal & 0.352 & 0.101 & 0.0414 & 0.663 \\
$f_{c}$ & $\mathrm{LN}(-1.68,0.300)$ & 0.194 & 0.0609 & 0.0735 & 0.468 \\
$w_{p}$ & $\mathrm{LN}(-2.40,0.250)$ & 0.0935 & 0.0246 & 0.0418 & 0.196 \\
$a w c$ & $\mathrm{LN}(-2.40,0.462)$ & 0.101 & 0.0454 & 0.0218 & 0.380 \\
$\alpha\left[\mathrm{cm}^{-1}\right]$ & $\mathrm{Beta}(1.576,3.625)$ & 0.0367 & 0.0202 & $3.51 \mathrm{E}-03$ & 0.113 \\
$n$ & $\mathrm{LN}(0.442,0.0730)$ & 1.56 & 0.114 & 1.24 & 1.95 \\
$h_{b}$ & $\mathrm{LN}(3.470,0.598)$ & 38.9 & 29.3 & 5.05 & 203. \\
$\lambda$ & Normal & 0.560 & 0.114 & 0.209 & 0.911 \\
$b$ & $\mathrm{LN}(1.08,0.271)$ & 3.07 & 0.900 & 1.28 & 6.82 \\
$K_{s}[\mathrm{~cm} / \mathrm{s}]$ & $\mathrm{LN}(-9.26,1.66)$ & $2.92 \mathrm{E}-04$ & $4.91 \mathrm{E}-04$ & $5.51 \mathrm{E}-07$ & 0.0159 \\
\hline
\end{tabular}

Table B-6. Recommended distributions for Silt Loam

\begin{tabular}{cccccc}
\hline Parameter & Distribution & Mean & Std. Deviation & Lower Limit $^{2}$ & Upper Limit $^{2}$ \\
\hline$\theta_{\mathrm{s}}$ & Normal & 0.45 & 0.0800 & 0.203 & 0.697 \\
$\theta_{\mathrm{r}}$ & Beta(3.349,2.566) & 0.0670 & 0.0142 & 0.0243 & 0.0998 \\
$p_{e}$ & Normal & 0.383 & 0.0813 & 0.132 & 0.634 \\
$f_{c}$ & Normal & 0.252 & 0.0776 & 0.0119 & 0.491 \\
$w_{p}$ & $\mathrm{LN}(-2.22,0.397)$ & 0.117 & 0.0471 & 0.0318 & 0.368 \\
$a w c$ & Normal & 0.135 & 0.0402 & 0.0107 & 0.259 \\
$\alpha\left[\mathrm{cm}^{-1}\right]$ & $\mathrm{LN}(-4.10,0.554)^{*}$ & 0.0193 & 0.0115 & $2.99 \mathrm{E}-03$ & 0.0919 \\
$n$ & $\mathrm{LN}(0.343,0.0851)$ & 1.41 & 0.120 & 1.08 & 1.83 \\
$h_{b}$ & $\mathrm{LN}(4.10,0.554)$ & 70.3 & 41.9 & 10.9 & 335. \\
$\lambda$ & Normal & 0.414 & 0.120 & 0.0417 & 0.786 \\
$b$ & $\mathrm{LN}(1.28,0.334)$ & 3.80 & 1.42 & 1.28 & 10.1 \\
$K_{s}[\mathrm{~cm} / \mathrm{s}]$ & $\mathrm{LN}(-10.4,1.49)^{*}$ & $9.33 \mathrm{E}-05$ & $2.24 \mathrm{E}-04$ & $3.12 \mathrm{E}-07$ & $3.11 \mathrm{E}-03$ \\
\hline
\end{tabular}


Table B-7. Recommended distributions for Silt

\begin{tabular}{cccccc}
\hline Parameter & Distribution & Mean & Std. Deviation & Lower Limit $^{2}$ & Upper Limit $^{2}$ \\
\hline$\theta_{\mathrm{s}}$ & Normal & 0.456 & 0.110 & 0.1206 & 0.799 \\
$\theta_{\mathrm{r}}$ & Beta(1.717,1.072) & 0.0352 & $8.97 \mathrm{E}-03$ & 0.0131 & 0.0490 \\
$p_{e}$ & Normal & 0.425 & 0.110 & 0.0839 & 0.766 \\
$f_{c}$ & Normal & 0.236 & 0.0578 & 0.0575 & 0.415 \\
$w_{p}$ & $\mathrm{LN}(-2.46,0.295)$ & 0.0890 & 0.0268 & 0.0342 & 0.212 \\
$a w c$ & Normal & 0.147 & 0.0395 & 0.0252 & 0.269 \\
$\alpha\left[\mathrm{cm}^{-1}\right]$ & Normal* & 0.0178 & $5.73 \mathrm{E}-03$ & $3.91 \mathrm{E}-05$ & 0.0355 \\
$n$ & Normal* & 1.38 & 0.0369 & 1.27 & 1.49 \\
$h_{b}$ & $\mathrm{LN}(4.10,0.403)$ & 68.1 & 74.8 & 17.3 & 209. \\
$\lambda$ & Normal & 0.380 & 0.0369 & 0.266 & 0.494 \\
$b$ & $\mathrm{LN}(1.16,0.140)$ & 3.21 & 0.465 & 2.06 & 4.89 \\
$K_{s}[\mathrm{~cm} / \mathrm{s}]$ & $\mathrm{LN}(-10.0,0.475)^{*}$ & $4.89 \mathrm{E}-05$ & $2.76 \mathrm{E}-05$ & $9.95 \mathrm{E}-06$ & $1.87 \mathrm{E}-04$ \\
\hline
\end{tabular}

Table B-8. Recommended distributions for Clay Loam

\begin{tabular}{cccccc}
\hline Parameter & Distribution & Mean & Std. Deviation & Lower Limit $^{2}$ & Upper Limit $^{2}$ \\
\hline$\theta_{\mathrm{s}}$ & Normal & 0.410 & 0.0900 & 0.132 & 0.688 \\
$\theta_{\mathrm{r}}$ & Normal & 0.0954 & $9.68 \mathrm{E}-03$ & 0.0655 & 0.125 \\
$p_{e}$ & Normal & 0.315 & 0.0905 & 0.0349 & 0.594 \\
$f_{c}$ & $\mathrm{LN}(-1.27,0.297)$ & 0.292 & 0.0862 & 0.112 & 0.700 \\
$w_{p}$ & $\mathrm{LN}(-1.84,0.257)$ & 0.164 & 0.0468 & 0.0714 & 0.350 \\
$a w c$ & $\mathrm{Beta}(2.986,4.318)$ & 0.128 & 0.0497 & $9.34 \mathrm{E}-03$ & 0.301 \\
$\alpha\left[\mathrm{cm}^{-1}\right]$ & $\mathrm{LN}(-4.22,0.719)^{*}$ & 0.0190 & 0.0153 & $1.59 \mathrm{E}-03$ & 0.136 \\
$n$ & Normal & 1.32 & 0.0973 & 1.02 & 1.62 \\
$h_{b}$ & $\mathrm{LN}(4.22,0.719)$ & 88.0 & 71.3 & 7.37 & 628. \\
$\lambda$ & Normal & 0.318 & 0.0973 & 0.0170 & 0.618 \\
$b$ & $\mathrm{LN}(1.73,0.323)$ & 5.97 & 2.37 & 2.08 & 15.3 \\
$K_{s}[\mathrm{~cm} / \mathrm{s}]$ & $\mathrm{LN}(-11.3,2.17)$ & $9.93 \mathrm{E}-05$ & $2.51 \mathrm{E}-04$ & $1.42 \mathrm{E}-08$ & $9.76 \mathrm{E}-03$ \\
\hline
\end{tabular}


Recommended Soil Parameter Distributions

Table B-9. Recommended distributions for Silty Clay Loam

\begin{tabular}{cccccc}
\hline Parameter & Distribution & Mean & Std. Deviation & Lower Limit $^{2}$ & Upper Limit $^{2}$ \\
\hline$\theta_{\mathrm{s}}$ & Normal & 0.430 & 0.0699 & 0.214 & 0.646 \\
$\theta_{\mathrm{r}}$ & Normal* & 0.0880 & $9.00 \mathrm{E}-03$ & 0.0602 & 0.116 \\
$p_{e}$ & Normal & 0.342 & 0.0705 & 0.124 & 0.560 \\
$f_{c}$ & Normal & 0.347 & 0.0710 & 0.127 & 0.566 \\
$w_{p}$ & LN(-1.61,0.233) & 0.205 & 0.0508 & 0.0970 & 0.410 \\
$a w c$ & Normal & 0.142 & 0.0333 & 0.0387 & 0.245 \\
$\alpha\left[\mathrm{cm}^{-1}\right]$ & $\mathrm{LN}(-4.72,0.563)$ & 0.0104 & $6.08 \mathrm{E}-03$ & $1.57 \mathrm{E}-03$ & 0.0508 \\
$n$ & Normal* & 1.23 & 0.0610 & 1.04 & 1.42 \\
$h_{b}$ & LN(4.72,0.563) & 132. & 81.4 & 19.7 & 638. \\
$\lambda$ & Normal & 0.230 & 0.0610 & 0.0416 & 0.418 \\
$b$ & LN(1.96,0.265) & 7.13 & 2.34 & 3.02 & 15.5 \\
$K_{s}[\mathrm{~cm} / \mathrm{s}]$ & LN(-12.3,1.59) & $1.54 \mathrm{E}-05$ & $3.38 \mathrm{E}-05$ & $3.44 \mathrm{E}-08$ & $6.49 \mathrm{E}-04$ \\
\hline
\end{tabular}

Table B-10. Recommended distributions for Sandy Clay

\begin{tabular}{cccccc}
\hline Parameter & Distribution & Mean & Std. Deviation & Lower Limit $^{2}$ & Upper Limit $^{\mathbf{2}}$ \\
\hline$\theta_{\mathrm{s}}$ & Normal & 0.380 & 0.0500 & 0.226 & 0.534 \\
$\theta_{\mathrm{r}}$ & Beta(4.000,1.487) & 0.0993 & 0.0116 & 0.0508 & 0.117 \\
$p_{e}$ & Normal & 0.281 & 0.0513 & 0.122 & 0.439 \\
$f_{c}$ & $\mathrm{LN}(-1.23,0.210)$ & 0.299 & 0.0623 & 0.153 & 0.559 \\
$w_{p}$ & $\mathrm{Beta}(1.142,4.640)$ & 0.165 & 0.0344 & 0.121 & 0.346 \\
$a w c$ & Normal & 0.134 & 0.0356 & 0.0238 & 0.244 \\
$\alpha\left[\mathrm{cm}^{-1}\right]$ & $\mathrm{LN}(-3.77,0.562)^{*}$ & 0.0270 & 0.0164 & $4.06 \mathrm{E}-03$ & 0.131 \\
$n$ & $\mathrm{LN}(0.241,0.0653)^{*}$ & 1.28 & 0.0834 & 1.04 & 1.56 \\
$h_{b}$ & $\mathrm{LN}(3.77,0.562)$ & 50.7 & 30.5 & 7.64 & 246. \\
$\lambda$ & Normal & 0.275 & 0.0834 & 0.0177 & 0.533 \\
$b$ & $\mathrm{LN}(1.89,0.260)$ & 6.90 & 2.27 & 2.97 & 14.8 \\
$K_{s}[\mathrm{~cm} / \mathrm{s}]$ & $\mathrm{LN}(-12.2,2.02)^{*}$ & $3.55 \mathrm{E}-05$ & $1.48 \mathrm{E}-04$ & $9.59 \mathrm{E}-09$ & $2.50 \mathrm{E}-03$ \\
\hline
\end{tabular}


Table B-11. Recommended distributions for Silty Clay

\begin{tabular}{cccccc}
\hline Parameter & Distribution & Mean & Std. Deviation & Lower Limit $^{2}$ & Upper Limit $^{2}$ \\
\hline$\theta_{\mathrm{s}}$ & Normal & 0.360 & 0.0698 & 0.144 & 0.576 \\
$\theta_{\mathrm{r}}$ & Normal & 0.0706 & 0.0228 & $1.47 \mathrm{E}-04$ & 0.141 \\
$p_{e}$ & Normal & 0.289 & 0.0735 & 0.0623 & 0.517 \\
$f_{c}$ & Normal & 0.334 & 0.0678 & 0.124 & 0.543 \\
$w_{p}$ & $\mathrm{LN}(-1.49,0.220)$ & 0.230 & 0.0512 & 0.114 & 0.444 \\
$a w c$ & Normal & 0.103 & 0.0303 & $9.63 \mathrm{E}-03$ & 0.197 \\
$\alpha\left[\mathrm{cm}^{-1}\right]$ & $\mathrm{LN}(-5.66,0.584)^{*}$ & $4.13 \mathrm{E}-03$ & $2.60 \mathrm{E}-03$ & $5.73 \mathrm{E}-04$ & 0.0211 \\
$n$ & $\mathrm{LN}(0.145,0.0430)$ & 1.16 & 0.0499 & 1.01 & 1.32 \\
$h_{b}$ & $\mathrm{LN}(5.66,0.584)$ & 340. & 216. & 47.3 & 1743. \\
$\lambda$ & $\mathrm{Beta}(2.591,3.268)$ & 0.157 & 0.0499 & 0.0404 & 0.304 \\
$b$ & $\mathrm{LN}(2.29,0.259)$ & 10.2 & 2.96 & 4.43 & 22.0 \\
$K_{s}[\mathrm{~cm} / \mathrm{s}]$ & $\mathrm{LN}(-13.9,1.31)^{*}$ & $2.19 \mathrm{E}-06$ & $4.08 \mathrm{E}-06$ & $1.64 \mathrm{E}-08$ & $5.37 \mathrm{E}-05$ \\
\hline
\end{tabular}

Table B-12. Recommended distributions for Clay

\begin{tabular}{cccccc}
\hline Parameter & Distribution & Mean & Std. Deviation & Lower Limit $^{2}$ & Upper Limit $^{2}$ \\
\hline$\theta_{\mathrm{s}}$ & Normal & 0.380 & 0.0900 & 0.102 & 0.658 \\
$\theta_{\mathrm{r}}$ & Beta(1.501,1.580) & 0.0685 & 0.0344 & $8.36 \mathrm{E}-04$ & 0.140 \\
$p_{e}$ & Normal & 0.311 & 0.0963 & 0.0138 & 0.609 \\
$f_{c}$ & Normal & 0.340 & 0.0893 & 0.0638 & 0.615 \\
$w_{p}$ & $\operatorname{Beta}(2.751,4.921)$ & 0.263 & 0.0770 & 0.0939 & 0.567 \\
$a w c$ & $\mathrm{LN}(-2.66,0.429)$ & 0.0761 & 0.0299 & 0.0186 & 0.263 \\
$\alpha\left[\mathrm{cm}^{-1}\right]$ & $\mathrm{LN}(-5.54,0.893)$ & $6.18 \mathrm{E}-03$ & $7.59 \mathrm{E}-03$ & $2.50 \mathrm{E}-04$ & 0.0621 \\
$n$ & $\operatorname{Beta}(0.8857,2.400)$ & 1.13 & 0.0697 & 1.04 & 1.36 \\
$h_{b}$ & $\operatorname{Beta}(0.8002,1.546)$ & 353. & 257. & 14.1 & 1007 \\
$\lambda$ & $\operatorname{Beta}(0.8854,2.399)$ & 0.127 & 0.0697 & 0.0397 & 0.365 \\
$b$ & $\operatorname{Beta}(1.751,11.61)$ & 14.1 & 6.24 & 4.93 & 75.0 \\
$K_{s}[\mathrm{~cm} / \mathrm{s}]$ & $\mathrm{LN}(-12.36,2.269)$ & $3.65 \mathrm{E}-05$ & $1.08 \mathrm{E}-04$ & $3.87 \mathrm{E}-09$ & $4.76 \mathrm{E}-03$ \\
\hline
\end{tabular}

1. $\operatorname{LN}()=,\operatorname{Lognormal}(\gamma, \zeta)$; see Section B.2. $\operatorname{Beta}()=,\operatorname{Beta}(q, r)$; see Section B.3.

2. Lower Limit and Upper Limit are 0.001 and 0.999 quantiles for Normal and Lognormal distributions.

* Indicates that the recommended distribution is the same type as used by Carsel and Parrish (1988). This applies to the parameters $\theta_{\mathrm{r}}, \alpha, n$, and $K_{s}$ only. 
Recommended Soil Parameter Distributions

\section{B.5 References}

Ang, A. H-S. and W. H. Tang, Probability Concepts in Engineering Planning and Design, Volume 1, Basic Principles, John Wiley \& Sons, New York, 409 pp., 1975.

Carsel, R. F., and R. S. Parrish, "Developing joint probability distributions of soil water retention characteristics," Water Resources Research, 24(5):755-770, 1988.

Meyer, P.D., M.L. Rockhold, and G.W. Gee, "Uncertainty Analyses of Infiltration and Subsurface Flow and Transport for SDMP Sites," NUREG/CR-6565, U.S. Nuclear Regulatory Commission, Washington, DC, 1997. 


\section{Appendix C: Soil Parameter Correlation Coefficients}

The correlation coefficient is a measure of the strength of a linear relationship between two random variables (i.e., soil parameters), $X$ and $Y$. Sample correlation coefficients were calculated as follows [e.g., Ang and Tang (1975)].

$$
\hat{\rho}=\frac{1}{N-1} \frac{\sum_{i=1}^{N} x_{i} y_{i}-N \overline{x y}}{s_{x} s_{y}}
$$

where

$\hat{\rho} \quad=$ sample correlation coefficient

$x_{i}, y_{i}=$ sample values for parameters $X$ and $Y$

$x, y=$ sample mean values calculated as

$$
\bar{x}=\frac{1}{N} \sum_{i=1}^{N} x_{i}
$$

$s_{x}, s_{y}=$ sample standard deviations calculated as

$$
s_{x}^{2}=\frac{1}{N-1} \sum_{i=1}^{N}\left(x_{i}-\bar{x}^{2}\right.
$$

$$
N \quad=\text { the number of sample values }
$$

Correlations between parameters were induced by applying the correlations between $\theta_{\mathrm{r}}, \alpha, n$, and $K_{s}$ given in Carsel and Parrish (1988). The rank correlation method of Iman and Conover (1982) as embodied in the Latin hypercube sampling code of Iman and Shortencarier (1984) was used. Note that the correlations given in the tables below do not necessarily appear to be the same as those of Carsel and Parrish (1988) since their correlations were calculated after the parameters were transformed to normal distributions. The correlations given below were calculated on the untransformed parameters. Definitions of parameters in the tables can be found in Appendix D.

\begin{tabular}{|c|c|c|c|c|c|c|c|c|c|c|c|c|}
\hline & $\theta_{\mathbf{s}}$ & $\theta_{\mathbf{r}}$ & $\mathbf{p}_{\mathbf{e}}$ & $\mathbf{f}_{\mathrm{c}}$ & $\mathbf{w}_{\mathbf{p}}$ & awc & $\alpha$ & $\mathbf{n}$ & $\mathbf{h}_{\mathbf{b}}$ & $\lambda$ & b & $\mathbf{K}_{\mathbf{s}}$ \\
\hline$\theta_{\mathrm{s}}$ & 1 & -0.01 & 0.99 & 0.15 & -0.01 & 0.38 & 0.00 & 0.00 & -0.02 & 0.00 & -0.29 & 0.00 \\
\hline$\theta_{\mathbf{r}}$ & & 1 & -0.18 & 0.94 & 1 & 0.59 & 0.12 & -0.84 & -0.12 & -0.84 & 0.91 & -0.50 \\
\hline $\mathbf{p}_{\mathbf{e}}$ & & & 1 & -0.02 & -0.18 & 0.27 & -0.02 & 0.15 & 0.01 & 0.15 & -0.44 & 0.08 \\
\hline $\mathbf{f}_{\mathbf{c}}$ & & & & 1 & 0.94 & 0.82 & -0.11 & -0.91 & 0.11 & -0.91 & 0.89 & -0.67 \\
\hline $\mathbf{w}_{\mathbf{p}}$ & & & & & 1 & 0.59 & 0.12 & -0.84 & -0.12 & -0.84 & 0.91 & -0.50 \\
\hline awc & & & & & & 1 & -0.49 & -0.79 & 0.49 & -0.79 & 0.59 & -0.78 \\
\hline$\alpha$ & & & & & & & 1 & 0.29 & -0.97 & 0.29 & -0.09 & 0.73 \\
\hline $\mathbf{n}$ & & & & & & & & 1 & -0.28 & 1 & -0.88 & 0.84 \\
\hline $\mathbf{h}_{\mathbf{b}}$ & & & & & & & & & 1 & -0.28 & 0.09 & -0.68 \\
\hline$\lambda$ & & & & & & & & & & 1 & -0.88 & 0.84 \\
\hline $\mathbf{b}$ & & & & & & & & & & & 1 & -0.65 \\
\hline $\mathbf{K}_{\mathbf{s}}$ & & & & & & & & & & & & 1 \\
\hline
\end{tabular}

This appendix was originally presented in NUREG/CR6565 (Meyer et al., 1997).

Table C-1. Correlation coefficients for Sand 
Table C-2. Correlation coefficients for Loamy Sand

\begin{tabular}{|c|c|c|c|c|c|c|c|c|c|c|c|c|}
\hline & $\theta_{\mathbf{s}}$ & $\theta_{\mathbf{r}}$ & $\mathbf{p}_{\mathbf{e}}$ & $\mathbf{f}_{\mathbf{c}}$ & $\mathbf{w}_{\mathbf{p}}$ & awc & $\alpha$ & $\mathbf{n}$ & $\mathbf{h}_{\mathbf{b}}$ & $\lambda$ & b & $\mathbf{K}_{\mathrm{s}}$ \\
\hline$\theta_{\mathbf{s}}$ & 1 & -0.01 & 0.99 & 0.27 & 0.00 & 0.49 & 0.00 & 0.01 & -0.03 & 0.01 & -0.50 & 0.01 \\
\hline$\theta_{\mathbf{r}}$ & & 1 & -0.16 & 0.85 & 1 & 0.34 & -0.29 & -0.58 & 0.16 & -0.58 & 0.71 & -0.34 \\
\hline $\mathbf{p}_{\mathbf{e}}$ & & & 1 & 0.13 & -0.16 & 0.42 & 0.05 & 0.10 & -0.05 & 0.10 & -0.60 & 0.07 \\
\hline $\mathbf{f}_{\mathrm{c}}$ & & & & 1 & 0.85 & 0.79 & -0.53 & -0.76 & 0.33 & -0.76 & 0.57 & -0.58 \\
\hline $\mathbf{w}_{\mathbf{p}}$ & & & & & 1 & 0.35 & -0.30 & -0.58 & 0.17 & -0.58 & 0.72 & -0.35 \\
\hline awc & & & & & & 1 & -0.60 & -0.68 & 0.39 & -0.68 & 0.19 & -0.63 \\
\hline$\alpha$ & & & & & & & 1 & 0.38 & -0.57 & 0.38 & -0.29 & 0.88 \\
\hline $\mathbf{n}$ & & & & & & & & 1 & -0.22 & 1 & -0.64 & 0.65 \\
\hline $\mathbf{h}_{\mathbf{b}}$ & & & & & & & & & 1 & -0.22 & 0.17 & -0.38 \\
\hline$\lambda$ & & & & & & & & & & 1 & -0.64 & 0.65 \\
\hline $\mathbf{b}$ & & & & & & & & & & & 1 & -0.41 \\
\hline $\mathbf{K}_{\mathbf{s}}$ & & & & & & & & & & & & 1 \\
\hline
\end{tabular}

Table C-3. Correlation coefficients for Sandy Loam

\begin{tabular}{|c|c|c|c|c|c|c|c|c|c|c|c|c|}
\hline & $\theta_{\mathrm{s}}$ & $\theta_{\mathbf{r}}$ & $\mathbf{p}_{\mathbf{e}}$ & $\mathbf{f}_{\mathrm{c}}$ & $\mathbf{w}_{\mathbf{p}}$ & awc & $\alpha$ & $\mathbf{n}$ & $\mathbf{h}_{b}$ & $\lambda$ & b & $\mathbf{K}_{\mathbf{s}}$ \\
\hline$\theta_{\mathbf{s}}$ & 1 & 0.00 & 0.98 & 0.38 & 0.03 & 0.54 & 0.01 & 0.00 & 0.01 & 0.00 & -0.44 & 0.01 \\
\hline$\theta_{\mathbf{r}}$ & & 1 & -0.19 & 0.72 & 1 & 0.34 & 0.14 & -0.79 & -0.17 & -0.79 & 0.77 & -0.22 \\
\hline $\mathbf{p}_{\mathbf{e}}$ & & & 1 & 0.24 & -0.16 & 0.46 & -0.02 & 0.15 & 0.04 & 0.15 & -0.57 & 0.05 \\
\hline $\mathbf{f}_{\mathrm{c}}$ & & & & 1 & 0.78 & 0.90 & -0.35 & -0.85 & 0.35 & -0.85 & 0.51 & -0.51 \\
\hline $\mathbf{w}_{\mathbf{p}}$ & & & & & 1 & 0.42 & 0.08 & -0.82 & -0.10 & -0.82 & 0.77 & -0.25 \\
\hline awc & & & & & & 1 & -0.56 & -0.65 & 0.57 & -0.65 & 0.20 & -0.56 \\
\hline$\alpha$ & & & & & & & 1 & 0.36 & -0.77 & 0.36 & -0.11 & 0.82 \\
\hline $\mathbf{n}$ & & & & & & & & 1 & -0.28 & 1 & -0.78 & 0.60 \\
\hline $\mathbf{h}_{\mathbf{b}}$ & & & & & & & & & 1 & -0.28 & 0.05 & -0.51 \\
\hline$\lambda$ & & & & & & & & & & 1 & -0.78 & 0.60 \\
\hline $\mathbf{b}$ & & & & & & & & & & & 1 & -0.33 \\
\hline $\mathbf{K}_{\mathbf{s}}$ & & & & & & & & & & & & 1 \\
\hline
\end{tabular}


Table C-4. Correlation coefficients for Sandy Clay Loam

\begin{tabular}{|c|c|c|c|c|c|c|c|c|c|c|c|c|}
\hline & $\theta_{\mathbf{s}}$ & $\theta_{\mathbf{r}}$ & $\mathbf{p}_{\mathbf{e}}$ & $\mathbf{f}_{\mathrm{c}}$ & $\mathbf{w}_{\mathbf{p}}$ & awc & $\alpha$ & $\mathbf{n}$ & $\mathbf{h}_{b}$ & $\lambda$ & b & $\mathbf{K}_{\mathrm{s}}$ \\
\hline$\theta_{\mathbf{s}}$ & 1 & 0.00 & 1 & 0.48 & 0.21 & 0.58 & -0.01 & 0.00 & -0.02 & 0.00 & -0.43 & -0.01 \\
\hline$\theta_{\mathbf{r}}$ & & 1 & -0.09 & -0.02 & 0.23 & -0.16 & 0.37 & -0.11 & -0.36 & -0.11 & 0.21 & 0.16 \\
\hline $\mathbf{p}_{\mathbf{e}}$ & & & 1 & 0.48 & 0.19 & 0.59 & -0.04 & 0.01 & 0.01 & 0.01 & -0.45 & -0.03 \\
\hline $\mathbf{f}_{\mathrm{c}}$ & & & & 1 & 0.88 & 0.97 & -0.67 & -0.81 & 0.66 & -0.81 & 0.42 & -0.50 \\
\hline $\mathbf{w}_{\mathbf{p}}$ & & & & & 1 & 0.73 & -0.51 & -0.81 & 0.68 & -0.81 & 0.65 & -0.33 \\
\hline awc & & & & & & 1 & -0.69 & -0.73 & 0.58 & -0.73 & 0.24 & -0.54 \\
\hline$\alpha$ & & & & & & & 1 & 0.77 & -0.70 & 0.77 & -0.49 & 0.82 \\
\hline $\mathbf{n}$ & & & & & & & & 1 & -0.65 & 1 & -0.76 & 0.71 \\
\hline $\mathbf{h}_{\mathbf{b}}$ & & & & & & & & & 1 & -0.65 & 0.57 & -0.39 \\
\hline$\lambda$ & & & & & & & & & & 1 & -0.76 & 0.71 \\
\hline b & & & & & & & & & & & 1 & -0.38 \\
\hline $\mathbf{K}_{\mathbf{s}}$ & & & & & & & & & & & & 1 \\
\hline
\end{tabular}

Table C-5. Correlation coefficients for Loam

\begin{tabular}{|c|c|c|c|c|c|c|c|c|c|c|c|c|}
\hline & $\theta_{\mathbf{s}}$ & $\theta_{\mathbf{r}}$ & $\mathbf{p}_{\mathbf{e}}$ & $\mathbf{f}_{\mathbf{c}}$ & $\mathbf{w}_{\mathbf{p}}$ & awc & $\alpha$ & $\mathbf{n}$ & $\mathbf{h}_{\mathbf{b}}$ & $\lambda$ & b & $\mathbf{K}_{\mathrm{s}}$ \\
\hline$\theta_{\mathbf{s}}$ & 1 & 0.00 & 0.99 & 0.55 & 0.18 & 0.63 & 0.03 & 0.00 & 0.04 & 0.00 & -0.46 & 0.03 \\
\hline$\theta_{\mathbf{r}}$ & & 1 & -0.13 & 0.29 & 0.79 & -0.03 & -0.04 & -0.70 & 0.07 & -0.70 & 0.67 & 0.14 \\
\hline $\mathbf{p}_{\mathbf{e}}$ & & & 1 & 0.50 & 0.08 & 0.63 & 0.03 & 0.09 & 0.03 & 0.09 & -0.54 & 0.01 \\
\hline $\mathbf{f}_{\mathbf{c}}$ & & & & 1 & 0.75 & 0.93 & -0.63 & -0.71 & 0.70 & -0.71 & 0.28 & -0.41 \\
\hline $\mathbf{w}_{\mathbf{p}}$ & & & & & 1 & 0.47 & -0.42 & -0.87 & 0.56 & -0.87 & 0.69 & -0.16 \\
\hline awc & & & & & & 1 & -0.62 & -0.49 & 0.63 & -0.49 & 0.00 & -0.46 \\
\hline$\alpha$ & & & & & & & 1 & 0.60 & -0.73 & 0.60 & -0.37 & 0.82 \\
\hline $\mathbf{n}$ & & & & & & & & 1 & -0.55 & 1 & -0.79 & 0.41 \\
\hline $\mathbf{h}_{\mathbf{b}}$ & & & & & & & & & 1 & -0.55 & 0.39 & -0.42 \\
\hline$\lambda$ & & & & & & & & & & 1 & -0.79 & 0.41 \\
\hline $\mathbf{b}$ & & & & & & & & & & & 1 & -0.21 \\
\hline $\mathbf{K}_{\mathbf{s}}$ & & & & & & & & & & & & 1 \\
\hline
\end{tabular}


Table C-6. Correlation coefficients for Silt Loam

\begin{tabular}{|c|c|c|c|c|c|c|c|c|c|c|c|c|}
\hline & $\theta_{\mathbf{s}}$ & $\theta_{\mathbf{r}}$ & $\mathbf{p}_{\mathbf{e}}$ & $\mathbf{f}_{\mathrm{c}}$ & $\mathbf{w}_{\mathbf{p}}$ & awc & $\alpha$ & $\mathbf{n}$ & $\mathbf{h}_{\mathbf{b}}$ & $\lambda$ & b & $\mathbf{K}_{\mathrm{s}}$ \\
\hline$\theta_{\mathrm{s}}$ & 1 & -0.01 & 0.98 & 0.48 & 0.20 & 0.70 & -0.02 & -0.01 & -0.02 & -0.01 & -0.20 & -0.02 \\
\hline$\theta_{\mathbf{r}}$ & & 1 & -0.18 & 0.50 & 0.66 & 0.18 & -0.29 & -0.59 & 0.27 & -0.59 & 0.63 & -0.25 \\
\hline $\mathbf{p}_{\mathbf{e}}$ & & & 1 & 0.39 & 0.08 & 0.66 & 0.03 & 0.10 & -0.06 & 0.10 & -0.31 & 0.03 \\
\hline $\mathbf{f}_{\mathbf{c}}$ & & & & 1 & 0.91 & 0.87 & -0.72 & -0.80 & 0.73 & -0.80 & 0.63 & -0.45 \\
\hline $\mathbf{w}_{\mathbf{p}}$ & & & & & 1 & 0.58 & -0.63 & -0.89 & 0.73 & -0.89 & 0.86 & -0.36 \\
\hline awc & & & & & & 1 & -0.65 & -0.50 & 0.54 & -0.50 & 0.20 & -0.44 \\
\hline$\alpha$ & & & & & & & 1 & 0.74 & -0.75 & 0.74 & -0.56 & 0.80 \\
\hline $\mathbf{n}$ & & & & & & & & 1 & -0.69 & 1 & -0.88 & 0.48 \\
\hline $\mathbf{h}_{\mathbf{b}}$ & & & & & & & & & 1 & -0.69 & 0.68 & -0.39 \\
\hline$\lambda$ & & & & & & & & & & 1 & -0.88 & 0.48 \\
\hline b & & & & & & & & & & & 1 & -0.31 \\
\hline $\mathbf{K}_{\mathbf{s}}$ & & & & & & & & & & & & 1 \\
\hline
\end{tabular}

Table C-7. Correlation coefficients for Silt

\begin{tabular}{ccccccccccccc}
\hline & $\theta_{\mathbf{s}}$ & $\theta_{\mathbf{r}}$ & $\mathbf{p}_{\mathbf{e}}$ & $\mathbf{f}_{\mathbf{c}}$ & $\mathbf{w}_{\mathbf{p}}$ & $\mathbf{a w c}$ & $\alpha$ & $\mathbf{n}$ & $\mathbf{h}_{\mathbf{b}}$ & $\lambda$ & $\mathbf{b}$ & $\mathbf{K}_{\mathbf{s}}$ \\
\hline$\theta_{\mathbf{s}}$ & 1 & -0.02 & 1 & 0.90 & 0.52 & 0.97 & 0.00 & 0.00 & 0.03 & 0.00 & -0.39 & 0.02 \\
$\theta_{\mathbf{r}}$ & & 1 & -0.10 & 0.25 & 0.57 & -0.02 & -0.19 & -0.60 & 0.04 & -0.60 & 0.70 & -0.21 \\
$\mathbf{p}_{\mathbf{e}}$ & & & 1 & 0.88 & 0.48 & 0.96 & 0.01 & 0.05 & 0.03 & 0.05 & -0.44 & 0.04 \\
$\mathbf{f}_{\mathbf{c}}$ & & & & 1 & 0.81 & 0.92 & -0.35 & -0.37 & 0.16 & -0.37 & -0.03 & -0.30 \\
$\mathbf{w}_{\mathbf{p}}$ & & & & 1 & 0.51 & -0.60 & -0.72 & 0.48 & -0.72 & 0.44 & -0.45 \\
$\mathbf{a w c}$ & & & & & & 1 & -0.10 & -0.06 & -0.09 & -0.06 & -0.35 & -0.14 \\
$\alpha$ & & & & & & & 1 & 0.55 & -0.49 & 0.55 & -0.41 & 0.89 \\
$\mathbf{n}$ & & & & & & & & 1 & -0.20 & 1 & -0.84 & 0.44 \\
$\mathbf{h}_{\mathbf{b}}$ & & & & & & & & 1 & -0.20 & 0.13 & -0.29 \\
$\lambda$ & & & & & & & & & 1 & -0.84 & 0.44 \\
$\mathbf{b}$ & & & & & & & & & & & & -0.34 \\
$\mathbf{K}_{\mathbf{s}}$ & & & & & & & & & & & & \\
\hline
\end{tabular}


Table C-8. Correlation coefficients for Clay Loam

\begin{tabular}{|c|c|c|c|c|c|c|c|c|c|c|c|c|}
\hline & $\theta_{\mathbf{s}}$ & $\theta_{\mathbf{r}}$ & $\mathbf{p}_{\mathbf{e}}$ & $\mathbf{f}_{c}$ & $\mathbf{w}_{\mathbf{p}}$ & awc & $\alpha$ & $\mathbf{n}$ & $\mathbf{h}_{b}$ & $\lambda$ & b & $\mathbf{K}_{\mathbf{s}}$ \\
\hline$\theta_{\mathbf{s}}$ & 1 & 0.00 & 0.99 & 0.65 & 0.38 & 0.76 & -0.02 & 0.00 & -0.04 & 0.00 & -0.40 & 0.01 \\
\hline$\theta_{\mathbf{r}}$ & & 1 & -0.11 & -0.50 & -0.46 & -0.43 & 0.73 & 0.58 & -0.74 & 0.58 & -0.35 & 0.51 \\
\hline $\mathbf{p}_{\mathbf{e}}$ & & & 1 & 0.69 & 0.43 & 0.80 & -0.10 & -0.06 & 0.04 & -0.06 & -0.36 & -0.04 \\
\hline $\mathbf{f}_{\mathbf{c}}$ & & & & 1 & 0.89 & 0.90 & -0.60 & -0.71 & 0.55 & -0.71 & 0.23 & -0.42 \\
\hline $\mathbf{w}_{\mathbf{p}}$ & & & & & 1 & 0.60 & -0.55 & -0.84 & 0.75 & -0.84 & 0.57 & -0.33 \\
\hline awc & & & & & & 1 & -0.52 & -0.45 & 0.26 & -0.45 & -0.13 & -0.42 \\
\hline$\alpha$ & & & & & & & 1 & 0.79 & -0.62 & 0.79 & -0.42 & 0.89 \\
\hline $\mathbf{n}$ & & & & & & & & 1 & -0.80 & 1 & -0.73 & 0.58 \\
\hline $\mathbf{h}_{\mathbf{b}}$ & & & & & & & & & 1 & -0.80 & 0.70 & -0.36 \\
\hline$\lambda$ & & & & & & & & & & 1 & -0.73 & 0.58 \\
\hline $\mathbf{b}$ & & & & & & & & & & & 1 & -0.26 \\
\hline $\mathbf{K}_{\mathbf{s}}$ & & & & & & & & & & & & 1 \\
\hline
\end{tabular}

Table C-9. Correlation coefficients for Silty Clay Loam

\begin{tabular}{|c|c|c|c|c|c|c|c|c|c|c|c|c|}
\hline & $\theta_{\mathbf{s}}$ & $\theta_{\mathbf{r}}$ & $\mathbf{p}_{\mathbf{e}}$ & $\mathbf{f}_{\mathrm{c}}$ & $\mathbf{w}_{\mathbf{p}}$ & awc & $\alpha$ & $\mathbf{n}$ & $\mathbf{h}_{\mathbf{b}}$ & $\lambda$ & b & $\mathbf{K}_{\mathrm{s}}$ \\
\hline$\theta_{\mathbf{s}}$ & 1 & 0.00 & 0.99 & 0.73 & 0.46 & 0.85 & -0.01 & 0.00 & 0.00 & 0.00 & -0.19 & -0.03 \\
\hline$\theta_{\mathbf{r}}$ & & 1 & -0.13 & -0.42 & -0.46 & -0.21 & 0.72 & 0.55 & -0.71 & 0.55 & -0.37 & 0.47 \\
\hline $\mathbf{p}_{\mathbf{e}}$ & & & 1 & 0.77 & 0.51 & 0.87 & -0.10 & -0.07 & 0.10 & -0.07 & -0.15 & -0.09 \\
\hline $\mathbf{f}_{\mathbf{c}}$ & & & & 1 & 0.90 & 0.75 & -0.62 & -0.65 & 0.58 & -0.65 & 0.35 & -0.45 \\
\hline $\mathbf{w}_{\mathbf{p}}$ & & & & & 1 & 0.40 & -0.68 & -0.84 & 0.79 & -0.84 & 0.69 & -0.42 \\
\hline awc & & & & & & 1 & -0.29 & -0.11 & 0.02 & -0.11 & -0.30 & -0.32 \\
\hline$\alpha$ & & & & & & & 1 & 0.86 & -0.75 & 0.86 & -0.57 & 0.83 \\
\hline $\mathbf{n}$ & & & & & & & & 1 & -0.84 & 1 & -0.82 & 0.60 \\
\hline $\mathbf{h}_{\mathbf{b}}$ & & & & & & & & & 1 & -0.84 & 0.80 & -0.41 \\
\hline$\lambda$ & & & & & & & & & & 1 & -0.82 & 0.60 \\
\hline b & & & & & & & & & & & 1 & -0.32 \\
\hline $\mathbf{K}_{\mathbf{s}}$ & & & & & & & & & & & & 1 \\
\hline
\end{tabular}


Table C-10. Correlation coefficients for Sandy Clay

\begin{tabular}{|c|c|c|c|c|c|c|c|c|c|c|c|c|}
\hline & $\theta_{\mathbf{s}}$ & $\theta_{\mathbf{r}}$ & $\mathbf{p}_{\mathbf{e}}$ & $\mathbf{f}_{\mathbf{c}}$ & $\mathbf{w}_{\mathbf{p}}$ & awc & $\alpha$ & $\mathbf{n}$ & $\mathbf{h}_{\mathbf{b}}$ & $\lambda$ & b & $\mathbf{K}_{\mathrm{s}}$ \\
\hline$\theta_{\mathbf{s}}$ & 1 & 0.00 & 0.97 & 0.58 & 0.35 & 0.68 & 0.02 & 0.00 & 0.01 & 0.00 & -0.23 & 0.05 \\
\hline$\theta_{\mathbf{r}}$ & & 1 & -0.23 & -0.70 & -0.82 & -0.42 & 0.75 & 0.88 & -0.92 & 0.88 & -0.78 & 0.28 \\
\hline $\mathbf{p}_{\mathbf{e}}$ & & & 1 & 0.72 & 0.53 & 0.75 & -0.15 & -0.20 & 0.22 & -0.20 & -0.05 & -0.02 \\
\hline $\mathbf{f}_{\mathrm{c}}$ & & & & 1 & 0.89 & 0.89 & -0.70 & -0.78 & 0.68 & -0.78 & 0.44 & -0.33 \\
\hline $\mathbf{w}_{\mathbf{p}}$ & & & & & 1 & 0.58 & -0.67 & -0.85 & 0.87 & -0.85 & 0.74 & -0.24 \\
\hline awc & & & & & & 1 & -0.58 & -0.55 & 0.35 & -0.55 & 0.05 & -0.35 \\
\hline$\alpha$ & & & & & & & 1 & 0.87 & -0.74 & 0.87 & -0.59 & 0.58 \\
\hline $\mathbf{n}$ & & & & & & & & 1 & -0.86 & 1 & -0.79 & 0.44 \\
\hline $\mathbf{h}_{\mathbf{b}}$ & & & & & & & & & 1 & -0.86 & 0.83 & -0.26 \\
\hline$\lambda$ & & & & & & & & & & 1 & -0.79 & 0.44 \\
\hline $\mathbf{b}$ & & & & & & & & & & & 1 & -0.23 \\
\hline $\mathbf{K}_{\mathbf{s}}$ & & & & & & & & & & & & 1 \\
\hline
\end{tabular}

Table C-11. Correlation coefficients for Silty Clay

\begin{tabular}{|c|c|c|c|c|c|c|c|c|c|c|c|c|}
\hline & $\theta_{\mathbf{s}}$ & $\theta_{\mathbf{r}}$ & $\mathbf{p}_{\mathbf{e}}$ & $\mathbf{f}_{\mathbf{c}}$ & $\mathbf{w}_{\mathbf{p}}$ & awc & $\alpha$ & $\mathbf{n}$ & $\mathbf{h}_{\mathbf{b}}$ & $\lambda$ & b & $\mathbf{K}_{\mathbf{s}}$ \\
\hline$\theta_{\mathbf{s}}$ & 1 & 0.00 & 0.95 & 0.94 & 0.74 & 0.84 & -0.01 & -0.01 & -0.01 & -0.01 & -0.31 & 0.02 \\
\hline$\theta_{\mathbf{r}}$ & & 1 & -0.31 & -0.29 & -0.49 & 0.19 & 0.89 & 0.79 & -0.88 & 0.79 & -0.46 & 0.64 \\
\hline $\mathbf{p}_{\mathbf{e}}$ & & & 1 & 0.98 & 0.86 & 0.74 & -0.28 & -0.25 & 0.26 & -0.25 & -0.15 & -0.18 \\
\hline $\mathbf{f}_{c}$ & & & & 1 & 0.91 & 0.70 & -0.32 & -0.33 & 0.24 & -0.33 & -0.07 & -0.24 \\
\hline $\mathbf{w}_{\mathbf{p}}$ & & & & & 1 & 0.34 & -0.50 & -0.64 & 0.52 & -0.64 & 0.32 & -0.34 \\
\hline awc & & & & & & 1 & 0.14 & 0.33 & -0.36 & 0.33 & -0.70 & 0.03 \\
\hline$\alpha$ & & & & & & & 1 & 0.84 & -0.72 & 0.84 & -0.47 & 0.86 \\
\hline $\mathbf{n}$ & & & & & & & & 1 & -0.78 & 1 & -0.77 & 0.64 \\
\hline $\mathbf{h}_{\mathbf{b}}$ & & & & & & & & & 1 & -0.78 & 0.63 & -0.44 \\
\hline$\lambda$ & & & & & & & & & & 1 & -0.77 & 0.64 \\
\hline b & & & & & & & & & & & 1 & -0.31 \\
\hline $\mathbf{K}_{\mathrm{s}}$ & & & & & & & & & & & & 1 \\
\hline
\end{tabular}


Table C-12. Correlation coefficients for Clay

\begin{tabular}{|c|c|c|c|c|c|c|c|c|c|c|c|c|}
\hline & $\theta_{\mathbf{s}}$ & $\theta_{\mathbf{r}}$ & $\mathbf{p}_{\mathbf{e}}$ & $\mathbf{f}_{\mathrm{c}}$ & $\mathbf{w}_{\mathbf{p}}$ & awc & $\alpha$ & $\mathbf{n}$ & $\mathbf{h}_{\mathbf{b}}$ & $\lambda$ & b & $\mathbf{K}_{\mathrm{s}}$ \\
\hline$\theta_{\mathrm{s}}$ & 1 & 0.00 & 0.93 & 0.88 & 0.73 & 0.76 & 0.00 & -0.01 & 0.00 & -0.01 & -0.26 & -0.01 \\
\hline$\theta_{\mathbf{r}}$ & & 1 & -0.36 & -0.38 & -0.50 & 0.13 & 0.70 & 0.79 & -0.85 & 0.79 & -0.52 & 0.53 \\
\hline $\mathbf{p}_{\mathbf{e}}$ & & & 1 & 0.96 & 0.85 & 0.66 & -0.25 & -0.29 & 0.31 & -0.29 & -0.06 & -0.20 \\
\hline $\mathbf{f}_{\mathrm{c}}$ & & & & 1 & 0.95 & 0.55 & -0.38 & -0.45 & 0.36 & -0.45 & 0.08 & -0.30 \\
\hline $\mathbf{w}_{\mathbf{p}}$ & & & & & 1 & 0.25 & -0.47 & -0.63 & 0.57 & -0.63 & 0.33 & -0.32 \\
\hline awc & & & & & & 1 & 0.09 & 0.28 & -0.38 & 0.28 & -0.63 & -0.06 \\
\hline$\alpha$ & & & & & & & 1 & 0.82 & -0.61 & 0.82 & -0.46 & 0.86 \\
\hline $\mathbf{n}$ & & & & & & & & 1 & -0.78 & 1 & -0.73 & 0.64 \\
\hline $\mathbf{h}_{\mathbf{b}}$ & & & & & & & & & 1 & -0.78 & 0.67 & -0.37 \\
\hline$\lambda$ & & & & & & & & & & 1 & -0.73 & 0.64 \\
\hline $\mathbf{b}$ & & & & & & & & & & & 1 & -0.30 \\
\hline $\mathbf{K}_{\mathbf{s}}$ & & & & & & & & & & & & 1 \\
\hline
\end{tabular}

\section{C.1 References}

Ang, A. H-S. and W. H. Tang, Probability Concepts in Engineering Planning and Design, Volume 1, Basic Principles, John Wiley \& Sons, New York, 409 pp., 1975.

Carsel, R. F., and R. S. Parrish, "Developing joint probability distributions of soil water retention characteristics," Water Resources Research, 24(5):755-770, 1988.

Iman, R. L. and W. J. Conover, "A distribution-free approach to inducing rank correlation among input variables," Communications in Statistics, B11(3):311-334, 1982.

Iman, R. L. and M. J. Shortencarier, "A FORTRAN 77 Program and User's Guide for the Generation of Lain Hypercube and Random Samples for Use with Computer Models," NUREG/CR-3624 (also SAND83-2365), U.S. Nuclear Regulatory Commission, Washington, D.C., 1984.

Meyer, P.D., M.L. Rockhold, and G.W. Gee, "Uncertainty Analyses of Infiltration and Subsurface Flow and Transport for SDMP Sites," NUREG/CR-6565, U.S. Nuclear Regulatory Commission, Washington, DC, 1997. 



\section{Appendix D: Summary of Water Retention and Conductivity Models}

This appendix defines the parameters appearing in the tables of Appendices B and C. The information in this appendix was taken from NUREG/CR-6565 (Meyer et al., 1997).

Richards equation (Richards, 1931) forms the basis for most process-based descriptions of water movement in the unsaturated zone. Richards equation can be expressed as

$$
\frac{\partial \theta}{\partial t}=\frac{\partial}{\partial z}\left[-K(h) \frac{\partial h}{\partial z}-K(h)\right]+u
$$

where

$$
\begin{aligned}
\theta= & \text { volumetric water content, or volume of water } \\
& \text { per unit bulk volume of soil, } \\
h= & \text { soil water tension, } h \geq 0 \\
z= & \text { depth, measured positive downward from the } \\
& \text { soil surface, } \\
t= & \text { time }, \\
K(h)= & \text { hydraulic conductivity, and } \\
u= & \text { a source or sink term used to account for } \\
& \text { water uptake by plant roots. }
\end{aligned}
$$

To solve Richards equation, constitutive functions relating the unsaturated hydraulic conductivity and the water content to the pressure head are needed. The most commonly used relationships are those of van Genuchten (1980), Brooks and Corey (1964), and Campbell (1974), although other expressions are available (Mualem, 1992; Rossi and Nimmo, 1994; Fayer and Simmons, 1995).

\section{D.1 Van Genuchten Model}

The van Genuchten water retention relationship is

$$
S_{e}(h)=\left[1+(\alpha h)^{n}\right]^{-m}
$$

where

$$
\begin{aligned}
& S_{e}=\text { effective saturation }=\frac{\theta-\theta_{r}}{\theta_{s}-\theta_{r}}, 0 \leq S_{e} \leq 1 \\
& \alpha=\text { curve fitting parameter related to air entry } \\
& \text { pressure } \\
& n, m=\text { curve fitting parameters related to pore size } \\
& \text { distribution; the relationship, } m=1-1 / n \text {, is } \\
& \text { often assumed } \\
& \theta_{r}=\text { residual water content } \\
& \theta_{s}=\text { saturated water content }
\end{aligned}
$$

The van Genuchten hydraulic conductivity relationship, based on the hydraulic conductivity model of Mualem (1976) is

$$
K\left(S_{e}\right)=K_{s} \sqrt{S_{e}}\left[1-\left(1-S_{e}^{1 / m}\right)^{m}\right]^{2} .
$$

or

$$
K(h)=K_{s} \frac{\left\{1-(\alpha h)^{n-1}\left[1+(\alpha h)^{n}\right]^{-m}\right\}^{2}}{\left[1+(\alpha h)^{n}\right]^{0.5 m}}
$$

where

$$
\mathrm{K}_{\mathrm{S}}=\text { saturated hydraulic conductivity }
$$

\section{D.2 Brooks-Corey Model}

The Brooks-Corey water retention relationship is

$$
\begin{gathered}
S_{e}(h)=\left(\frac{h_{b}}{h}\right)^{\lambda} \text { for } h \geq h_{b} \\
S_{e}(h)=1 \text { otherwise. }
\end{gathered}
$$

When combined with the relative permeability model of Burdine (1953), Brooks and Corey derived the following hydraulic conductivity relationship.

$$
K\left(S_{e}\right)=K_{s}\left(S_{e}\right)^{3+2 / \lambda}
$$

or

$$
\begin{gathered}
K(h)=K_{s}\left(\frac{h_{b}}{h}\right)^{2+3 \lambda} \text { for } h \geq h_{b} \\
\text { and } K(h)=K_{s} \text { otherwise. }
\end{gathered}
$$

where

$$
\begin{aligned}
& h_{b}= \text { curve fitting parameter related to air entry } \\
& \text { pressure }
\end{aligned}
$$

Carsel and Parrish (1988) used the following equivalence between the Brooks-Corey and van Genuchten parameters:

$$
h_{b}=\alpha^{-1} \text { and } \lambda=n-1 .
$$

\section{D.3 Campbell Model}

Campbell (1974) adopted a water retention relationship similar to Brooks and Corey's, but with $\theta_{r}=0$.

$$
\begin{gathered}
\frac{\theta}{\theta_{s}}=\left(\frac{h_{b}}{h}\right)^{1 / b} \text { for } h \geq h_{b} \\
\frac{\theta}{\theta_{s}}=1 \text { otherwise. }
\end{gathered}
$$

Note that because $\theta_{r}=0, b \neq 1 / \lambda$. Campbell (1974) derived a corresponding hydraulic conductivity relationship. 


$$
K(\theta)=K_{s}\left(\frac{\theta}{\theta_{s}}\right)^{2 b+3}
$$

or

$$
\begin{gathered}
K(h)=K_{s}\left(\frac{h_{b}}{h}\right)^{2+3 / b} \quad \text { for } h \geq h_{b} \\
\text { and } K(h)=K_{s} \text { otherwise. }
\end{gathered}
$$

where

$$
\begin{aligned}
& b=\text { curve fitting parameter related to pore size } \\
& \text { distribution. }
\end{aligned}
$$

Note that all of these single-valued relationships (Equations D-2 through D-14) assume that hysteresis is not important.

\section{D.3.1 Calculation of Campbell's b Parameter}

An expression for $b$ in terms of $\theta_{s}, \theta_{r}$, and $\lambda$ is derived by assuming that the Brooks-Corey model (Equation D-7) and the Campbell model (Equation D-12) predict the same hydraulic conductivity for a given value of water content. In this case, the water content used is that corresponding to an effective saturation of 0.5 . Assuming $S_{e}=0.5$ and using the definition of effective saturation given above, it follows that

$$
\frac{\theta}{\theta_{s}}=\frac{0.5\left(\theta_{s}-\theta_{r}\right)+\theta_{r}}{\theta_{s}}=0.5\left(1+\theta_{r} / \theta_{s}\right)
$$

Substituting this expression in Equation D-12 and equating this with Equation D-7 leads to

$$
\left(0.5\left(1+\theta_{r} / \theta_{s}\right)\right)^{3+2 b}=0.5^{3+2 / \lambda}
$$

Equation D-16 can be solved for $b$,

$$
b=0.5\left\{\frac{\ln (0.5)(3+2 / \lambda)}{\ln \left[0.5\left(1+\theta_{r} / \theta_{s}\right)\right]}-3\right\}
$$

\section{D.4 Additional Parameters}

Several additional soil hydraulic parameters may be required by dose assessment codes. These parameters and the methods by which they were calculated are discussed here.

- Effective porosity, $p_{e}=\theta_{\mathrm{s}}-\theta_{\mathrm{r}}$

- Field capacity, $f_{c}=\theta\left(K=10^{-8} \mathrm{~cm} / \mathrm{s}\right)$

Field capacity is generally interpreted as the water content at which drainage from a field soil becomes negligible (see the discussion by Hillel, 1980). Field capacity is often calculated as the water content at a specified tension, usually taken to be $340 \mathrm{~cm}$ (1/3 bar). Hillel (1980) argues, however, that the field capacity should be based on the drainage rate considered negligible (which is a function of the intended application). Field capacity was calculated here as the water content at which the unsaturated hydraulic conductivity equals $10^{-8} \mathrm{~cm} / \mathrm{s}$ using the van Genuchten model $\left(10^{-8} \mathrm{~cm} / \mathrm{s} \cong 3 \mathrm{~mm} / \mathrm{yr}\right)$. The value of $10^{-8} \mathrm{~cm} / \mathrm{s}$ was chosen because it represents a water flux at which contaminant transport is likely to be insignificant. This value also results in somewhat larger field capacity values and a more realistic available water capacity for very coarse textured soils than using the water content at 1/3 bar soil pressure. See Meyer and Gee (1999) for a more detailed discussion of field capacity.

- Wilting point, $w_{p}=\theta(h=15,300 \mathrm{~cm})$

Wilting point is the minimum water content (or maximum tension) at which plants can extract water from the soil. Wilting point was calculated as the water content at a tension of $15,300 \mathrm{~cm}$ (15 bars).

- Available water capacity, $a w c=f_{c}-w_{p}$ Available water capacity represents the amount of water available for plant uptake.

\section{D.5 References}

Brooks, R. H., and A. T. Corey, "Hydraulic Properties of Porous Media," Hydrology Paper 3, Colorado State Univ., Ft. Collins, CO, 1964.

Burdine, N. T. "Relative permeability calculations from pore-size distribution data." Petr. Trans., Am. Inst. Mining Metall. Eng., 198:71-77, 1953.

Campbell, G. S., "A simple method for determining unsaturated conductivity from moisture retention data," Soil Sci., 117:311-314, 1974.

Fayer, M. J., and C. S. Simmons, "Modified soil water retention functions for all matric suctions," Water Resources Research, 31:1233-1238, 1995.

Meyer, P.D., M.L. Rockhold, and G.W. Gee, "Uncertainty Analyses of Infiltration and Subsurface Flow and Transport for SDMP Sites," NUREG/CR-6565, U.S. Nuclear Regulatory Commission, Washington, DC, 1997.

Meyer, P. D. and G. W. Gee, "Flux-based estimation of field capacity," Journal of Geotechnical and Geoenvironmental Engineering, 125(7):595-599, 1999.

Mualem, Y., "A new model for predicting the hydraulic conductivity of unsaturated porous media," Water Resources Research, 12(3):513-522, 1976.

Mualem, Y., "Modeling the Hydraulic Conductivity of Unsaturated Porous Media," in Indirect Methods for Estimating the Hydraulic Properties of Unsaturated Soils, M. Th. van Genuchten, F. J. Leij, and L. J. Lund (eds.), University of California, Riverside, CA, pp. 15-36, 1992. 
Rossi, C. and J. R. Nimmo, "Modeling of soil water retention from saturation to oven dryness," Water Resources Research, 30(3):701-708, 1994.

van Genuchten, M. Th., "A closed-form equation for predicting the hydraulic conductivity of unsaturated soils," Soil Sci. Soc. Am. J., 44:892-898, 1980. 
